\author{
UNIVERSIDADE DE SÃO PAULO \\ FACULDADE DE SAÚDE PÚBLICA \\ SAÚDE, CICLOS DE VIDA E SOCIEDADE \\ PROGRAMA DE PÓS-GRADUAÇÃO EM SAÚDE PÚBLICA
}

ABUSO SEXUAL NA INFÂNCIA DE MULHERES BRASILEIRAS

GABRIELA BRITO DE CASTRO

São Paulo/SP

Agosto de 2011 


\author{
UNIVERSIDADE DE SÃO PAULO \\ FACULDADE DE SAÚDE PÚBLICA \\ SAÚDE, CICLOS DE VIDA E SOCIEDADE \\ PROGRAMA DE PÓS-GRADUAÇÃO EM SAÚDE PÚBLICA
}

\title{
ABUSO SEXUAL NA INFÂNCIA DE MULHERES BRASILEIRAS
}

GABRIELA BRITO DE CASTRO

Dissertação apresentada ao Programa de Pós-Graduação em Saúde Pública da Faculdade de Saúde Pública, como requisito parcial para obtenção do título de mestre em Saúde Pública.

Orientador: Prof. Dr. Ivan França Junior

São Paulo/SP

Agosto de 2011 
Dedico este trabalho às mulheres que tiveram a infância marcada pela violência. 


\section{AGRADECIMENTOS}

Agradeço a todos que contribuíram direta ou indiretamente para a construção deste trabalho.

Agradeço a Deus pela minha vida, por estar comigo em todos os momentos e por colocar pessoas tão especiais em meu caminho. Sou grata também por todas as oportunidades a que sempre tive acesso.

Agradeço ao meu pai, Edmundo, e à minha mãe, Terezinha, por acreditarem e me fazerem acreditar que eu poderia chegar aonde quisesse. Não tenho palavras para agradecer o imenso amor que sempre me dedicaram, a família maravilhosa que construíram e os exemplos que sempre foram para mim. Muito obrigada pelo incentivo à minha formação e pelo apoio em minhas escolhas e decisões.

Agradeço às minhas lindas e amadas irmãs, Renata, Dayane e Bárbara, minhas melhores amigas, e ao meu cunhado, Felps, por quem tenho carinho de irmã, que mesmo distantes, sempre se fizeram presentes. Com vocês cresci, amadureci e aprendi o valor da família, do amor e da amizade. Vocês são verdadeiros anjos que Deus preparou para que eu nunca me sinta sozinha. Tenho muito orgulho de vocês! Obrigada por acreditar em mim!

Agradeço ao Marcel, pelo apoio incondicional, pela força que sempre me dá, por todo amor, carinho e atenção que me dedica, por cuidar de mim. Você se tornou meu maior incentivador e minha motivação para alcançar meus sonhos e objetivos. Este período não teria sido tão especial sem você! Obrigada por tornar minha vida mais bonita e feliz e por me permitir te amar e aprender tanto com você todos os dias. Agradeço também à sua família, que me acolheu com tamanho carinho e por quem tenho tanto afeto.

Agradeço à minha família, em especial aos meus avós, vovô Vino, vovó Zoraide, vovô Chico e vovó Nita, cujas lembranças enchem meu coração de alegria e de saudades. Saudades da minha infância, tão feliz, dos carinhos, dos afagos, das lições aprendidas. Em especial, agradeço ao vovô Chico, meu primeiro grande professor, que com toda sua sabedoria me fez brilhar os olhos diante dos conhecimentos que acumulou não na escola, mas durante sua vida. Ainda mais especial é meu agradecimento à vovó Zoraide, que me sempre me fez me sentir a pessoa mais amada e importante do mundo, 
que tinha lindos sonhos para meu futuro e de quem sinto tanta falta. Saudades eternas de todos vocês.

Agradeço à minha família de São Paulo, Esther e Du, que não deixaram que me sentisse sozinha um só dia. Não teria outra palavra para definir vocês senão família. Vocês tornaram minha estada em São Paulo mais alegre, mais leve e melhor do que eu poderia imaginar. Obrigada pelas conversas, pela paciência, pelas idas ao Pub (como sinto falta disso!), pelas risadas, pelos colos, pelos choros e tudo mais que compartilhamos nesses dois anos maravilhosos! Torço muito por vocês sempre!

Agradeço à Esther e sua família pela acolhida, sem a qual não seria possível a realização deste trabalho. Espero um dia retribuir tudo o que fizeram por mim. Serei sempre muito grata!

Agradeço a todas as minhas amigas e amigos, de agora ou de sempre, cujo carinho contribuiu e muito para o desenvolvimento deste mestrado.

Agradeço às minhas amigas e companheiras Marininha e Flavi, com quem descobri a beleza de São Paulo. Saímos de Uberlândia e viemos à São Paulo com o mesmo ideal e eu não poderia escolher melhores companhias para esse período. Vocês foram minhas referências e me ajudaram a me sentir em casa nessa cidade.

Às amigas queridas Marcela e Gabi Tannús. Juntas trilhamos passos rumo à carreira acadêmica, dividimos sonhos, angústias e conquistas. Obrigada pelo carinho e pela companhia de sempre.

Às amigas Dani, Tati e Rudgy, verdadeiros presentes que recebi na Faculdade de Saúde Pública, grandes companheiras de estudo, pesquisas, congressos. Espero tê-las sempre por perto.

Agradeço aos professores que suscitaram reflexões, dúvidas, descobertas e aprendizado e que contribuíram para minha formação como psicóloga e em Saúde Pública. É inestimável tudo o que aprendi com vocês.

Agradeço em especial ao meu orientador, Ivan França Junior, com quem tanto aprendo e quem tanto admiro. Muito obrigada por todas as contribuições, orientações, oportunidades e pela confiança. Você se tornou um exemplo para mim.

Aos colegas orientandos do Prof. Ivan, Carlos, Eliana, Ligia, Hugo, Raquel pelas contribuições e trocas e, em especial, à Claudinha pelas verdadeiras aulas e pela amizade. 
Aos funcionários da Faculdade de Saúde Pública e da biblioteca, pelo apoio e pelo auxílio imprescindíveis.

À Anamaria Silva Neves, minha inspiração, que despertou em mim o desejo pela vida acadêmica e voltou meu olhar para estudo da violência sexual infantil. Muito obrigada pelo exemplo, pelo carinho, pelo incentivo, por tudo o que me ensina e por me fazer perceber que podemos contribuir para o combate da violência.

À Revista de Saúde Pública, nas figuras da Professora Teresinha, a quem respeito e admiro, e Keilla, minha chefe, professora e amiga. O período em que estive na revista foi essencial para minha formação enquanto pesquisadora. Não tenho palavras para agradecer o carinho e a acolhida.

À Secretaria de Desenvolvimento Social e Transferência de Renda do Distrito Federal, por me conceder afastamento para estudos, e aos colegas do Centro de Referência da Assistência Social de Planaltina e do Centro de Referência Especializado da Assistência Social, com quem divido ideais, angústias e práticas.

Ao Conselho Nacional de Desenvolvimento Científico e Tecnológico e à Fundação de Amparo à Pesquisa do Estado de São Paulo, pelo financiamento a esta pesquisa.

A todas as mulheres que participaram desta pesquisa e que dividiram conosco suas histórias.

Por fim, agradeço a todas as pessoas que não foram aqui citadas, mas que, de alguma forma, contribuíram para a realização deste trabalho. Muito obrigada! 


\section{CASTRO, G. B. (2011) ABUSO SEXUAL NA INFÂNCIA DE MULHERES}

BRASILEIRAS (Dissertação de Mestrado). São Paulo. Programa de Pós-Graduação em Saúde Pública - Faculdade de Saúde Pública da Universidade de São Paulo.

INTRODUÇÃO: O Abuso sexual na infância (ASI) tem sido associado a outras formas de violência, bem como a vários desfechos de saúde. Dados acerca do ASI, mesmo subestimados, são elevados, e apontam para estreita relação com questões de gênero. Escassos são os estudos que tratam da prevalência do ASI e ainda mais raros são aqueles sobre fatores associados a esta violência. OBJETIVOS: Estimar a prevalência de ASI entre mulheres brasileiras de áreas rurais e urbanas e analisar fatores associados. MÉTODO: São analisados dados brasileiros oriundos do estudo transversal, multicêntrico em 11 países, coordenado pela Organização Mundial de Saúde. A amostra probabilística brasileira foi representativa e composta por 2.645 mulheres de 15 a 49 anos, residentes no município de São Paulo (SP) e na Zona da Mata de Pernambuco (ZMP) entre 2000 e 2001. Foi realizada análise de regressão logística não condicional para variáveis socioeconômicas, familiares, relacionadas a questões de gênero e à experiência do ASI. Foram estimados os odds ratios (OR) e os respectivos intervalos de confiança (IC95\%). Foram propostos dois modelos estatísticos: um com variáveis temporalmente anteriores ou próximas ao ASI para a amostra total e outro sem restrição de temporalidade para SP e para a ZMP. RESULTADOS: A prevalência em SP foi de $7,67 \%$ e de 4,68\% na ZMP. A violência ocorreu sobretudo entre 12 e 15 anos. O principal agressor foi familiar do sexo masculino de 30 a 39 anos. O abuso ocorreu em múltiplas ocasiões em aproximadamente um terço dos casos. Proporção significativa de mulheres teve sua iniciação sexual forçada, inclusive antes dos 15 anos. No primeiro modelo, variáveis associadas foram: mãe ter sido agredida por companheiro, os pais não morarem juntos ou não saber da violência. No segundo modelo, para SP, foram: abuso sexual após os 15 anos, primeira relação sexual antes dessa idade, uso de medicamentos para dor, tristeza ou sono nas últimas quatro semanas, sofrer violência exclusivamente física por parceiro íntimo e marido/companheiro ter sofrido violência física por familiar na infância. Por outro lado, para ZMP, foram: abuso sexual após os 15 anos, primeira relação sexual antes dessa idade, uso diário de álcool, sofrer violência física, psicológica e sexual combinadas ou violência exclusivamente sexual perpetrada por parceiro íntimo 
e mãe sofrer violência por parceiro íntimo, a mulher não se lembrar dessa violência ou os pais não morarem juntos. CONCLUSÕES: O primeiro modelo aqui testado, que buscou explorar mais as causas do ASI, indica que o ASI é determinado pela violência contra a mãe da criança. Concluímos que a violência de gênero atinge mulheres adultas e suas filhas. No segundo modelo, voltado a identificar marcadores de risco de ASI retrospectivo, concluo que há muitas variáveis que podem servir para identificar as mulheres que tenham experienciado o ASI, a quem se pode oferecer cuidado psicossocial. Reduzir a prevalência de ASI, elevada em áreas urbanas e rurais brasileiras, requer a interrupção das violências sofridas pela mulher, principalmente por parceiro íntimo em áreas urbanas brasileiras.

Descritores: prevalência, maus tratos sexuais infantis, fatores associados, mulheres. 
CASTRO, G. B. (2011) SEXUAL ABUSE IN CHILDHOOD OF BRAZILIAN WOMEN (Master's Dissertation). São Paulo. Programa de Pós-graduação em Saúde Pública - Faculdade de Saúde Pública da Universidade de São Paulo.

BACKGROUND: Child sexual abuse (CSA) has been associated with other forms of violence, as well as various health outcomes. Data on the CSA, even underestimated, are high, and point to close relationship with gender issues. Scarce are the studies dealing with the prevalence of ASI and even rarer are those on factors associated with this violence. OBJECTIVES: To estimate the prevalence of CSA among Brazilian women from rural and urban areas and to analyze factors associated. METHODS: We analyzed data from the Brazilian cross-sectional study, a multicenter in 11 countries, coordinated by the World Health Organization The Brazilian probability sample was representative and composed of 2,645 women aged 15 to 49 years living in São Paulo (SP) and in the Zona da Mata of Pernambuco (ZMP) between 2000 and 2001. Analysis was performed conditional logistic regression for socioeconomic variables, familyrelated issues of gender and experience of the ASI. We estimated odds ratios (OR) and confidence intervals $(95 \%)$. We proposed two statistical models: one with variables temporally previous or next to the CSA for the total sample and one without restriction of temporality to SP and the ZMP. RESULTS: The prevalence of SP was $7.67 \%$ and $4.68 \%$ in the ZMP. The violence occurred most often between 12 and 15 years. The main perpetrator was male relative 30 to 39 years. The abuse occurred on multiple occasions in approximately one third of cases. Proportion of women had forced sexual initiation, even before age 15. In the first model, associated variables were: mother had been assaulted by fellow parents not living together or not knowing the violence. In the second model for SP were: sexual abuse after 15 years, first sexual relations before this age, use of medications for pain, sadness, or sleep in the last four weeks, only to suffer physical violence by an intimate partner and husband/partner have suffered physical violence by family members in childhood. On the other hand, for ZMP were: sexual abuse after 15 years, first sexual relations before this age, daily alcohol use, suffer physical, psychological and sexual abuse combined or exclusively sexual violence perpetrated by an intimate partner and mother suffering partner violence intimate, the 
woman does not remember this violence or parents not living together. CONCLUSIONS: The first model tested here, which sought to further explore the causes of the CSA, indicates that the CSA is determined by the violence against the child's mother. We conclude that gender violence affects women and their adult daughters. In the second model, aimed to identify risk markers for CSA retrospective, I conclude that there are many variables that can serve to identify women who have experienced the CSA, who can provide psychosocial care. Reducing the prevalence of CSA, high in urban and rural areas in Brazil, requires a halt to the violence suffered by women, particularly intimate partner in Brazilian urban areas.

Descriptors: prevalence; child sexual abuse; factors associated; women. 
SUMÁRIO

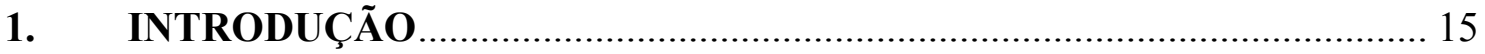

2 - OBJETIVOS:

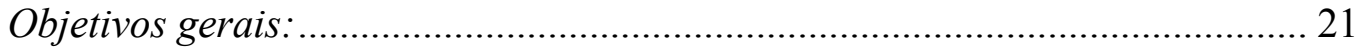

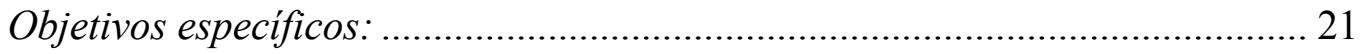

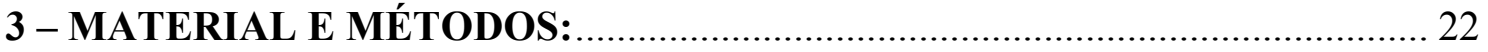

A pesquisa multicêntrica da OMS ............................................................... 22

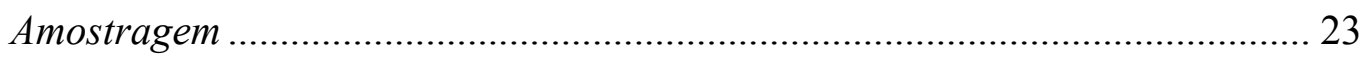

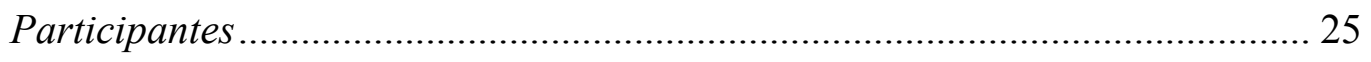

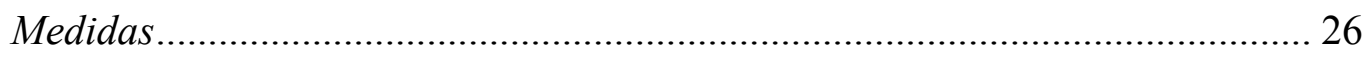

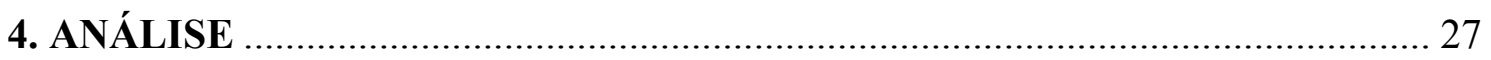

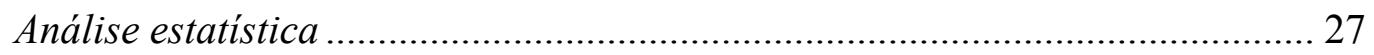

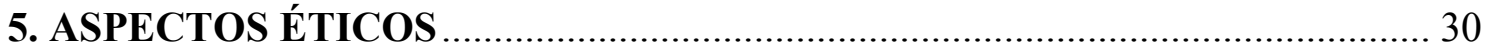

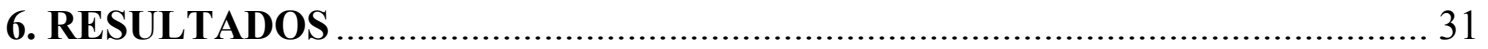

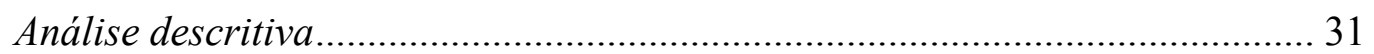

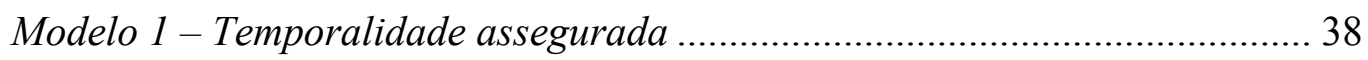

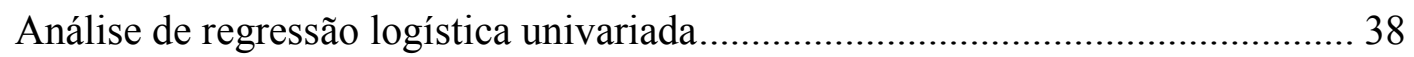

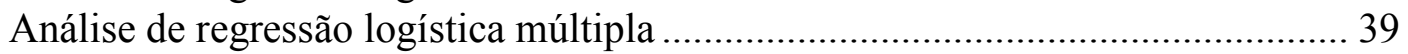

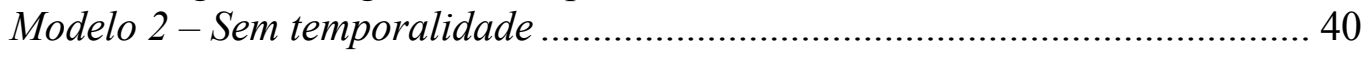

Análise de regressão logística univariada.......................................................... 40

Análise de regressão logística múltipla ................................................................. 44

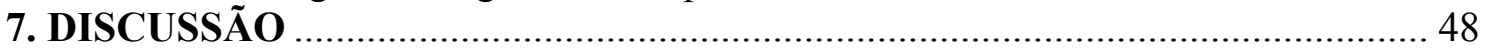

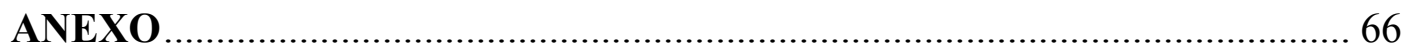




\section{ÍNDICE DE FIGURAS}

Figura 1: Seleção das unidades amostrais em São Paulo, SP. 2000........................................... 24

Figura 2: Seleção das unidades amostrais na Zona da Mata de Pernambuco, PE. 2000.............. 25

Figura 3: Perdas amostrais. São Paulo e Zona da Mata de Pernambuco.................................... 25

Figura 4. Curva ROC para modelo múltiplo de associação ao abuso sexual infantil. São Paulo e

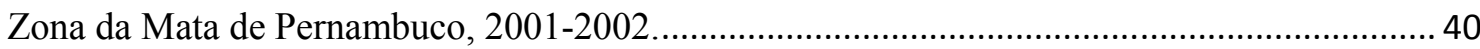

Figura 5. Curva ROC para modelo múltiplo de associação ao abuso sexual infantil. São Paulo, SP, 2001-2002 47 


\section{ÍNDICE DE TABELAS}

Tabela 1: Prevalência de abuso sexual na infância em mulheres por país, segundo região (rural ou urbana), idade na entrevista e ano de publicação do estudo

Tabela 2: Prevalência de abuso sexual na infância por país, segundo sexo, idade na entrevista e ano de publicação do estudo.

Tabela 3. Características das mulheres entrevistadas em São Paulo e na Zona da Mata de Pernambuco, 2000-2001.

Tabela 4. Características do abuso sexual infantil entre mulheres de São Paulo e da Zona da Mata de Pernambuco, 2000-2001

Tabela 5. Freqüência dos episódios de abuso sexual infantil, segundo autor da violência. São

Paulo e Zona da Mata de Pernambuco, 2000-2001.

Tabela 6. Características sociodemográficas das mulheres segundo abuso sexual na infância.

São Paulo e Zona da Mata de Pernambuco, 2000-2001. N = 2.645...

Tabela 7. Experiências familiares de violência das mulheres segundo abuso sexual infantil. São

Paulo e Zona da Mata de Pernambuco, 2000-2001. N = 2.645

Tabela 8. Conectividade sociofamiliar das mulheres segundo abuso sexual infantil. São Paulo e

Zona da Mata de Pernambuco, 2000-2001. N = 2.645

Tabela 9. Aspectos relacionados a questões de gênero das mulheres segundo abuso sexual na infância. São Paulo, 2000-2001. N = 2.645

Tabela 10. Associação entre características das mulheres e abuso sexual na infância. São Paulo, SP, e Zona da Mata, PE, 2000-2001.

Tabela 11. Associação entre experiências familiares de violência das mulheres e abuso sexual na infância. São Paulo, SP, e Zona da Mata, PE, 2000-2001 39

Tabela 12. Fatores associados ao abuso sexual na infância. São Paulo, SP, e Zona da Mata, PE, 2000-2001.

Tabela 13. Associação entre características sociodemográficas das mulheres e abuso sexual na infância. São Paulo, SP, e Zona da Mata, PE, 2000-2001

Tabela 14. Associação entre experiências familiares de violência das mulheres e abuso sexual na infância. São Paulo, SP, e Zona da Mata, PE, 2000-2001

Tabela 16: Associação entre aspectos relacionados a questões de gênero das mulheres e abuso sexual na infância. São Paulo, SP, Zona da Mata, PE, 2000-2001.

Tabela 17: Associação entre saúde das mulheres e abuso sexual na infância. São Paulo, SP, e Zona da Mata de Pernambuco, PE, 2000-2001 
Tabela 18. Características sociodemográficas, experiências familiares de violência, aspectos relacionados a questões de gênero e saúde e sua associação com abuso sexual na infância. São Paulo, SP, e Zona da Mata, PE, 2000-2001. 


\section{INTRODUÇÃO}

A violência é considerada uma importante questão de saúde pública. Segundo o relatório sobre Violência e Saúde da Organização Mundial de Saúde (2002), em 1996, a 49 Assembléia Mundial de Saúde declarou a violência como um grande e crescente problema em todo o mundo e de sérias conseqüências para indivíduos, famílias, comunidades e países, além de apresentar graves efeitos nos serviços de saúde.

Por abuso sexual infantil (ASI), define-se o envolvimento de uma criança em atividades sexuais, as quais não pode livremente compreender ou consentir, em razão da idade, desenvolvimento ou da natureza da relação com o abusador (WHO, 1999).

O ASI pode afetar profundamente e de forma imediata a saúde de quem o sofre, além de produzir conseqüências em longo prazo (BRIERE e RUNTZ, 1993; HALL et al, 1993; KRUG et al, 2002; GARCIA-MORENO et al, 2005). Entre as conseqüências imediatas estão a vergonha, a culpa, auto-imagem negativa, dificuldades de socialização, desconfiança, déficits no desenvolvimento físico, cognitivo e psíquico, problemas escolares, dentre outros (ECHEBURÚA e CORRAL, 2006).

O abuso é freqüentemente associado a agravos físicos (LAWS, 1993; LEROI et al, 1995; WALKER et al, 1999; LESERMAN, 2005) e à autopercepção negativa da saúde, sobretudo quando a violência é recorrente (GOLDING, COOPER e GEORGE, 1999). Há indícios de que sua ocorrência esteja fortemente associada ao desenvolvimento de psicopatologias ao longo da vida (PRIBOR e DINWIDDIE, 1992; SPATARO, 2004), como depressão (HALL et al, 1993), transtornos de ansiedade (GOLDING, COOPER e GEORGE, 1999), transtorno de estresse pós-traumático, principalmente entre mulheres (HARRIET et al, 2001) e transtornos alimentares (CONNORS e MORSE, 1993). Comportamento suicida (MOLNAR, BERKMAN e BUKA, 2001), auto-mutilação (ROMANS et al, 1995) e disfunção sexual (NOLL, TRICKET e PUTNAN, 2003) também são descritos como possíveis conseqüências do ASI. Soma-se a isso, o risco de contração doenças sexualmente transmissíveis (JOHNSON, 2009), inclusive aids (LENDERKING et al, 1997), menor uso de contraceptivos em relacionamentos posteriores, ocorrência de gravidez indesejada, 
problemas relacionados ao uso e abuso de álcool (WINDLE et al, 1995; MONCRIEFF et al, 1996) e de outras drogas (MOLNAR, BERKMAN e BUKA, 2001).

Além disso, é comum a revitimização de pessoas com história de ASI, i.e., pessoas sexualmente abusadas na infância possuem risco aumentado de sofrerem novos abusos na idade adulta, inclusive sexuais (COID et al, 2009) e de serem vítimas de violência por parceiro íntimo, principalmente entre mulheres (SCHRAIBER et al, 2007).

Estudos que tratam da prevalência do ASI na população mundial são escassos, e o mesmo ocorre para a população brasileira.

Em levantamento bibliográfico na base de dados SCOPUS (eleita em função de sua abrangência e do grande número de periódicos indexados em nível internacional) utilizando o termo de busca 'child sexual abuse', foi possível observar que publicações sobre o tema começaram a emergir na literatura internacional, sobretudo na segunda metade da década de 1990. A partir de meados dos anos 2000, houve considerável aumento de pesquisas que adotam a violência sexual perpetrada contra crianças e adolescentes como foco de estudo e que se interessavam em compreender a magnitude do problema. Isso sugere recente e crescente preocupação mundial acerca do tema, entretanto, ainda hoje, os estudos são incipientes.

Pesquisas publicadas apresentam basicamente três maneiras de investigar a prevalência dessa modalidade de violência na infância. A primeira, de caráter documental, diz respeito ao levantamento dos casos registrados junto às instituições de atendimento às crianças e adolescentes em situação de violência sexual. Essa metodologia de coleta de dados tem como benefício a não exposição e a não revitimização do sujeito. Entretanto, diante da sabida sub-notificação de casos, ou mesmo do expressivo número estimado que sequer chega ao conhecimento das autoridades ou das instituições, esse método pode apresentar vieses importantes no delineamento de prevalências (LONDON et al, 2008).

Outra forma de coleta utilizada é o inquérito realizado diretamente à criança ou ao adolescente sobre ter ou não sofrido violência sexual. A vantagem é que o investigado está temporalmente mais próximo à pergunta, mas eticamente pode ser questionado, uma vez que pode proporcionar danos psicológicos ao suscitar a exposição de crianças e adolescentes a um assunto tão delicado (LONDON et al, 2008). 
Por fim, podem ser realizadas entrevistas retrospectivas com adultos reportando experiências de violência sexual na infância. Esse é o método mais utilizado em publicações, pois, apesar de possíveis vieses de memória, possibilita a obtenção de dados com maior fidedignidade e menor potencial de danos às pessoas que participam do estudo (LONDON et al, 2008).

Dentre os estudos de prevalência do ASI entre mulheres segundo região, Tanzânia e Nova Zelândia apresentam os índices mais elevados (ELLSBERG e HEISE, 2005; FANSLOW et al, 2007). No Brasil, a prevalência é semelhante à de países como Tailândia, El Salvador e Honduras. Etiópia, Samoa e Sérvia e Montenegro possuem as menores proporções (ELLSBERG e HEISE, 2005) (Tabela 1).

Tabela 1: Prevalência de abuso sexual na infância em mulheres por país, segundo região (rural ou urbana), idade na entrevista e ano de publicação do estudo.

\begin{tabular}{|c|c|c|c|c|}
\hline \multirow{2}{*}{ País } & \multicolumn{2}{|c|}{ Prevalência (\%) } & \multirow{2}{*}{$\begin{array}{c}\text { Idade na } \\
\text { entrevista (anos) }\end{array}$} & \multirow{2}{*}{$\begin{array}{c}\text { Ano de } \\
\text { publicação do } \\
\text { estudo }\end{array}$} \\
\hline & Urbana & Rural & & \\
\hline Etiópia & - & 0,2 & 15 a 49 & 2005 \\
\hline Samoa* & & & 15 a 49 & 2005 \\
\hline Sérvia e Montenegro & 1,9 & - & 15 a 49 & 2005 \\
\hline Bangladesh & 7,4 & 1,0 & 15 a 49 & 2005 \\
\hline Guatemala* & & & 15 a 49 & 2008 \\
\hline Namíbia & 4,7 & - & 15 a 49 & 2005 \\
\hline Tailândia & 7,6 & 4,7 & 15 a 49 & 2005 \\
\hline El Salvador* & & & 15 a 49 & 2008 \\
\hline Brasil & 7,8 & 4,8 & 15 a 49 & 2005 \\
\hline Honduras* & & & 15 a 49 & 2008 \\
\hline Japão & 9,6 & - & 15 a 49 & 2005 \\
\hline Peru & 19,5 & 7,9 & 15 a 49 & 2005 \\
\hline Tanzânia & 44,4 & 4,2 & 15 a 49 & 2005 \\
\hline Nova Zelândia & 23,5 & 28,2 & 18 a 64 & 2007 \\
\hline
\end{tabular}

Em estudos com homens e mulheres, a prevalência de ASI foi maior entre mulheres no Brasil (BASSANI et al, 2009) e na Suíça, cujos índices foram os mais elevados (BOUVIER et al, 1999). Na China, por outro lado, possivelmente por questões 
culturais, os valores foram maiores entre homens (LUO, PARISH e LAUMANN, 2008) (Tabela 2).

Tabela 2: Prevalência de abuso sexual na infância por país, segundo sexo, idade na entrevista e ano de publicação do estudo

\begin{tabular}{|c|c|c|c|c|}
\hline \multirow{2}{*}{ País } & \multicolumn{2}{|c|}{ Prevalência (\%) } & \multirow{2}{*}{$\begin{array}{c}\text { Idade na entrevista } \\
\text { (anos) }\end{array}$} & \multirow{2}{*}{$\begin{array}{c}\text { Ano de publicação } \\
\text { do estudo }\end{array}$} \\
\hline & Feminino & Masculino & & \\
\hline Taiwan* & 2 & & Adolescentes & 2008 \\
\hline China & 3,3 & 5,1 & 20 a 64 & 2008 \\
\hline Brasil & 5,6 & 1,6 & 14 ou mais & 2009 \\
\hline Suíça & 33,8 & 10,9 & 14 a 16 anos & 1999 \\
\hline
\end{tabular}

*Sem distinção entre homens e mulheres e da idade dos participantes

Fonte: BOUVIER et al (1999); LUO, PARISH e LAUMANN (2008); BASSANI et al (2009).

De acordo com Plichta e Falik (2001), cerca de quatro em dez mulheres nos Estados Unidos vivenciaram uma ou mais formas de violência, inclusive na infância $(17,8 \%)$.

Segundo Krug et al (2002), a variabilidade das proporções apresentadas pode decorrer de diferenças reais em diferentes culturas, mas pode ser devida a metodológicas. Estudos que adotam definições mais amplas do abuso sexual infantil podem chegar a prevalências maiores que aqueles que se utilizam de definições mais restritas ou específicas. Da mesma forma a população estudada pode interferir nos resultados de acordo com os critérios de inclusão e exclusão adotados. Como dito anteriormente, pesquisas podem ser conduzidas com adultos, crianças, adolescentes ou seus responsáveis. Distinções no delineamento dos estudos também podem produzir diferenças significativas nas prevalências (KRUG et al, 2002). Em função da natureza sensível do objeto de estudo, o modo de condução da coleta dos dados empíricos também pode interferir nos resultados dos estudos.

Crianças do sexo feminino estão mais suscetíveis ao abuso sexual que as do sexo masculino (SAFFIOTI, 1997). Acredita-se que 20\% das mulheres e $10 \%$ dos homens de todo o mundo tenham sofrido violência sexual na infância. Em 2004, inquérito populacional brasileiro com universo amostral de 2.502 mulheres com idade igual ou superior a 16 anos, documentou a ocorrência de 13\% de violência sexual em pelo menos uma situação na vida (UNICEF, 2006). 
A violência sexual é uma das menos visíveis, já que normalmente é cometida por alguém próximo, em quem a criança confia. Estima-se que $96 \%$ dos casos de violência física e $64 \%$ dos casos de abuso sexual contra crianças de até seis anos de idade sejam cometidos por familiares e que os principais autores de violência sexual sejam pessoas do sexo masculino, sobretudo pais, padrinhos, avós, irmãos, tios (UNICEF, 2006). Os lares são os locais de maior ocorrência. A violência sexual na qual existe laço familiar, direto ou não, ou uma mera relação de responsabilidade é definida como incesto (ABRAPIA, 1997). Esse vínculo familiar contribui para que a violência torne-se invisível, por não ser facilmente denunciada. Acredita-se que no Brasil menos de $10 \%$ dos casos cheguem às delegacias (RIBEIRO, FERRIANI e REIS, 2004).

Entre 40 e $60 \%$ da violência sexual na família ocorre mais comumente contra meninas de 15 anos ou menos, e diferenças regionais ou culturais não parecem ser significativas neste sentido. Um estudo nos Países Baixos mostrou que aproximadamente $45 \%$ das vítimas de violência sexual no ambiente doméstico têm menos de 18 anos (UNICEF, 2006).

No Brasil, grande parte dos estudos que visam estudar a violência sexual na infância parte de dados documentais ou de estudos de caso. São raros os que se propõem a realizar pesquisas de base populacional. $\mathrm{O}$ único estudo publicado estimou prevalência de 5,6\% de ASI entre mulheres e 1,6\% entre homens de 14 anos ou mais no contexto urbano no sul do Brasil (BASSANI et al, 2009).

Para muitas mulheres e crianças, a coerção sexual e o abuso são definidos como partes de suas vidas. Embora meninos e meninas possam ser alvos desse tipo de violência, uma revisão de 25 estudos ao redor do mundo indicou que a prevalência de casos denunciados de abuso contra meninas é pelo menos 1,5 a três vezes maior que contra meninos (ELLSBERG e HEISE, 2005).

Apesar de homens e mulheres possam ser vítimas ou perpetradores da violência, as características da violência contra as mulheres parecem diferir sensivelmente da cometida contra os homens. Homens são mais provavelmente mortos ou feridos em guerras ou propensos ao envolvimento com conflitos em gangues ou guetos, e são mais fisicamente agredidos ou mortos na rua por um estranho do que mulheres. Homens também são mais freqüentemente os perpetradores da violência e os agressores de violência sexual. Em contraste, mulheres são mais propensas a serem psicologicamente ultrajadas ou serem mortas por alguém que conheçam, freqüentemente um membro da 
família ou um parceiro íntimo. Elas também apresentam maior risco de vivenciarem violência ou exploração sexual na infância, adolescência ou mesmo na idade adulta (ELLSBERG e HEISE, 2005).

Conforme afirmam Schraiber, D'Oliveira e França Junior (2009), a violência sexual adquire status de ocorrência estreitamente vinculada ao gênero, afirmando a subordinação vivenciada pelas mulheres em suas relações com os homens.

A violência de gênero, em si, reproduz representações historicamente construídas, atribuindo a homens e mulheres lugares e relações de poder distintas na sociedade. Relações assimetricamente mantidas pela violência, e muitas vezes, pela violência sexual (SCHREINER, 2008).

Especificamente a violência sexual contra a menina traduz-se como uma forma diferenciada da violência de gênero, uma vez que representa a violência praticada por um adulto, comumente do sexo masculino, e que detém maior credibilidade e confiabilidade em relação à criança. Essa relação, marcadamente desigual em vários aspectos, atribui à criança do sexo feminino o lugar da submissão e da sujeição, e não raro, de culpabilização (SCHREINER, 2008).

Narvaz e Koller (2007) discorrem sobre a culpa há muito atribuída às meninas pela violência sexual por elas vivenciada. Concluem que tal representação advém de preconceitos sexistas e androcêntricos implícitos nos discursos sobre a provocação, a sedução e a culpabilidade feminina diante da violação, seja ela adulta ou criança.

Ainda mais escassos do que os estudos de prevalência, são os estudos acerca dos fatores associados à violência sexual na infância. A maior parte das pesquisas destina-se a estimar as conseqüências (físicas, psíquicas, sociais e outras) decorrentes da violência (LUO et al, 2008; MARK et al, 2008; FANSLOW et al, 2007).

Pesquisas sobre fatores associados à violência sexual, considerando essa variável como desfecho, em geral, dizem respeito à população adulta (CASEY e NURIUS, 2006; RAGHAVAN et al, 2004; RICKERT et al, 2004). Aquelas que se dedicam ao abuso na infância apontam fatores de risco para a ocorrência da violência sexual, como: ser menina, sofrer violência física, não ter em quem confiar, ser socialmente isolado, estar exposto a conflitos entre os pais, pais com problemas com álcool, possuir algum tipo de deficiência, sobretudo mental (FRANÇA JUNIOR, 2003; KRUG et al, 2002; FLEMING, MULLEN e BAMMER, 1997; FERGUSSON, LYNSKEY e HORWOOD, 1996). 
Raras são as pesquisas que buscam estabelecer relações causais para o ASI a partir da análise de variáveis anteriores à sua ocorrência. Um exemplo é o estudo casocontrole de Paveza (1989), que visou identificar fatores de risco à violência sexual de pais contra filhas. Na maior parte das publicações, são estabelecidas associações entre variáveis atuais e a ocorrência do abuso na infância. Os fatores decorrentes dessas associações podem ser considerados marcadores de risco da violência. Marcadores de risco são características associadas à probabilidade de que o desfecho esteja presente (KAUFMAN KANTOR e JASINSKI, 1998).

Estudo sobre os fatores associados ao ASI na população brasileira reiterou pesquisas anteriores e apontou associações que podem ser entendidas como marcadores de risco. O ASI esteve associado à violência física e o sexo foi destacado como característica de elevado risco para a ocorrência do desfecho. Renda, anos de estudo e idade no momento da entrevista, não se mostraram associados (BASSANI et al, 2009).

Para França Junior (2003), a lacuna decorrente da escassez de trabalhos e pesquisas que se dedicam ao estudo do ASI contribui para que o número e a proporção de crianças afetadas pelo abuso tornem-se ainda mais invisíveis, assim como os fatores associados à ocorrência deste tipo de violência, quer como fatores predisponentes ou como marcadores de risco.

\section{2 - OBJETIVOS:}

Objetivos gerais:

- Estimar a prevalência de violência sexual na infância de mulheres

- Analisar os fatores associados à violência sexual infantil

Objetivos específicos:

- Descrever características do abuso sexual infantil

- Comparar as prevalências de abuso sexual infantil entre áreas de características rurais e urbanas 
- Comparar fatores associados ao abuso em áreas de características rurais e urbanas

\section{3-MATERIAL E MÉTODOS:}

Estudo transversal, de base populacional, com 2.645 mulheres de 15 a 49 anos, 1.172 da cidade de São Paulo (SP) e 1.473 de 15 municípios da Zona da Mata de Pernambuco (ZMP), entre 2000 e 2001. Os dados analisados são oriundos de pesquisa multicêntrica da OMS.

\section{A pesquisa multicêntrica da OMS}

Nos anos 2000 e 2001, a OMS implementou uma pesquisa multicêntrica internacional, contando com o suporte técnico da London School of Hygiene and Tropical Medicine. Esta pesquisa teve por objetivo suprir a carência de dados populacionais acerca das várias formas de violência vivenciada por mulheres em seus relacionamentos íntimos, levando em consideração as questões de gênero. Tal estudo foi realizado em 11 países: Brasil, Peru, Bangladesh, Japão, Tailândia, Samoa, Namíbia, Etiópia, Sérvia, Nova Zelândia e Tanzânia (SCHRAIBER et al, 2007).

Para tanto, foram estabelecidos metodologia e instrumentos comuns de coleta de dados e inquéritos domiciliares foram conduzidos. Em cinco dos países, tais inquéritos ocorreram concomitantemente em uma metrópole e em regiões rurais, ao passo que, nos demais, a coleta foi realizada apenas em grandes cidades, à exceção da Etiópia (exclusivamente rural).

Foram abordados aspectos socioeconômicos, relação comunitárias, condições de saúde, relações com o companheiro e filhos, questões ligadas ao gênero, enfrentamento da violência e outros, tendo sempre as diversas formas de violência como pano de fundo, inclusive a violência sexual.

No Brasil, o estudo foi coordenado por pesquisadores da Universidade de São Paulo (USP) e foram eleitos o município de SP, (área urbana) e outros 15 da ZMP, (área urbano-rural). 
As entrevistas foram conduzidas por mulheres, treinadas previamente por um mês. Os questionários utilizados eram também padronizados, formulados em inglês, traduzidos para o português e re-traduzidos para o inglês, com verificação da própria equipe da OMS, a fim de garantir a fidedignidade do instrumento. Por fim, as perguntas sobre violência foram adaptadas à cultura nacional a partir de pesquisas qualitativas, realizadas com homens, mulheres e profissionais de serviços nos locais em que a seria realizada a coleta de dados, mostrando alta consistência interna dos itens abordados. ${ }^{1}$

\section{Amostragem}

A amostra foi construída para ser representativa, valendo-se da estratégia de amostragem por conglomerados em múltiplos estágios. ${ }^{1}$ Para tanto, na cidade de SP, foi utilizada a matriz probabilística elaborada pelo Instituto Brasileiro de Geografia e Estatística (IBGE) para a realização da Pesquisa Nacional por Amostragem de Domicílios (PNAD) em 1995. Esta matriz era composta por 263 setores selecionados, com probabilidade proporcional ao tamanho (SCHRAIBER et al, 2007).

A seleção das unidades amostrais ocorreu em três estágios. No primeiro, setores censitários foram sorteados a partir da matriz, ordenados segundo a proporção de chefes de família com escolaridade inferior a um ano. No segundo, um número fixo de domicílios foi sorteado sistematicamente em cada setor censitário. Por último, em cada domicílio com mulheres de 15 a 49 anos completos, apenas uma mulher foi sorteada para a entrevista (Figura 1).

\footnotetext{
${ }^{1}$ Informações detalhadas podem ser encontradas em: SCHRAIBER, L.B. et al. Prevalência da violência contra a mulher por parceiro íntimo em regiões do Brasil. Rev. Saúde Pública, São Paulo, v. 41, n. 5, out. 2007.
} 


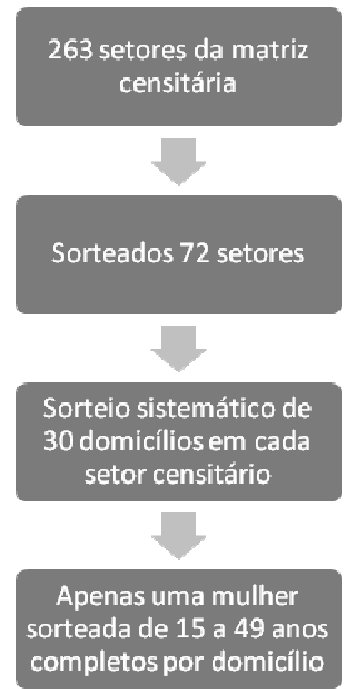

Figura 1: Seleção das unidades amostrais em São Paulo, SP. 2000.

Na ZMP, a seleção das unidades amostrais deu-se em quatro estágios. Os municípios foram ordenados segundo densidade demográfica, taxa de urbanização e taxa de analfabetismo dos chefes de família, e selecionados sistematicamente com probabilidade proporcional ao tamanho. No segundo, setores foram selecionados em cada município; no terceiro, foi selecionada uma amostra de domicílios em cada setor censitário. Por fim, uma mulher de 15 a 49 anos foi sorteada por domicílio (Figura 2).

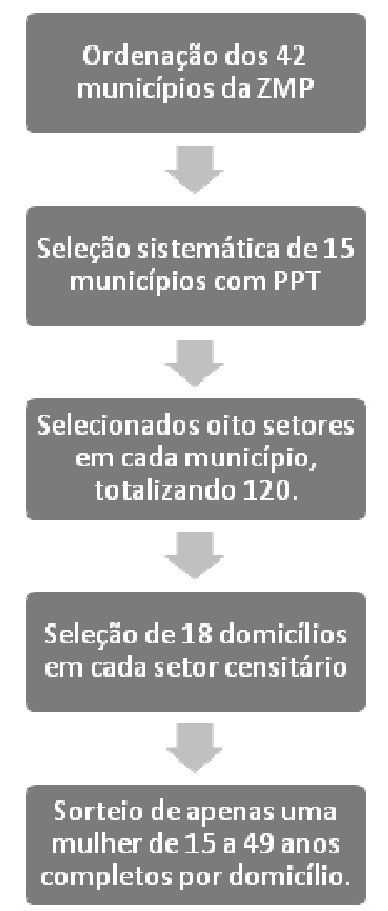

PPT: Probabilidade proporcional ao tamanho. 
Figura 2: Seleção das unidades amostrais na Zona da Mata de Pernambuco, PE. 2000.

Foram registradas baixas taxas de recusa entre as mulheres elegíveis abordadas: $3,7 \%$ em SP e 1,2\% na ZMP (Figura 3).

Não localizados: 347

$(16 \%)$ em SP e 180

$(8,4 \%)$ na ZMP
Os sorteios resultaram

em 2.163 domicílios em SP e 2.136 na ZMP

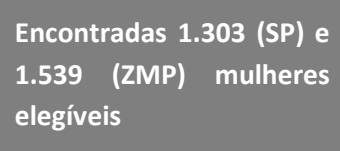

elegiveis

Em SP, $412 \quad(24 \%)$

domicílios e 401 (20,7\%)

na ZMP não apresentavam

mulheres de 15 a 49 anos
Baixas taxas de recusas: em SP 3,7\% e em ZMP $1,2 \%$
Completas

entrevistas em SP (90\%) e $1.473(95,7 \%)$ na ZMP

Figura 3: Perdas amostrais. São Paulo e Zona da Mata de Pernambuco

\section{$\underline{\text { Participantes }}$}

As mulheres de SP eram, em sua maioria, casadas, com idades entre 20 e 29 anos, escolaridade entre nove e 11 anos de estudo (ensino médio no Brasil), de origem urbana, migrantes e com até duas pessoas por cômodo. Na ZMP, a maior parte não possuía parceiro íntimo (solteiras, separadas, divorciadas ou viúvas), tinha de 20 a 29 anos, de zero a quatro anos de estudo (anos iniciais do ensino fundamental), era de origem rural, migrante e com até duas pessoas por cômodo (Tabela 3 ).

Tabela 3. Características das mulheres entrevistadas em São Paulo e na Zona da Mata de Pernambuco, 2000-2001.

\begin{tabular}{|c|c|c|c|c|}
\hline Característica & $\begin{array}{c}\text { São Paulo } \\
\left(\begin{array}{c}N=1.172) \\
\%\end{array}\right. \\
\end{array}$ & $\begin{array}{c}\text { Zona da Mata de } \\
\text { Pernambuco }(N=1.473) \\
\% \\
\end{array}$ & $\begin{array}{c}\text { Total } \\
(\mathrm{N}=\mathbf{2 . 6 4 5}) \\
\% \\
\end{array}$ & $\mathbf{p}^{\mathbf{a}}$ \\
\hline Faixa etária (anos completos) ${ }^{b}$ & & & & 0,0554 \\
\hline 15 a 19 & 18,8 & 20,5 & 19,7 & \\
\hline
\end{tabular}




\begin{tabular}{|c|c|c|c|c|}
\hline 20 a 29 & 30,2 & 33,4 & 33,1 & \\
\hline 30 a 39 & 27,0 & 24,2 & 25,4 & \\
\hline 40 a 49 & 24,0 & 19,9 & 21,8 & \\
\hline Escolaridade (anos completos) & & & & 0,0000 \\
\hline 12 ou mais & 21,7 & 05,0 & 12,4 & \\
\hline 9 a 11 & 35,3 & 23,5 & 28,7 & \\
\hline 5 a 8 & 27,5 & 30,0 & 28,9 & \\
\hline 0 a 4 & 15,5 & 41,5 & 30,0 & \\
\hline Situação conjugal & & & & 0,0000 \\
\hline Atualmente casada & 36,2 & 30,6 & 33,0 & \\
\hline Vivendo com parceiro & 13,4 & 26,4 & 20,6 & \\
\hline Namoro com relação sexual & 15,5 & 08,1 & 11,4 & \\
\hline Separada, divorciada, solteira ou viúva & 34,9 & 34,9 & 34,9 & \\
\hline Origem & & & & 0,0000 \\
\hline Rural & 06,7 & 80,7 & 47,9 & \\
\hline Urbana & 93,3 & 19,3 & 52,1 & \\
\hline Migração & & & & 0,0000 \\
\hline Não & 16,6 & 30,4 & 24,3 & \\
\hline Sim & 83,4 & 69,6 & 75,7 & \\
\hline Número de pessoas por cômodo & & & & 0,5768 \\
\hline Até 2 & 63,4 & 61,8 & 62,5 & \\
\hline Mais de 2 & 33,6 & 38,2 & 37,5 & \\
\hline
\end{tabular}

\footnotetext{
${ }^{\mathrm{a}}$ Teste de qui-quadrado (significante $\alpha<0,05$ )

${ }^{\mathrm{b}}$ Informação disponível para 1.472 mulheres em Pernambuco.
}

\section{$\underline{\text { Medidas }}$}

Os dados analisados dizem respeito a experiências de violência sexual na infância (antes dos 15 anos) e possíveis fatores associados, conforme consta no questionário utilizado para a coleta de dados em inquérito domiciliar (Anexo, p. 62).

Foram analisadas as respostas às seguintes perguntas:

“Antes dos 15 anos, você se lembra se alguém em sua família tocou em você sexualmente ou obrigou-a a uma atividade sexual que você não queria?

SE SIM: quem fez isso com você?

SE SIM OU NÃO, CONTINUE: Talvez alguém na escola?

Quem sabe algum amigo ou vizinho?

Mais alguma outra pessoa lhe fez isso?

SE SIM, quem?” 


\section{ANALISE}

\section{Análise estatística}

As respostas às perguntas apresentadas anteriormente foram analisadas a fim de descrever a prevalência de ASI junto à população estudada. As pessoas que responderam SIM a qualquer dessas perguntas foram consideradas casos, enquanto aquelas, cuja resposta foi NÃO a todas, foram entendidas como não-casos.

Para os casos, foram descritas as variáveis a seguir.

- Idade à época da violência sexual (anos) (12 a 15; oito a 11; antes dos oito; não sabe)

- Tipo de violência (intrafamiliar; extrafamiliar)

- Idade aproximada do agressor (anos) (15 a 29; 30 a 39; 40 a 49; 50 ou mais; não sabe)

- Freqüência de episódios de violência sexual (uma ou duas; poucas; muitas)

- Sexo do agressor (masculino; feminino)

- Primeira relação sexual (> 15 anos, não forçada; > 15 anos, forçada; < 15 anos, não forçada; $<15$ anos, forçada)

Os dados foram apresentados na forma de médias, número e proporções, usando o qui-quadrado de Pearson para testar eventuais diferenças em proporções. Foram consideradas estatisticamente significantes aquelas diferenças com $\alpha<5 \%$.

Para estimar os fatores associados ao ASI, foi realizada análise de regressão logística não condicional no modelo forward stepwise para calcular os odds ratios (OR) e respectivos intervalos de confiança (IC95\%).

A regressão logística tem por finalidade analisar a relação entre um desfecho (variável dependente) e um conjunto simultâneo de variáveis explanatórias (independentes), mediante um modelo que tenha bom ajuste, que seja plausível e que obedeça ao princípio da parcimônia (GIMENO e SOUZA, 1995). 
A variável dependente foi violência sexual na infância (antes dos 15 anos).

Foram testados dois modelos estatísticos. No primeiro, foi estimada a associação de variáveis independentes temporalmente anteriores ou próximas à dependente. Para esse modelo, foi utilizada a amostra total, para que lugar de residência (SP ou ZMP) fosse testado como exposição. As variáveis independentes foram didaticamente organizadas nos seguintes blocos de análise:

Bloco 1 - Características sociodemográficas:

- Origem (rural; urbana)

- Migração (sim; não)

- Local de residência (São Paulo; Zona da Mata de Pernambuco)

Bloco 2 - Experiências familiares de violência:

- Mãe ter sido agredida pelo companheiro (sim; não; pais não moravam juntos/não sabe)

- Ter visto ou ouvido esta violência durante a infância (sim; não; não se lembra)

A análise ROC (Receiver Operating Characteristic) foi utilizada para estimar o poder preditivo do modelo e o teste de Hosmer-Lemenshow goodness of fit para o ajuste.

No segundo modelo, em que foram explorados os possíveis marcadores de risco, foi estimada a associação entre variáveis independentes e o relato de ASI, sem a restrição da temporalidade, separadamente para SP e para a ZMP. As variáveis foram inseridas no modelo do menor para o maior valor de $\mathrm{p}$.

As variáveis independentes foram:

Bloco 1 - Características sociodemográficas:

- Faixa etária (anos completos) (15 a 19; 20 a 29; 30 a 39; 40 a 49)

- Escolaridade (anos completos) (0 a 4; 5 a 8; 9 a 11; 12 ou mais)

- Situação conjugal (atualmente casada; vivendo com parceiro; namoro com relação sexual; separada, divorciada, solteira ou viúva)

- Número de pessoas na casa por cômodo (até duas; mais de duas) 
- Origem (rural; urbana)

- Migração (sim; não)

Bloco 2 - Experiências familiares de violência:

- Mãe agredida pelo companheiro (sim; não; pais não moravam juntos/não sabe)

- Ter visto ou ouvido a violência contra a mãe durante a infância (sim; não; não se lembra)

- Mãe do marido/companheiro agredida fisicamente pelo companheiro (sim; não; pais não moravam juntos/não sabe)

- Marido/companheiro viu ou ouviu a violência (sim; não; não sabe)

- Marido/companheiro (atual ou mais recente) apanhava regularmente ou era agredido fisicamente por alguém da família (sim; não; não sabe)

- Irmã ter sido agredida por companheiro (sim; não; não sabe)

Bloco 3 - Aspectos relacionados a questões de gênero:

- Violência por parceiro íntimo (não sofreu; exclusivamente psicológica; psicológica e física; psicológica, física e sexual; exclusivamente física; sexual (não exclusiva)

- Abuso sexual após os 15 anos (não; sim)

- Freqüência dos episódios de violência na vida (uma ou poucas vezes; muitas vezes)

- Bens próprios (possui bens próprios sozinha; possui bens próprios partilhados; não possui bens próprios)

- Renda própria (sim; não)

- Idade na primeira relação sexual (anos) $(\geq 15 ;<15)$

Bloco 4 - Conectividade sociofamiliar:

- Ajuda sociocomunitária (sim; pouca; não)

- Apoio familiar (sim; não)

- Contato com a família (sim; não)

- Atitudes com relação aos papéis de gênero (autonomia; submissão) 
Bloco 5 - Saúde:

- Percepção sobre a saúde (excelente/boa; regular/ruim/muito ruim)

- Saúde Mental (sem transtorno mental comum; com transtorno mental comum)

- Tentativa/ideação de suicídio (não; sim)

- Uso diário de álcool (não; sim)

- Problemas relacionados ao uso de álcool (não; sim)

- Uso de medicamentos para dor, tristeza ou sono nas últimas quatro semanas (não; sim)

As variáveis que obtiveram $\mathrm{p}<0,20$ na análise univariada de regressão logística foram selecionadas para a modelagem. Foram mantidas no modelo estatístico aquelas com nível de significância de $\mathrm{p}<0,05$, atentando-se para os possíveis fatores de confusão. Variáveis, mesmo que não associadas ao ASI, foram mantidas no modelo quando eles ajustavam em 10\% (qualquer direção) outras variáveis. As variáveis selecionadas para análise no primeiro modelo foram utilizadas no segundo para ajuste.

Análises estatísticas foram realizadas utilizando o programa Stata 10.0 (StataCorp., College Station, TX). O comando svy foi utilizado para corrigir o efeito do delineamento amostral.

\section{ASPECTOS ÉTICOS}

O estudo do qual se origina este projeto foi aprovado pelo Comitê de Ética em Pesquisa da Faculdade de Medicina da USP e Hospital das Clínicas (CAPPesq-609/98) em 11/11/1998 e pela Comissão Nacional de Ética em Pesquisa (Parecer 002/99) em 11/1/1999. O presente estudo teve aprovação pelo Comitê de Ética em Pesquisa da Faculdade de Saúde Pública (OF.COEF/241/09) em 14/08/2009.

Durante a coleta de dados, especial atenção foi destinada aos aspectos éticos e à segurança pessoal das entrevistadas e entrevistadoras, considerando a natureza e a complexidade do tema tratado (SCHRAIBER et al, 2007).

No início de cada entrevista, realizada exclusivamente por mulheres treinadas especificamente para este fim, a participante recebia informações acerca do estudo e 
sobre a possibilidade de interromper a entrevista a qualquer momento e seu consentimento era solicitado (SCHRAIBER et al, 2007).

Várias medidas foram adotadas a fim de resguardar a confidencialidade e o sigilo, como: garantia de privacidade durante a entrevista domiciliar, em que era permitida apenas a presença de crianças menores de dois anos no local; utilização de veículos adaptados para a realização da entrevista, caso o domicílio fosse identificado como inseguro ou com pouca privacidade; não identificação pessoal da entrevistada nos questionários; elaboração de questionário alternativo a ser utilizado em situações de ameaça à privacidade (chegada do parceiro ou de outras pessoas no local da entrevista); estratégias de maior segurança na logística de acesso aos domicílios, tal como o trabalho de equipes geograficamente muito próximas e uso de telefonia celular para rápida comunicação, inclusive com o escritório central da pesquisa; suporte psicológico às entrevistadoras e suportes assistenciais às entrevistadas (SCHRAIBER et al, 2007). ${ }^{2}$

\section{RESULTADOS}

\section{Análise descritiva}

Das 2.645 mulheres, 177 relataram abuso sexual antes dos 15 anos, perfazendo a prevalência de 6,0\%. A prevalência de ASI em SP foi de 7,7\% e de 4,7\% na ZMP.

A maioria dos casos de ASI foi cometida por familiares na amostra total. Em SP, mais da metade foi marcada pela violência intrafamiliar, ao contrário da ZMP, cujos casos foram prioritariamente de violência extrafamiliar. Contudo, as diferenças não foram significativas (Tabela 4).

A faixa etária de maior ocorrência do abuso difere significativamente nos sítios da pesquisa. Em São Paulo, a violência esteve presente principalmente dos oito aos 11 anos, enquanto, na ZMP, a maior ocorrência foi entre 12 e 15 anos. Os autores da violência tinham de 30 a 39 anos e, em sua maioria, eram predominantemente do sexo masculino, sem diferenças significativas para as duas regiões. A primeira relação sexual das mulheres ocorreu, em média, aos 18,3 anos (Desvio-padrão - DP = 3,4) na amostra

\footnotetext{
${ }^{2}$ Maiores detalhes sobre as condutas éticas adotadas podem ser visualizados em: SCHRAIBER, L. B. et al. Prevalência da violência contra a mulher por parceiro íntimo em regiões do Brasil. Rev. Saúde Pública, São Paulo, v. 41, n. 5, out. 2007.
} 
total. A idade mínima foi sete e a máxima, 35 anos. Primeira relação antes dos 15 anos foi relatada por 203 mulheres (9,6\%), 60,1\% forçadas. Entre todas as mulheres, 20,3\% tiveram sua iniciação sexual forçada, das quais 22,8\% aconteceram antes dos 15 anos (14,3\% em São Paulo e 29,5\% na ZMP). A primeira relação sexual forçada foi mais freqüente na ZMP (Tabela 4).

Tabela 4. Características do abuso sexual infantil entre mulheres de São Paulo e da Zona da Mata de Pernambuco, 2000-2001.

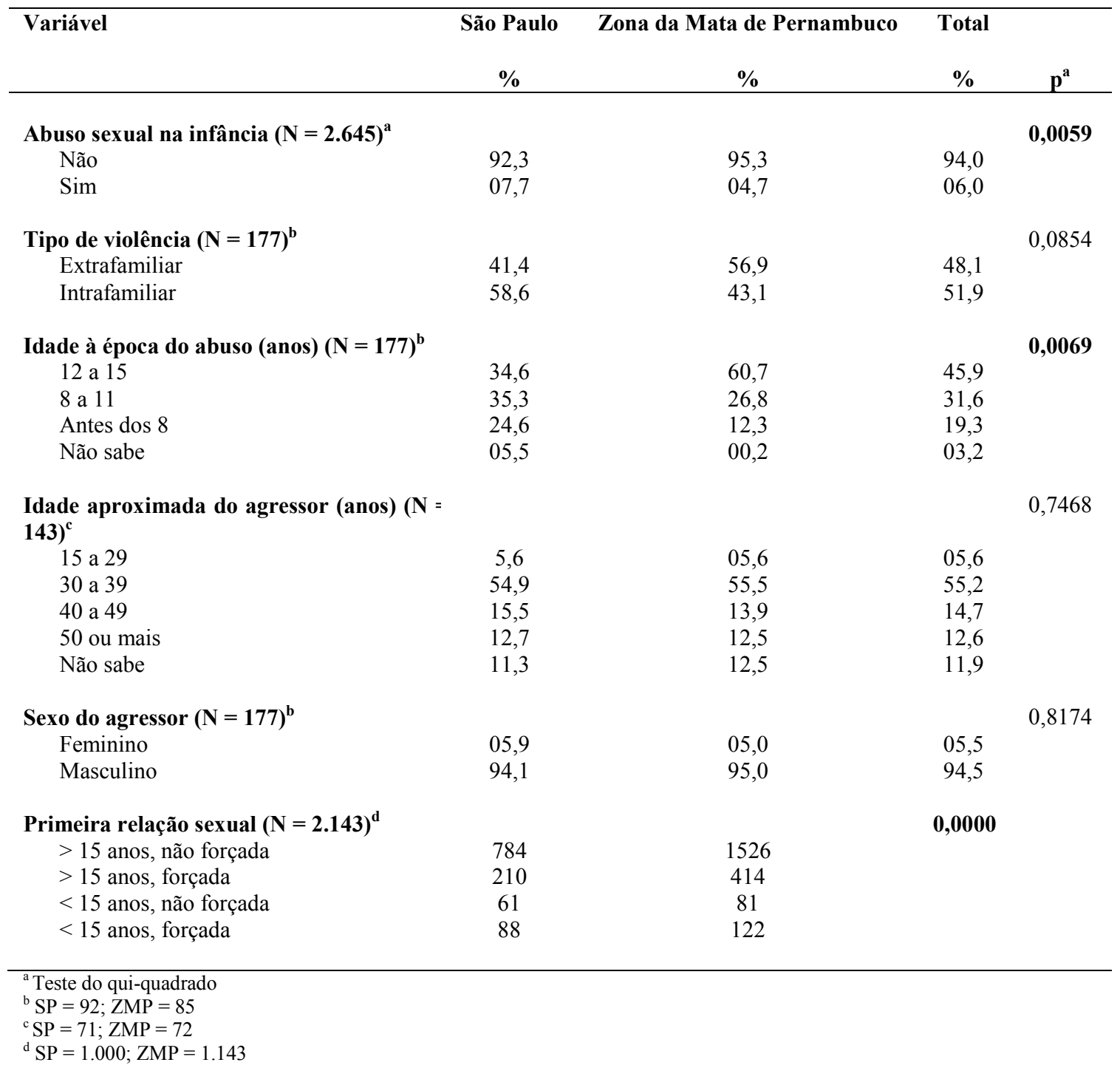

A maioria era conhecida pela vítima $(80,0 \%$, dentre os quais $59,0 \%$ eram familiares) na amostra total (Tabela 5). O principal agressor foi um homem membro da família (43,6\%), seguido por homem amigo da família $(12,4 \%)$, estranho $(10,2 \%)$ e outra pessoa (10,2\%). O padrasto foi responsável por $8,6 \%$ dos casos de ASI. O pai e 
namorado obtiveram o mesmo percentual: 4,3\%. Mulher membro da família foi mencionada por $2,7 \%$ das entrevistadas, e amigas da família em 1,6\%, assim como alguém no trabalho. Padres ou líderes religiosos representaram $0,5 \%$. Não houve relato de ASI por professores ou policiais/soldados.

Maior percentual de mulheres alegou freqüência do abuso em uma ou duas vezes, embora $35,3 \%$ tenham relatado regularidade na violência $(18,7 \%$ disseram ter sofrido a violência poucas vezes e 16,6\%, muitas vezes). Nos casos em que o perpetrador era algum familiar, essa regularidade foi mais proeminente (Tabela 5).

Tabela 5. Freqüência dos episódios de abuso sexual infantil, segundo autor da violência. São Paulo e Zona da Mata de Pernambuco, 2000-2001.

\begin{tabular}{|c|c|c|c|c|}
\hline \multirow[t]{2}{*}{ Autor do abuso } & \multicolumn{4}{|c|}{$\begin{array}{c}\text { Freqüência (vezes) } \\
\%\end{array}$} \\
\hline & $\begin{array}{c}\text { Uma ou } \\
\text { duas } \\
(\mathrm{N}=\mathbf{1 2 1})\end{array}$ & $\begin{array}{l}\text { Poucas } \\
(N=35)\end{array}$ & $\begin{array}{l}\text { Muitas } \\
(\mathbf{N}=\mathbf{3 1})\end{array}$ & $\begin{array}{c}\text { Total } \\
(\mathbf{N}=\mathbf{1 8 7})\end{array}$ \\
\hline Familiar $^{\mathrm{a}}$ & 52,8 & 23,6 & 23,6 & 100,0 \\
\hline Conhecido $^{\mathrm{b}}$ & 84,6 & 12,8 & 2,6 & 100,0 \\
\hline Estranho $^{c}$ & 89,5 & 10,5 & 0,0 & 100,0 \\
\hline Não identificado & 68,4 & 10,5 & 21,5 & 100,0 \\
\hline Total & 64,7 & 18,6 & 16,6 & $100,0^{\mathrm{d}}$ \\
\hline
\end{tabular}

${ }^{a}$ Pai, padrasto, homem membro da família, mulher membro da família

${ }^{\mathrm{b}}$ Professor, homem amigo da família, mulher amiga da família, namorado, alguém no trabalho, líder religioso

${ }^{c}$ Policial/soldado, estranho

${ }^{\mathrm{d}}$ há casos de mais de um autor para a mesma mulher

A maioria de mulheres com relato de ASI tinha entre 40 e 49 anos no momento da entrevista em SP e de 20 a 29 anos na ZMP (sem significância estatística para esta região). A média de idade da amostra total foi de 30,4 anos ( $\mathrm{DP}=9,4)$. Em média, as mulheres possuíam sete anos de estudos completos ( $\mathrm{DP}=4,3$ ), o que corresponde ao ensino fundamental brasileiro, e maior escolaridade foi observada em SP em relação à ZMP, embora não tenha havido significância estatística para esta variável. Maior parte das mulheres de SP não possuía parceiro íntimo (separada, divorciada, solteira ou viúva), de origem urbana, migrante e vivia com até duas pessoas por cômodo em sua casa. Na ZMP, a maioria vivia com parceiro, era de origem rural, havia realizado migração e vivia com até duas pessoas por cômodo da residência. As três últimas variáveis apresentaram $p>0,05$ (Tabela 6).

Tabela 6. Características sociodemográficas das mulheres segundo abuso sexual na infância. São Paulo e Zona da Mata de Pernambuco, 2000-2001. N = 2.645 


\begin{tabular}{|c|c|c|c|c|c|}
\hline \multirow[t]{3}{*}{ Característica } & \multicolumn{5}{|c|}{ Abuso sexual infantil } \\
\hline & \multicolumn{2}{|c|}{$\begin{array}{l}\text { São Paulo } \\
(\mathbf{N}=1.172)\end{array}$} & \multicolumn{2}{|c|}{$\begin{array}{l}\text { Zona da Mata de Pernambuco } \\
\qquad(\mathrm{N}=1.473)\end{array}$} & \multirow{2}{*}{$\begin{array}{c}\text { Total } \\
(\mathrm{N}=\mathbf{2 . 6 4 5}) \\
\% \\
\end{array}$} \\
\hline & $\%$ & $\mathbf{p}^{*}$ & $\%$ & $\mathbf{p}^{*}$ & \\
\hline Faixa etária (anos) & & $\mathbf{0 , 0 3 8 6}$ & & 0,7041 & \\
\hline 15 a 19 & 18,64 & & 17,40 & & 20,68 \\
\hline 20 a 29 & 42,45 & & 34,22 & & 35,45 \\
\hline 30 a 39 & 15,28 & & 29,80 & & 23,90 \\
\hline 40 a 49 & 23,64 & & 18,59 & & 19,97 \\
\hline Escolaridade (anos completos) & & 0,2274 & & 0,8623 & \\
\hline 12 ou mais & 17,23 & & 04,95 & & 04,99 \\
\hline 9 a 11 & 42,34 & & 19,85 & & 23,68 \\
\hline 5 a 8 & 30,31 & & 28,58 & & 30,03 \\
\hline 0 a 4 & 10,12 & & 46,68 & & 41,30 \\
\hline Situação conjugal & & 0,0091 & & 0,0004 & \\
\hline Atualmente casada & 20,31 & & 20,72 & & 31,06 \\
\hline Vivendo com parceiro & 21,83 & & 48,09 & & 25,32 \\
\hline Namoro com relação sexual & 21,61 & & 13,14 & & 07,89 \\
\hline Separada, divorciada, solteira ou viúva & 36,25 & & 18,06 & & 35,73 \\
\hline Origem & & 0,0750 & & 0,2339 & \\
\hline Rural & 02,49 & & 74,63 & & 80,98 \\
\hline Urbana & 97,51 & & 25,37 & & 19,02 \\
\hline Migração & & 0,7152 & & 0,8087 & \\
\hline Não & 15,04 & & 28,96 & & 30,44 \\
\hline Sim & 84,96 & & 71,04 & & 69,56 \\
\hline Número de pessoas por cômodo & & 0,0870 & & 0,6836 & \\
\hline Até 2 & 53,58 & & 64,14 & & 61,63 \\
\hline Mais de 2 & 46,42 & & 35,86 & & 38,37 \\
\hline
\end{tabular}

*Teste de qui-quadrado

A agressão física por parceiro íntimo à mãe foi presente na infância das entrevistadas vítimas de ASI, assim como na infância de seus maridos/companheiros (para estes, significativo apenas em SP), embora a maioria não tenha relatado esta experiência nas duas regiões. Dentre as que referiram tal violência, quase todas disseram ter visto ou ouvido os episódios, bem como seus maridos e companheiros. Elevada proporção de mulheres afirmou ter irmã(s) agredida(s) fisicamente por companheiro em SP e na ZMP, sem diferenças significantes (Tabela 7).

Tabela 7. Experiências familiares de violência das mulheres segundo abuso sexual infantil. São Paulo e Zona da Mata de Pernambuco, 2000-2001. N = 2.645 


\begin{tabular}{|c|c|c|c|c|}
\hline & \multicolumn{2}{|c|}{$\begin{array}{l}\text { São Paulo } \\
(\mathbf{N}=1.172)\end{array}$} & \multicolumn{2}{|c|}{$\begin{array}{l}\text { Zona da Mata de Pernambuco } \\
\qquad(\mathrm{N}=1.473)\end{array}$} \\
\hline & $\%$ & $\mathbf{p}^{\mathbf{a}}$ & $\%$ & $\mathrm{p}^{\mathrm{a}}$ \\
\hline $\begin{array}{lr}\text { Mãe ter sido } & \text { agredida } \\
\text { fisicamente } & \text { por } \\
\text { companheiro } & \end{array}$ & & 0,0028 & & 0,0001 \\
\hline Não & 59,5 & & 51,8 & \\
\hline Sim & 35,8 & & 33,2 & \\
\hline $\begin{array}{c}\text { Pais não moravam } \\
\text { juntos/não sabe }\end{array}$ & 04,7 & & 15,0 & \\
\hline $\begin{array}{l}\text { Ver ou ouvir na infância } \\
\text { mãe agredida por } \\
\text { companheirob }\end{array}$ & & 0,6605 & & 0,8258 \\
\hline Não & 06,3 & & 11,3 & \\
\hline Sim & 93,7 & & 88,7 & \\
\hline Não lembra & 00,0 & & 00,0 & \\
\hline $\begin{array}{l}\text { Mãe } \\
\text { marido/companheiro do } \\
\text { agredida fisicamente por } \\
\text { companheiroc }\end{array}$ & & 0,0185 & & 0,6003 \\
\hline Não & 56,0 & & 60,3 & \\
\hline Sim & 16,3 & & 15,4 & \\
\hline $\begin{array}{l}\text { Pais dele não moravam } \\
\text { juntos/não sabe }\end{array}$ & 27,7 & & 24,3 & \\
\hline $\begin{array}{l}\text { Marido/companheiro viu } \\
\text { ou ouviu na infância mãe } \\
\text { agredida } \\
\text { companheirod }^{\text {d }}\end{array}$ & & 0,3150 & & 0,3717 \\
\hline Não & 21,7 & & 06,7 & \\
\hline Sim & 78,3 & & 93,3 & \\
\hline Não sabe & 00,0 & & 00,0 & \\
\hline $\begin{array}{l}\text { Marido/companheiro } \\
\text { apanhava regularmente }\end{array}$ & & 0,0406 & & 0,0178 \\
\hline $\begin{array}{l}\text { ou era agredido } \\
\text { fisicamente por alguém da } \\
\text { família }^{c}\end{array}$ & & & & \\
\hline Não & 56,7 & & 59,6 & \\
\hline Sim & 37,1 & & 33,2 & \\
\hline Não sabe & 06,2 & & 07,2 & \\
\hline agredida(s) & & 0,4870 & & 0,4081 \\
\hline $\begin{array}{l}\text { fisicamente } \\
\text { companheiro }\end{array}$ & & & & \\
\hline Não & 29,7 & & 32,3 & \\
\hline Sim & 62,7 & & 62,6 & \\
\hline Não sabe & 07,6 & & 05,1 & \\
\hline
\end{tabular}

Teste do qui-quadrado

${ }^{\mathbf{b}} \mathrm{N}=247$

Das mulheres que sofreram ASI em SP e na ZMP, a maior parte disse possuir pouca ajuda sociocomunitária, mas alegou ter apoio familiar (significativo apenas para ZMP) e contato com a família. Praticamente todas as entrevistadas apresentaram atitudes de submissão em relação aos papéis de gênero (Tabela 8). 
Tabela 8. Conectividade sociofamiliar das mulheres segundo abuso sexual infantil. São Paulo e Zona da Mata de Pernambuco, 2000-2001. N = 2.645

\begin{tabular}{|c|c|c|c|c|}
\hline \multirow[t]{4}{*}{ Variável } & \multicolumn{4}{|c|}{ Abuso sexual infantil } \\
\hline & \multirow{2}{*}{\multicolumn{2}{|c|}{ São Paulo }} & \multicolumn{2}{|c|}{ Zona da Mata de Pernambuco } \\
\hline & & & \multicolumn{2}{|c|}{$(\mathrm{N}=1.473)$} \\
\hline & $\%$ & $\mathbf{p}^{\mathbf{a}}$ & $\%$ & $\mathbf{p}^{\mathbf{a}}$ \\
\hline Ajuda sociocomunitária & & 0,1760 & & 0,2925 \\
\hline Sim & 19,0 & & 29,1 & \\
\hline Pouca & 74,3 & & 69,1 & \\
\hline Não & 06,7 & & 01,8 & \\
\hline Apoio familiar & & 0,3274 & & $\mathbf{0 , 0 2 8 2}$ \\
\hline Sim & 80,8 & & 70,5 & \\
\hline Não & 19,2 & & 29,5 & \\
\hline Contato com a família & & 0,2386 & & 0,5637 \\
\hline Sim & 94,8 & & 86,6 & \\
\hline Não & 05,2 & & 13,4 & \\
\hline $\begin{array}{l}\text { Atitudes com relação aos } \\
\text { papéis de gênero }\end{array}$ & & & & 0,1111 \\
\hline Autonomia & 00,0 & & 02,1 & \\
\hline Submissão & 07,5 & & 97,9 & \\
\hline
\end{tabular}

O abuso sexual após os 15 anos esteve presente em um quarto dessas mulheres em SP e em cerca de um quinto na ZMP. Tais violências aconteceram uma ou poucas vezes. Mais da metade das mulheres com história de ASI em SP relatou violência por parceiro íntimo, mesma proporção apresentada na ZMP. Dentre as violências sofridas, a violência física aliada à psicológica foi a mais comum para mulheres de SP e, para das da ZMP, as violências física, psicológica e sexual combinadas. As mulheres de SP e da ZMP, em sua maioria, possuíam bens próprios partilhados e renda própria (significante apenas para São Paulo). Um quinto das mulheres de São Paulo que sofreram ASI e quase dois quintos dessas mulheres residentes na ZMP relataram primeira relação sexual antes dos 15 anos (Tabela 9).

Tabela 9. Aspectos relacionados a questões de gênero das mulheres segundo abuso sexual na infância. São Paulo, 2000-2001. N = 2.645 


\begin{tabular}{|c|c|c|c|c|}
\hline & \multicolumn{2}{|c|}{$\begin{array}{l}\text { São Paulo } \\
(\mathrm{N}=1.172)\end{array}$} & \multicolumn{2}{|c|}{$\begin{array}{l}\text { Zona da Mata de Pernambucc } \\
\qquad(\mathrm{N}=1.473)\end{array}$} \\
\hline & $\%$ & $\mathbf{P}$ & $\mathbf{N}(\%)$ & p \\
\hline $\begin{array}{l}\text { Abuso sexual após os } 15 \\
\text { anos }\end{array}$ & & 0,0000 & & 0,0000 \\
\hline Não & 5,7 & & $72(83,00)$ & \\
\hline Sim & 24,3 & & $13(17,00)$ & \\
\hline $\begin{array}{l}\text { Freqüência dos episódios } \\
\text { de violência (na vida) }\end{array}$ & & 0,2664 & & 0,9584 \\
\hline Uma ou poucas vezes & 91,1 & & 93,1 & \\
\hline Muitas vezes & 08,9 & & 06,9 & \\
\hline $\begin{array}{l}\text { Violência por parceiro } \\
\text { íntimo }\end{array}$ & & 0,0004 & & 0,0001 \\
\hline Não sofreu & 25,0 & & 25,2 & \\
\hline $\begin{array}{l}\text { Exclusivamente } \\
\text { psicológica }\end{array}$ & 24,1 & & 10,9 & \\
\hline Psicológica e física & 26,7 & & 16,8 & \\
\hline $\begin{array}{l}\text { Psicológica, física e } \\
\text { sexual }\end{array}$ & 12,7 & & 31,3 & \\
\hline Exclusivamente física & 08,6 & & 07,2 & \\
\hline Sexual (não exclusiva) & 02,9 & & 08,6 & \\
\hline Bens próprios & & 0,0312 & & 0,2538 \\
\hline Possui sozinha & 31,9 & & 23,0 & \\
\hline Possui partilhados & 65,9 & & 63,1 & \\
\hline Não possui & 02,2 & & 13,9 & \\
\hline Renda própria & & 0,3188 & & 0,1680 \\
\hline Sim & 69,8 & & 48,4 & \\
\hline Não & 30,2 & & 51,6 & \\
\hline $\begin{array}{l}\text { Idade na primeira relação } \\
\text { sexual (anos) }\end{array}$ & & 0,0000 & & 0,0000 \\
\hline$\geq 15$ & 79,1 & & 61,0 & \\
\hline$<15$ & 20,9 & & 39,0 & \\
\hline
\end{tabular}

Aproximadamente dois terços das mulheres vítimas de ASI da ZMP avaliaram sua saúde como regular, ruim ou muito ruim, ao passo que dois quintos das entrevistadas de SP a julgaram dessa forma. As mulheres de SP apresentaram mais transtorno mental comum e uso de medicamentos para dor, tristeza ou sono nas quatro semanas que antecederam a entrevista do que as da ZMP. A tentativa ou ideação de suicídio foi maior na ZMP, apresentando proporções consideráveis nas duas áreas. Uso diário de álcool e problemas relacionados ao uso de álcool tiveram baixas freqüências entre as vítimas de ASI (Tabela 10).

Tabela 10: Saúde das mulheres entrevistadas segundo abuso sexual na infância. São Paulo e Zona da Mata de Pernambuco, 2000-2001. 


\begin{tabular}{|c|c|c|c|c|}
\hline \multirow[t]{3}{*}{ Variável } & \multicolumn{4}{|c|}{ Abuso sexual infantil } \\
\hline & \multicolumn{2}{|c|}{$\begin{array}{l}\text { São Paulo } \\
(\mathbf{N}=1.172)\end{array}$} & \multicolumn{2}{|c|}{$\begin{array}{l}\text { Zona da Mata de Perna } \\
\qquad(\mathrm{N}=1.473)\end{array}$} \\
\hline & $\%$ & $\mathbf{p}^{\mathbf{a}}$ & $\%$ & $\mathbf{p}^{\mathbf{a}}$ \\
\hline Percepção sobre a saúde & & 0,0803 & & 0,0895 \\
\hline Excelente/boa & 60,9 & & 35,2 & \\
\hline Regular/Ruim/Muito ruim & 39,1 & & 64,8 & \\
\hline Saúde mental & & 0,0149 & & $\mathbf{0 , 0 2 2 0}$ \\
\hline Sem transtono mental comum & 60,3 & & 47,8 & \\
\hline $\begin{array}{l}\text { Com transtorno mental } \\
\text { comum }\end{array}$ & 39,7 & & 52,2 & \\
\hline Tentativa/ideação de suicídio & & 0,0019 & & 0,0009 \\
\hline Não & 54,0 & & 63,6 & \\
\hline Sim & 46,0 & & 36,4 & \\
\hline Uso diário de álcool & & $\mathbf{0 , 0 3 9 0}$ & & $\mathbf{0 , 0 0 0 0}$ \\
\hline Não & 95,9 & & 96,0 & \\
\hline Sim & 04,1 & & 04,0 & \\
\hline $\begin{array}{l}\text { Problemas relacionados ao uso } \\
\text { de álcool }\end{array}$ & & 0,2442 & & 0,6224 \\
\hline Não & 86,9 & & 83,6 & \\
\hline Sim & 13,1 & & 16,4 & \\
\hline $\begin{array}{l}\text { Uso de medicamentos para dor, } \\
\text { tristeza ou sono nas últimas } \\
\text { quatro semanas }\end{array}$ & & 0,0043 & & 0,2803 \\
\hline Não & 28,8 & & 49,0 & \\
\hline Sim & 71,2 & & 51,0 & \\
\hline
\end{tabular}

a Teste do qui-quadrado (significante $\alpha<0,05$ )

Modelo 1 - Temporalidade assegurada

$\underline{\text { Análise de regressão logística univariada }}$

Origem urbana e residir em São Paulo mostraram-se associados ao ASI na análise de regressão logística univariada (Tabela 10).

Tabela 10. Associação entre características das mulheres e abuso sexual na infância. São Paulo, SP, e Zona da Mata, PE, 2000-2001.

\begin{tabular}{lccc}
\hline Variável & \multicolumn{3}{c}{ Abuso sexual infantil } \\
& OR bruto & IC95\% & $\mathbf{p}^{\mathbf{a}}$ \\
\hline Origem & & & $\mathbf{0 , 0 0 2 0}$ \\
$\quad$ Rural & 1 & & \\
$\quad$ Urbana & 1,9 & 1,$26 ; 2,77$ & \\
Migração & & & 0,3660 \\
\hline
\end{tabular}




\begin{tabular}{lcccc}
\hline Não & 1 & - & \\
Sim & 1,2 & 0,$80 ; 1,84$ & \\
$\begin{array}{l}\text { Local de residência } \\
\text { Zona da Mata de de }\end{array}$ & 1 & & $\mathbf{0 , 0 0 6 3}$ \\
$\begin{array}{l}\text { Pernambuco } \\
\text { São Paulo }\end{array}$ & & 1,7 & - & \\
\hline$<0,20$ & & & 1,$16 ; 2,47$ & \\
\end{tabular}

Violência física por parceiro íntimo sofrida pela mãe das mulheres esteve associada ao desfecho, o que não ocorreu para ver ou ouvir a violência na infância (Tabela 11).

Tabela 11. Associação entre experiências familiares de violência das mulheres e abuso sexual na infância. São Paulo, SP, e Zona da Mata, PE, 2000-2001.

\begin{tabular}{|c|c|c|c|}
\hline \multirow[t]{2}{*}{ Variável } & \multicolumn{2}{|c|}{ Abuso sexual infantil } & \multirow[b]{2}{*}{$\mathbf{p}^{\mathbf{a}}$} \\
\hline & OR & IC $95 \%$ & \\
\hline $\begin{array}{l}\text { Mãe ter sido agredida por } \\
\text { companheiro }\end{array}$ & & & 0,0000 \\
\hline Não & 1 & - & \\
\hline $\operatorname{Sim}$ & 2,4 & 1,$59 ; 3,55$ & \\
\hline $\begin{array}{l}\text { Pais não moravam juntos/não } \\
\text { sabe }\end{array}$ & 4,0 & 1,$92 ; 8,39$ & \\
\hline $\begin{array}{l}\text { Ver ou ouvir na infância mãe } \\
\text { agredida por companheiro }\end{array}$ & & & 0,6650 \\
\hline Não & 1 & - & \\
\hline Sim & 1,2 & 0,$46 ; 3,33$ & \\
\hline
\end{tabular}

Análise de regressão logística múltipla

Mãe ter sido agredida por companheiro, os pais não morarem juntos ou não saber da violência mantiveram-se associados ao desfecho. Migração e origem da entrevistada deixaram de ser significantes na modelagem e local de residência foi usado para ajuste da origem (Tabela 12).

Tabela 12. Fatores associados ao abuso sexual na infância. São Paulo, SP, e Zona da Mata, PE, 2000-2001.

\begin{tabular}{|c|c|c|}
\hline \multirow{2}{*}{ Variável } & \multicolumn{2}{|c|}{ Abuso sexual infantil } \\
\hline & $\mathrm{OR}^{\mathrm{a}}$ & IC95\% \\
\hline
\end{tabular}




\begin{tabular}{|c|c|c|c|}
\hline \multicolumn{4}{|l|}{$\begin{array}{l}\text { Mãe ter sido agredida por } \\
\text { companheiro }\end{array}$} \\
\hline Não & 1 & - & - \\
\hline Sim & 2,34 & 1,$58 ; 3,48$ & 0,000 \\
\hline $\begin{array}{l}\text { Pais não moravam } \\
\text { juntos/não sabe }\end{array}$ & 4,52 & 2,$13 ; 9,60$ & 0,000 \\
\hline \multicolumn{4}{|l|}{ Origem da entrevistada } \\
\hline Rural & 1 & - & \\
\hline Urbana & 1,53 & 0,$94 ; 2,60$ & 0,084 \\
\hline \multicolumn{4}{|l|}{ Local de residência } \\
\hline Zona da Mata de Pernambuco & 1 & - & \\
\hline São Paulo & 1,31 & 0,$80 ; 2,13$ & 0,283 \\
\hline
\end{tabular}

O modelo múltiplo teve bom ajuste $(0,4530)$ e acurácia considerável $(62,3 \%)$ (Figura 4).

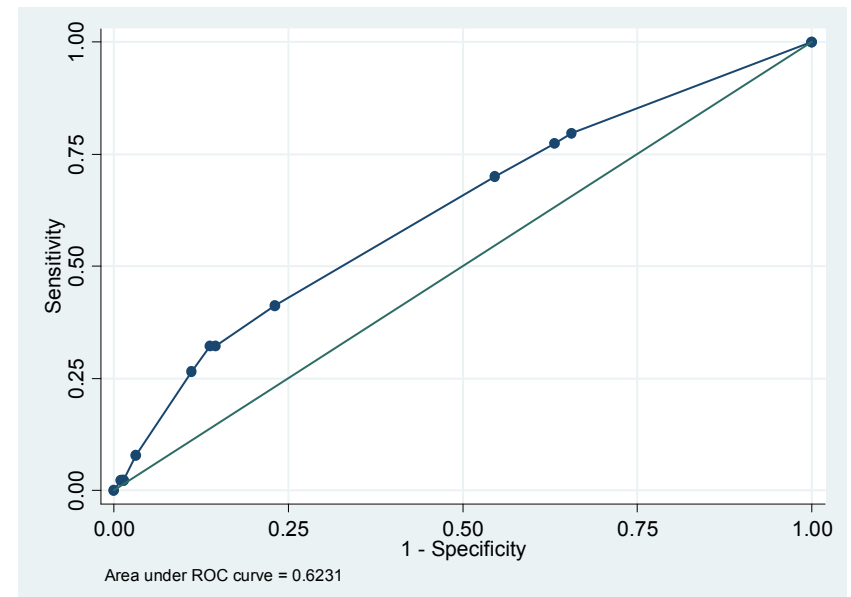

Figura 4. Curva ROC para modelo múltiplo de associação ao abuso sexual infantil. São Paulo e Zona da Mata de Pernambuco, 2001-2002.

\section{Modelo 2 - Sem temporalidade}

\section{$\underline{\text { Análise de regressão logística univariada }}$}

Faixa etária, situação conjugal, origem, número de pessoas por cômodo, mãe ter sido agredida por companheiro, mãe do marido/companheiro agredida, ele ter presenciado esse violência, marido/companheiro ter sido agredido fisicamente por familiar na infância, ajuda sociocomunitária, abuso sexual após os 15 anos, violência por parceiro íntimo, bens próprios, idade na primeira relação sexual, percepção sobre a saúde, saúde mental, tentativa/ideação suicida, uso diário de álcool e uso de medicamentos para dor, tristeza ou dormir nas últimas foram selecionados para análise 
múltipla em SP. Na ZMP, as variáveis selecionadas foram: situação conjugal, mãe ter sido agredida por companheiro, marido/companheiro ter sido agredido fisicamente por familiar na infância, apoio familiar, atitudes com relação a papéis de gênero, abuso sexual após os 15 anos, violência por parceiro íntimo, idade na primeira relação sexual, renda própria, percepção sobre a saúde, saúde mental, tentativa/ideação suicida e uso diário de álcool (Tabelas 13, 14, 15, 16 e 17).

Tabela 13. Associação entre características sociodemográficas das mulheres e abuso sexual na infância. São Paulo, SP, e Zona da Mata, PE, 2000-2001.

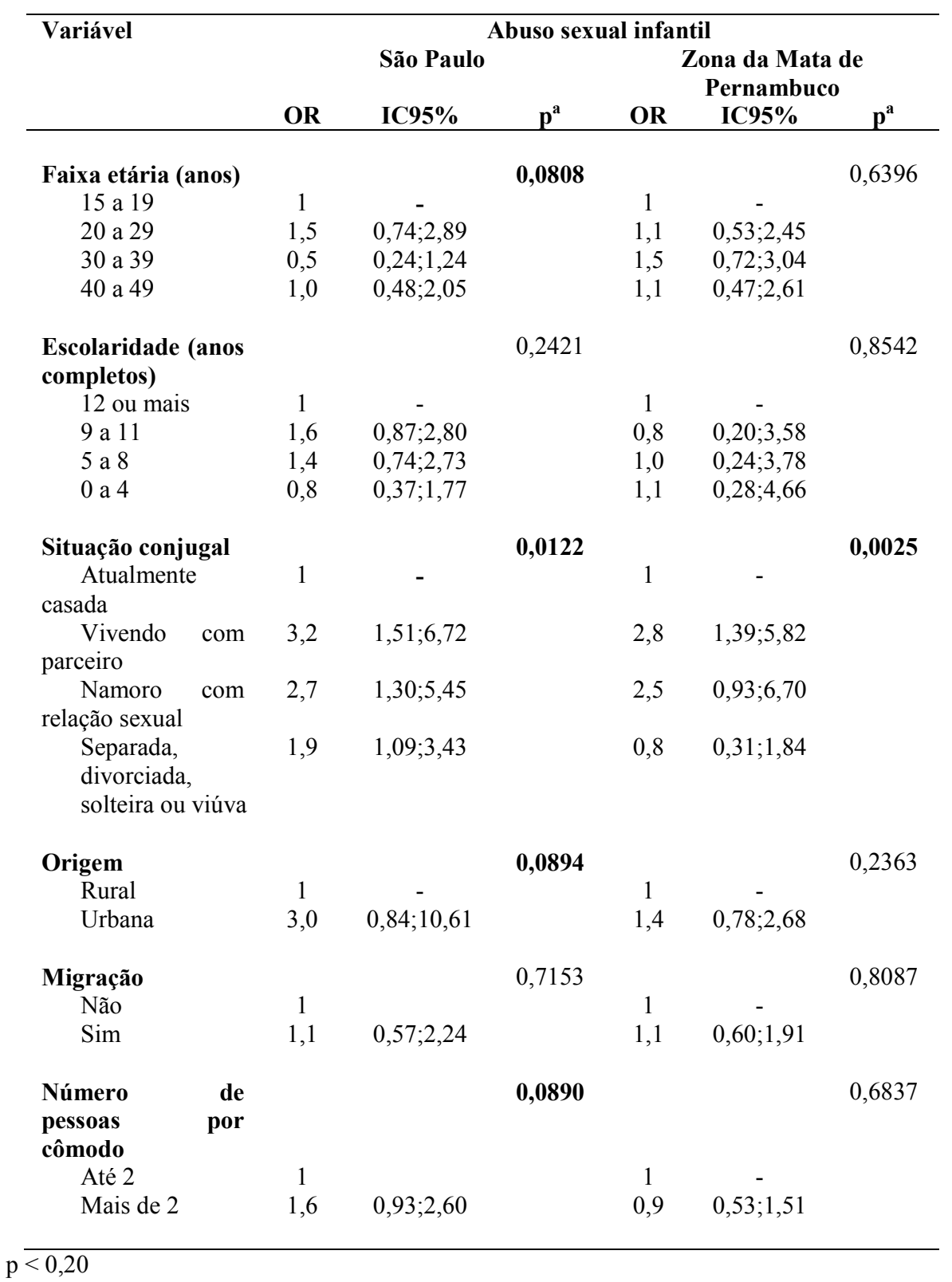


Tabela 14. Associação entre experiências familiares de violência das mulheres e abuso sexual na infância. São Paulo, SP, e Zona da Mata, PE, 2000-2001.

\begin{tabular}{|c|c|c|c|c|c|c|}
\hline \multirow[t]{3}{*}{ Variável } & \multicolumn{6}{|c|}{ Abuso sexual infantil } \\
\hline & \multirow[b]{2}{*}{ OR } & \multirow{2}{*}{$\begin{array}{r}\text { São Paulo } \\
\text { IC95\% } \\
\end{array}$} & \multirow[b]{2}{*}{$\mathbf{p}^{\mathrm{a}}$} & \multicolumn{3}{|c|}{ Zona da Mata de Pernambuco } \\
\hline & & & & OR & IC95\% & $\mathbf{p}^{\mathbf{a}}$ \\
\hline $\begin{array}{l}\text { Mãe ter sido agredida por } \\
\text { companheiro }\end{array}$ & & & 0,0046 & & & 0,0005 \\
\hline Não & 1 & - & & 1 & - & \\
\hline Sim & 2,4 & 1,$35 ; 4,17$ & & 2,4 & 1,$38 ; 4,23$ & \\
\hline $\begin{array}{l}\text { Pais não moravam } \\
\text { juntos/não sabe }\end{array}$ & 3,0 & 0,$91 ; 10,09$ & & 5,5 & 2,$09 ; 14,71$ & \\
\hline $\begin{array}{l}\text { Ver ou ouvir na infância mãe } \\
\text { agredida por companheiro }\end{array}$ & & & 0,5766 & & & 0,7790 \\
\hline Não & 1 & - & & 1 & - & \\
\hline Sim & 1,4 & 0,$39 ; 5,21$ & & 0,8 & 0,$18 ; 3,68$ & \\
\hline $\begin{array}{l}\text { Mãe do marido/companheiro } \\
\text { agredida fisicamente por } \\
\text { companheiro }\end{array}$ & & & $\mathbf{0 , 0 2 2 7}$ & & & 0,5615 \\
\hline Não & 1 & - & - & 1 & - & - \\
\hline Sim & 1,0 & 0,$56 ; 1,97$ & & 1,1 & 0,$48 ; 2,36$ & \\
\hline $\begin{array}{l}\text { Pais dele não moravam } \\
\text { juntos/não sabe }\end{array}$ & 2,2 & 1,$18 ; 4,02$ & & 1,4 & 0,$76 ; 2,56$ & \\
\hline $\begin{array}{l}\text { Marido/companheiro viu ou } \\
\text { ouviu na infância mãe } \\
\text { agredida por companheiro }\end{array}$ & & & 0,1915 & & & 0,2972 \\
\hline Não & 1 & - & - & 1 & - & \\
\hline $\operatorname{Sim}$ & 0,4 & 0,$87 ; 1,65$ & & 3,3 & 0,$34 ; 31,97$ & \\
\hline Não sabe & & & & & & \\
\hline $\begin{array}{l}\text { Marido/companheiro } \\
\text { apanhava regularmente ou } \\
\text { era agredido fisicamente por } \\
\text { alguém da família }\end{array}$ & & & 0,0470 & & & 0,0199 \\
\hline Não & 1 & - & - & 1 & - & - \\
\hline Sim & 2,1 & 1,$11 ; 3,87$ & & 2,2 & 1,$26 ; 3,84$ & \\
\hline Não sabe & 0,78 & 0,$22 ; 2,58$ & & 0,9 & 0,$32 ; 2,58$ & \\
\hline Irmã(s) $\quad$ agredida(s) & & & 0,5790 & & & 0,4340 \\
\hline fisicamente por companheiro & & & & & & \\
\hline Não & 1 & - & & 1 & - & \\
\hline Sim & 1,1 & 0,$68 ; 1,96$ & & 1,4 & 0,$84 ; 2,32$ & \\
\hline Não sabe & 1,9 & 0,$57 ; 6,14$ & & 1,1 & 0,$37 ; 3,09$ & \\
\hline
\end{tabular}


Tabela 15. Associação entre conectividade sociofamiliar das mulheres e abuso sexual infantil. São Paulo, SP, e Zona da Mata, PE, 2000-2001.

\begin{tabular}{|c|c|c|c|c|c|c|}
\hline \multirow[t]{3}{*}{ Variável } & \multicolumn{6}{|c|}{ Abuso sexual infantil } \\
\hline & \multirow[b]{2}{*}{ OR } & \multirow{2}{*}{$\begin{array}{r}\text { São Paulo } \\
\text { IC95\% } \\
\end{array}$} & & \multicolumn{3}{|c|}{ Zona da Mata de Pernambuco } \\
\hline & & & $\mathbf{p}^{\mathbf{a}}$ & OR & IC95\% & $\mathbf{p}^{\mathbf{a}}$ \\
\hline Ajuda sociocomunitária & & & 0,1005 & & & 0,3430 \\
\hline Sim & 1 & - & & 1 & - & \\
\hline Pouca & 1,0 & 0,$45 ; 1,85$ & & 1,5 & 0,$87 ; 2,44$ & \\
\hline Não & 2,4 & 1,$05 ; 5,52$ & & 1,5 & 0,$33 ; 7,11$ & \\
\hline Apoio familiar & & & 0,3291 & & & 0,0309 \\
\hline Sim & 1 & - & & 1 & - & \\
\hline Não & 1,4 & 0,$72 ; 2,61$ & & 2,0 & 1,$06 ; 3,65$ & \\
\hline Contato com a família & & & 0,2444 & & & 0,5645 \\
\hline Sim & 1 & - & & 1 & - & \\
\hline Não & 0,6 & 0,$22 ; 1,48$ & & 1,3 & 0,$57 ; 2,75$ & \\
\hline $\begin{array}{l}\text { Atitudes com relação aos } \\
\text { papéis de gênero }\end{array}$ & & & & & & 0,1372 \\
\hline Autonomia & & & & 1 & - & \\
\hline Submissão & & & & 0,3 & 0,$05 ; 1,53$ & \\
\hline
\end{tabular}

Tabela 16: Associação entre aspectos relacionados a questões de gênero das mulheres e abuso sexual na infância. São Paulo, SP, Zona da Mata, PE, 2000-2001.

\begin{tabular}{|c|c|c|c|c|c|c|}
\hline \multirow[t]{3}{*}{ Variável } & \multicolumn{6}{|c|}{ Abuso sexual infantil } \\
\hline & \multicolumn{3}{|c|}{ São Paulo } & \multicolumn{3}{|c|}{ Zona da Mata de Pernambuco } \\
\hline & OR & IC95\% & $\mathbf{p}^{\mathbf{a}}$ & OR & IC95\% & $\mathbf{p}^{\mathbf{a}}$ \\
\hline Abuso sexual após os 15 anos & & & 0,000 & & & 0,0000 \\
\hline Não & 1 & - & & 1 & - & \\
\hline Sim & 6,5 & 3,$37 ; 12,57$ & & 4,8 & 2,$43 ; 9,41$ & \\
\hline $\begin{array}{l}\text { Freqüiência dos episódios de violência } \\
\text { na vida }\end{array}$ & & & 0,271 & & & 0,9584 \\
\hline Uma ou poucas vezes & 1 & - & & 1 & - & \\
\hline Muitas vezes & 1,7 & 0,$65 ; 4,56$ & & 1,0 & 0,$35 ; 2,68$ & \\
\hline Violência por parceiro íntimo & & & 0,004 & & & 0,0001 \\
\hline Não sofreu & 1 & - & & 1 & - & \\
\hline Exclusivamente psicológica & 2,9 & 1,$24 ; 6,99$ & & 1,1 & 0,$36 ; 3,09$ & \\
\hline Psicológica e física & 4,4 & 1,$84 ; 10,32$ & & 1,8 & 0,$81 ; 4,24$ & \\
\hline Psicológica, física e sexual & 4,3 & 1,$75 ; 10,78$ & & 6,0 & 2,$66 ; 13,48$ & \\
\hline Exclusivamente física & 5,7 & 2,$11 ; 15,20$ & & 3,9 & 0,$89 ; 16,71$ & \\
\hline Sexual (não exclusiva) & 2,7 & 0,$69 ; 10,74$ & & 4,9 & 1,$64 ; 14,90$ & \\
\hline Bens próprios & & & 0,051 & & & 0,3083 \\
\hline Possui bens próprios sozinha & 1 & - & & 1 & - & \\
\hline Possui bens próprios partilhados & 0,6 & 0,$37 ; 1,04$ & & 0,6 & 0,$32 ; 1,17$ & \\
\hline Não possui bens próprios & 0,2 & 0,$04 ; 0,89$ & & 0,6 & 0,$25 ; 1,36$ & \\
\hline Renda própria & & & 0,320 & & & 0,1696 \\
\hline Sim & 1 & - & & 1 & - & \\
\hline Não & 0,8 & 0,$44 ; 1,31$ & & 0,7 & 0,$45 ; 1,15$ & \\
\hline Idade na primeira relação sexual (anos) & & & 0,000 & & & $\mathbf{0 , 0 0 0 0}$ \\
\hline
\end{tabular}




\begin{tabular}{lcccc}
\hline $\begin{array}{l}\geq 15 \\
<15\end{array}$ & 1 & - & 1 & - \\
& 3,5 & 1,$97 ; 6,14$ & 4,6 & 2,$77 ; 7,53$ \\
\hline
\end{tabular}

Tabela 17: Associação entre saúde das mulheres e abuso sexual na infância. São Paulo, SP, e Zona da Mata de Pernambuco, PE, 2000-2001.

\begin{tabular}{|c|c|c|c|c|c|c|}
\hline \multirow[t]{3}{*}{ Variável } & \multicolumn{6}{|c|}{ Abuso sexual infantil } \\
\hline & \multirow[b]{2}{*}{ OR } & \multirow{2}{*}{$\begin{array}{l}\text { São Paulo } \\
\text { IC95\% }\end{array}$} & & \multicolumn{3}{|c|}{ Zona da Mata de Pernambuco } \\
\hline & & & $\mathbf{p}^{\mathbf{a}}$ & OR & IC95\% & $\mathbf{p}^{\mathbf{a}}$ \\
\hline Percepção sobre a saúde & & & 0,0829 & & & 0,0919 \\
\hline Excelente/boa & 1 & - & & 1 & - & \\
\hline Regular/Ruim/Muito ruim & 1,7 & 0,$93 ; 2,95$ & & 1,6 & 0,$93 ; 2,68$ & \\
\hline Saúde Mental & & & 0,0164 & & & 0,0239 \\
\hline $\begin{array}{l}\text { Sem transtorno mental } \\
\text { comum }\end{array}$ & 1 & - & & 1 & - & \\
\hline $\begin{array}{l}\text { Com transtorno mental } \\
\text { comum }\end{array}$ & 2,0 & 1,$14 ; 3,48$ & & 1,9 & 1,$09 ; 3,23$ & \\
\hline Tentativa/ideação de suicídio & & & 0,0025 & & & 0,0012 \\
\hline Não & 1 & - & & 1 & - & \\
\hline Sim & 2,5 & 1,$40 ; 4,55$ & & 2,4 & 1,$43 ; 4,20$ & \\
\hline Uso diário de álcool & & & 0,0567 & & & $\mathbf{0 , 0 0 0 0}$ \\
\hline Não & 1 & - & & 1 & - & \\
\hline Sim & 4,2 & 0,$96 ; 18,61$ & & 7,7 & 1,$28 ; 46,05$ & \\
\hline $\begin{array}{l}\text { Problemas relacionados ao uso } \\
\text { de álcool }\end{array}$ & & & 0,2514 & & & 0,6232 \\
\hline Não & 1 & - & & 1 & - & \\
\hline Sim & 1,9 & 0,$62 ; 5,85$ & & 1,3 & 0,$49 ; 3,28$ & \\
\hline $\begin{array}{l}\text { Uso de medicamentos para } \\
\text { dor, tristeza ou sono nas } \\
\text { últimas quatro semanas }\end{array}$ & & & 0,0024 & & & 0,2930 \\
\hline Não & 1 & - & & 1 & - & \\
\hline Poucas vezes & 2,4 & 1,$40 ; 4,04$ & & 1,1 & 0,$64 ; 1,93$ & \\
\hline Muitas vezes & 2,7 & 1,$30 ; 5,81$ & & 1,8 & 0,$85 ; 3,81$ & \\
\hline
\end{tabular}

\section{$\underline{\text { Análise de regressão logística múltipla }}$}

Mulheres que sofreram abuso sexual após os 15 anos, cuja primeira relação sexual ocorreu antes dessa idade, que usaram de medicamentos para dor, tristeza ou sono nas últimas quatro semanas, que sofreram violência exclusivamente física por parceiro íntimo e cujo marido/companheiro tenha sofrido violência física por familiar na infância apresentaram maior probabilidade de terem sofrido abuso sexual na infância segundo análise múltipla para SP. Mãe do marido/companheiro agredida por companheiro, mãe ter sido agredida por companheiro e situação conjugal foram 
utilizados para ajuste. As demais variáveis (faixa etária, número de pessoas por cômodo, marido/companheiro ter presenciado a violência contra a mãe por companheiro, ajuda sociocomunitária, bens próprios, percepção sobre a saúde, saúde mental e tentativa/ideação suicida) perderam a significância estatística na modelagem (Tabela $18)$.

$\mathrm{Na}$ ZMP, mulheres que foram abusadas sexualmente após os 15 anos, que tiveram primeira relação sexual antes dessa idade, que faziam uso diário de álcool, sofreram violência física, psicológica e sexual combinadas ou violência exclusivamente sexual perpetrada por parceiro íntimo, cujas mães sofreram violência por parceiro íntimo, ou não se lembraram dessa violência ou os pais não moravam juntos também apresentaram maior problabilidade de ASI. Tentativa/ideação suicida, mãe do marido agredida por parceiro íntimo, mãe agredida por parceiro íntimo e situação conjugal foram usados como ajuste. As demais variáveis (situação conjugal, marido/companheiro ter sido agredido fisicamente por familiar na infância, apoio familiar, atitudes com relação a papéis de gênero, renda própria, percepção sobre a saúde, saúde mental e tentativa/ideação suicida) perderam a significância estatística (Tabela 18).

Tabela 18. Características sociodemográficas, experiências familiares de violência, aspectos relacionados a questões de gênero e saúde e sua associação com abuso sexual na infância. São Paulo, SP, e Zona da Mata, PE, 2000-2001.

\begin{tabular}{|c|c|c|c|c|c|c|}
\hline \multirow[t]{3}{*}{ Característica } & \multicolumn{6}{|c|}{ Abuso sexual infantil" } \\
\hline & \multirow[b]{2}{*}{ OR } & \multirow{2}{*}{$\begin{array}{r}\text { São Paulo } \\
\text { IC95\% }\end{array}$} & \multirow[b]{2}{*}{$\mathbf{p}^{\mathrm{a}}$} & \multicolumn{3}{|c|}{ Zona da Mata de Pernambuco } \\
\hline & & & & OR & IC95\% & $\mathbf{p}^{\mathrm{a}}$ \\
\hline \multicolumn{7}{|c|}{$\begin{array}{l}\text { Abuso sexual após os } 15 \\
\text { anos }\end{array}$} \\
\hline Não & 1 & - & - & 1 & - & - \\
\hline Sim & 4,5 & 2,$22 ; 9,07$ & 0,000 & 4,7 & 2,$07 ; 10,56$ & $\mathbf{0 , 0 0 0}$ \\
\hline \multicolumn{7}{|c|}{$\begin{array}{l}\text { Idade da primeira relação } \\
\text { sexual (anos) }\end{array}$} \\
\hline$\geq 15$ & 1 & - & - & 1 & - & - \\
\hline$<15$ & 2,9 & 1,$53 ; 5,48$ & 0,001 & 2,2 & 1,$09 ; 4,28$ & 0,028 \\
\hline \multicolumn{7}{|c|}{$\begin{array}{l}\text { Uso de medicamentos para } \\
\text { dor, tristeza ou sono nas } \\
\text { últimas quatro semanas }\end{array}$} \\
\hline Não & 1 & - & - & & & \\
\hline Sim & 1,7 & 1,$03 ; 3,01$ & $\mathbf{0 , 0 3 9}$ & & & \\
\hline Uso diário de álcool & & & & 1 & - & - \\
\hline Não & & & & 4,7 & 1,$06 ; 21,00$ & 0,041 \\
\hline \multicolumn{7}{|l|}{ Sim } \\
\hline Tentativa/ideação & & & & & & \\
\hline
\end{tabular}


suicídio

Não

Sim

$\begin{array}{ccc}1 & - & - \\ 1,3 & 0,62 ; 2,83 & 0,466\end{array}$

Mãe

marido/companheiro

agredida por companheiro

$\begin{array}{lccc}\text { Não } & 1 & - & - \\ \text { Sim } & 0,7 & 0,35 ; 1,48 & 0,114 \\ \text { Não sabe } & 1,7 & 0,88 ; 3,35 & 0,110 \\ & & & \\ \text { Mãe ter sido agredida por } & & & \\ \text { ompanheiro } & & & - \\ \text { Não } & 1 & - & 0,211 \\ \text { Sim } & 1,5 & 0,78 ; 2,99 & 0,538 \\ \text { Pais não moravam } & 1,7 & 0,32 ; 8,80 & 0,538\end{array}$

juntos/não sabe

\section{Violência por parceiro íntimo}

Não sofreu

Exclusivamente

psicológica

Psicológica e física $\quad 2,4 \quad 0,90 ; 6,35$

Psicológica, física e $\quad 1,6 \quad 0,52 ; 4,92$

sexual

Exclusivamente física

Sexual (não exclusiva)

$\begin{array}{cc}1 & - \\ 1,4 & 0,62 ; 3,23 \\ & \\ 2,4 & 0,90 ; 6,35 \\ 1,6 & 0,52 ; 4,92 \\ & \\ \mathbf{3 , 4} & \mathbf{1 , 1 7 ; 9 , 9 1} \\ 1,1 & 0,21 ; 5,71\end{array}$

$1,1 \quad 0,21 ; 5,71$
1

2,2

1,$13 ; 4,24$

$\mathbf{0 , 0 2 1}$

4,3

1,$67 ; 11,40$

Situação conjugal

Atualmente casada

Vivendo com parceiro

$1,9 \quad 0,83 ; 4,52 \quad 0,122$

Namoro com relação sexual

Separada, divorciada $\quad 1,5 \quad 0,53 ; 4,30 \quad 0,427$

solteira ou viúva

Marido/companheiro sofreu violência física por familiar na infância

Não

Sim

Não sabe

${ }^{\mathrm{a}} \mathrm{p}<0,05$

* Os espaços em branco indicam que não houve associação.

Os modelos apresentaram bom ajuste $(0,1695$ para SP e 0,6381 para a ZMP) e considerável acurácia $(75,28 \%$ e 74,73\% para SP e ZMP, respectivamente) (Figuras 5 e $6)$. 


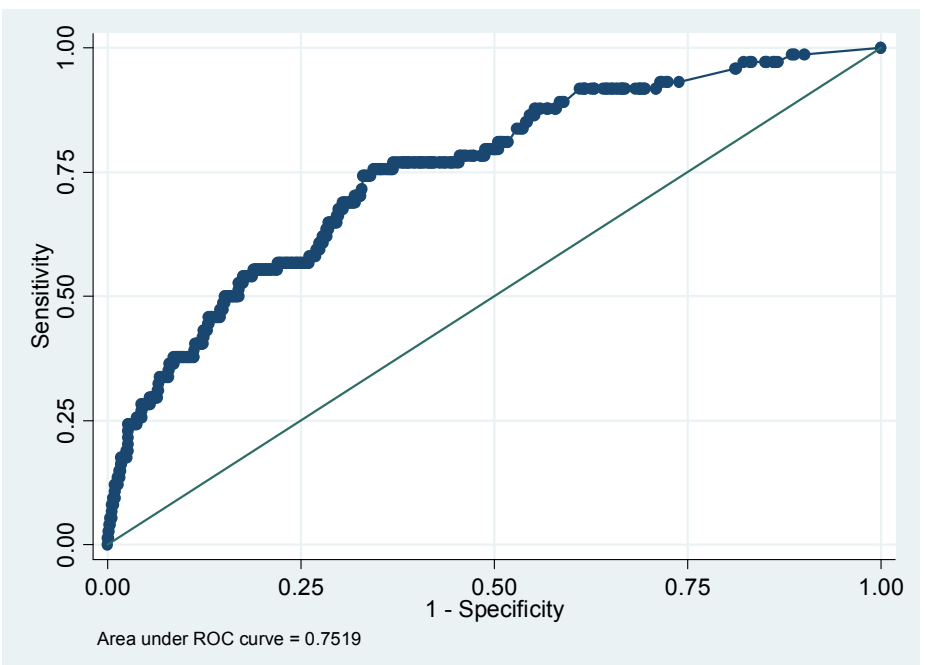

Figura 5. Curva ROC para modelo múltiplo de associação ao abuso sexual infantil. São Paulo, SP, 2001-2002.

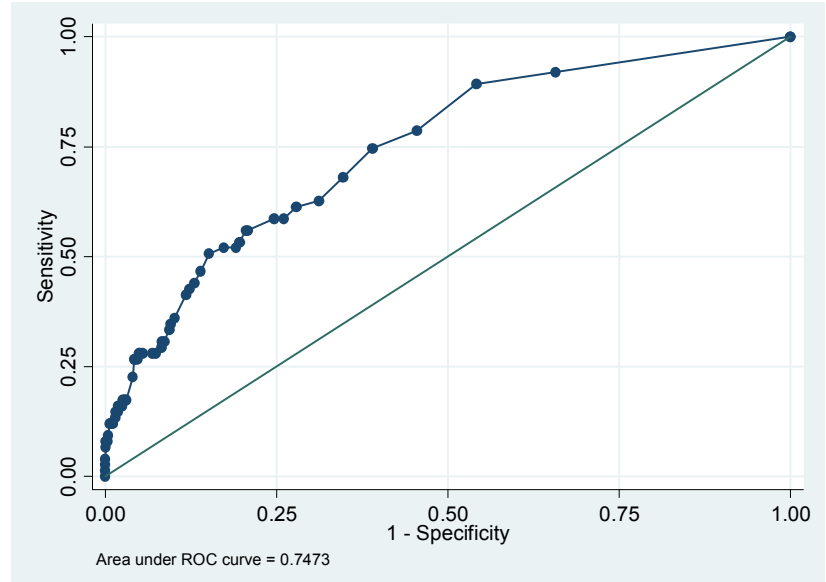

Figura 6. Curva ROC para modelo múltiplo de associação ao abuso sexual infantil. Zona da Mata de Pernambuco, PE, 2001-2002. 


\section{DISCUSSÃO}

Este é um dos poucos estudos populacionais brasileiros sobre ASI e o primeiro a estimar sua prevalência em áreas de características urbanas e rurais no País. É também pioneiro por ser comparável a estudos internacionais que compartilham do mesmo método e instrumento.

\section{Ocorrência e características do ASI}

A magnitude do abuso sexual na infância de mulheres no Brasil é significativa. O abuso sexual é uma das formas mais severas de violência contra a criança. Configurase como violação à sua integridade física, psíquica e social, aos seus direitos e aos direitos humanos de forma geral. Como tal, espera-se que o abuso não ocorra e que não acometa a nenhuma criança. Qualquer valor diferente de zero em sua prevalência deve ser considerado elevado.

Os números do abuso sexual na infância brasileira são elevados. O censo brasileiro registrou 3.135.015 mulheres de 15 a 49 anos na cidade de São Paulo no ano $2000,{ }^{3}$ ano de coleta de dados da presente pesquisa. Pode-se inferir que 244.532 mulheres residentes em SP teriam sofrido ASI. No mesmo período, havia 316.881 mulheres dessa faixa etária na ZMP, o que corresponderia a 15.211 mulheres vítimas de violência sexual em sua infância.

A proporção de ASI no Brasil não está entre as maiores se comparada a dados internacionais. Entre os países participantes da pesquisa multicêntrica da OMS, as prevalências variaram de 0,2\% (Etiópia) a 44,4\% (Tanzânia) em áreas urbanas e de $1,0 \%$ (Bangladesh) a 28,2\% (Nova Zelândia) em áreas rurais. As taxas no Brasil apresentaram valores intermediários em relação aos demais para as duas regiões $(7,8 \%$ em área urbana e 4,8\% em área rural) e próximos a países como Bangladesh $(7,4 \%$ em região metropolitana), Tailândia (7,6\% e 4,7\% em cidade e província, respectivamente) e Tanzânia (4,2\% em região rural) (Tabela 1). Não há publicações que discutam os dados desses países e que permitam comparações com a realidade brasileira. Distinções

\footnotetext{
${ }^{3}$ Kishor S, Johnson K. Profiling domestic violence: a multi-country study. Caverton (Maryland): ORC Macro; 2004. [acesso em 03 mar 2011]. Disponível em: http://www.measuredhs.com/pubs/pdf/OD31/OD31.pdf
} 
nas prevalências podem corresponder à proporção real de crianças que sofrem abuso sexual no cenário mundial, mas também podem significar maior facilidade de relato em algumas regiões do planeta do que em outras (FANSLOW et al, 2007). Diferenças culturais entre os países podem interferir nas estimativas de ASI, seja na ocorrência, seja no relato.

Maiores índices foram observados em SP em relação à ZMP, mesma relação obtida para a maioria dos países, i.e, ASI foi mais freqüente em cidades do que em regiões de características rurais (GARCIA-MORENO et al, 2005). Embora maiores proporções de violência contra a mulher sejam descritas em localidades rurais (GARCIA-MORENO et al, 2005; SCHRAIBER et al, 2007), para casos de abuso na infância ocorreu o oposto. Talvez, porque mulheres dessas áreas relatem menos esse tipo de violência, uma vez que essas regiões são mais conservadoras e possuem padrões mais tradicionais nas relações de gênero (SCHRAIBER et al, 2007) e familiares.

O governo brasileiro e organizações não governamentais têm promovido várias campanhas contra a violência sexual infantil nos últimos anos. Tais campanhas possuem ampla disseminação no País, sobretudo em áreas urbanas, e estimulam a imediata denúncia ante a menor suspeita de violência, conforme preconizado pelo Estatuto da Criança e Adolescente (1990). Além disso, os serviços de atendimento às vítimas estão localizados nas cidades, sobretudo nos grandes centros, como SP. Essas ações podem contribuir para que a violência seja mais discutida e menos tolerada, e conseqüentemente, mais relatada, o que poderia explicar em parte as maiores prevalências de ASI em áreas urbanas brasileiras.

As proporções do abuso no presente estudo foram maiores do que as encontradas no único estudo populacional brasileiro sobre o tema, realizado em uma cidade do Sul, segundo o qual 5,6\% das mulheres relataram a violência (BASSANI et al, 2009). As diferenças entre as prevalências podem decorrer de aspectos metodológicos, uma vez que foram utilizados delineamento, instrumentos, definições de ASI e faixa etária dos entrevistados distintos. Esses aspectos podem interferir substancialmente nos dados produzidos (BRIERE, 1992; MARTIN et al, 1991). Por outro lado, questões regionais podem estar ligadas aos resultados, considerando que São Paulo, Zona da Mata de Pernambuco e a cidade do Sul pertencem a regiões brasileiras diferentes (Sudeste, Nordeste e Sul, respectivamente). Essas regiões, além de geograficamente distantes, possuem características econômicas, sociais e políticas particulares entre si, que podem 
refletir nas relações interpessoais de seus habitantes. Essa hipótese deve ser mais bem investigada em outros estudos.

Os dados deste estudo podem estar subestimados, apesar de todos os cuidados éticos e metodológicos. A natureza altamente sensível do tema pode contribuir para a subestimação. Para calcular essa subestimação, ao final de cada entrevista, foi entregue um cartão à mulher, no qual havia apenas duas figuras: um rosto triste e um rosto feliz. Sem que se identificasse em tais cartões, solicitou-se que a mulher fizesse uma marca sobre o rosto triste caso tivesse sido tocada sexualmente ou obrigada a uma atividade sexual quando não queria antes de completar 15 anos. Se isso jamais tivesse acontecido, pedia-lhe que marcasse o rosto feliz. Em seguida, o cartão era depositado em uma caixa, garantindo o anonimato das respondentes. Com essa estratégia, a prevalência de ASI foi maior nas duas regiões (11,6\% em SP e 8,7\% na ZMP) (ELLSBERG e HEISE, 2005).

Além disso, possíveis vieses de memória podem ter ocorrido. Memórias de ASI estão mais propensas a erros do que lembranças de questões menos complexas (HARDT et al, 2006). Ainda assim, os dados estariam mais próximos à realidade do que em pesquisas documentais, cuja subestimação tende a ser ainda maior (RIBEIRO, FERRIANI e REIS, 2004).

O principal agressor era do sexo masculino, assim como em outros estudos (FLEMING, 1997; KRUG et al, 2002; RIBEIRO, FERRIANI e REIS, 2004; GARCIAMORENO et al, 2005; FANSLOW et al, 2007). O ASI é marcado pelas relações de gênero, que têm por base a submissão feminina nas relações desiguais entre homens e mulheres. A violência perpetrada por homens freqüentemente é banalizada e entendida como parte da natureza masculina ou resultado de sua genética ou compleição física. Em outras vezes, a vítima é culpabilizada, como se houvesse provocado a agressão a que é submetida (SCHRAIBER et al, 2005).

A compreensão sobre a violência distancia-se dessas explicações simplistas; a violência é uma construção sociocultural, valorizada ou não em determinada época ou situação. Homens e mulheres modulam suas construções acerca de sua identidade a partir das representações sociais sobre os papéis femininos e masculinos e de suas interações ao longo da vida. Dessa forma, são construídas masculinidades e feminilidades. A violência do homem contra a mulher pode ocorrer na tentativa de que se estabeleça o padrão esperado, ou mesmo, como forma de afirmar essa masculinidade. Esse padrão pode estar impregnado de estereótipos que, em uma sociedade patriarcal, 
oferecem maior valor e poder à condição masculina, além de características de agressividade, competitividade, austeridade, virilidade, entre outros. A violência seria por si só fonte de poder legitimada pela sociedade (SCHRAIBER et al, 2005), exercida nas relações familiares, em que o homem praticamente possui o domínio total.

A violência sexual infantil ocorreu principalmente na família, conforme mostra a literatura (GARCIA-MORENO et al, 2005; UNICEF, 2006; FANSLOW et al, 2007). A família, no imaginário social, é tida como um grupo harmonioso, fonte de conforto, segurança, carinho e alegria a seus membros. Entretanto, esse mesmo grupo pode ser palco de tensões e conflitos entre gêneros e entre gerações (SCHRAIBER et al, 2005). Guerra (1998) define como síndrome do pequeno poder as explosões emocionais contra os mais próximos e indefesos; a vítima de um poder mais forte exerce seu pequeno poder sobre o mais fraco. O abuso sexual deflagra condições de hierarquia e de poder, em que o adulto subordina a criança à satisfação de seus desejos e impulsos sexuais. A história da infância é marcada por sua dominação pela família, pelas instituições e pelo Estado, em relações não raro violentas (ÁRIES, 1986). A vitimização, portanto, ocorre no território físico e simbólico da estrutura familiar (RIBEIRO, FERRIANI e REIS, 2004). A ZMP, contudo, mostrou maior proporção de abuso extrafamiliar, embora sem significância estatística. Mais uma vez, esse resultado poderia representar a dificuldade que mulheres de áreas rurais teriam em falar sobre o abuso cometido na família, em razão do conservadorismo e do patriarcalismo dessas regiões.

Crianças são mais vitimadas sexualmente por homens membros da família (JESSIE ANDERSON, 1993), diferentes de pais e padrastos. Na Nova Zelândia, os principais agressores são os tios (FANSLOW et al, 2004). Outros estudos apontam o pai e o padrasto como os maiores autores de ASI (ESPINOSA e SANCHEZ, 2007; RIBEIRO, FERRIANI e REIS, 2004). Entretanto, esses dados são decorrentes de pesquisas documentais, o que pode significar de o ASI seja mais denunciado quando acometido por pais/padrastos. Em pesquisas populacionais, cujos resultados tendem a ser mais fiéis à realidade, parentes do sexo masculino são os principais perpetradores da violência (GARCIA-MORENO et al, 2005).

O ASI tende a ser recorrente quando o autor é parte da família. A violência incestuosa geralmente envolve um ambiente dissimulado, que envolve carícias, toques, beijos (ECHEBURÚA et al, 2006) e outras formas de estimulação que raramente deixam marcas físicas. Isso pode durar muito tempo, até que se chegue ao coito 
(MORALES e SCHRAMM, 2002). Essa recorrência contribui para o aumento da gravidade da violência e de suas conseqüências na vida das vítimas (RUDIN, ZALEWSKI, BODMER-TURNER, 1995). Por outro lado, o abuso extrafamiliar, sobretudo se cometido por estranhos, tende a ocorrer de forma isolada e com envolvimento de condutas violentas ou de ameaças (ECHEBURÚA et al, 2006).

A idade de maior ocorrência do abuso é dos 12 aos 15 anos, seguida da faixa de oito a 11 anos, semelhante ao descrito por Ribeiro, Ferriani e Reis (2004). Segundo FANSLOW et al (2004), abuso ocorre em média aos nove anos entre meninas, ao passo que FLEMING (1997) estima que seja aos dez anos, idades que coincidem com o inicio da puberdade. O abuso é pouco relatado em idades precoces. Talvez isso se deva a possível viés de memória, i.e., o abuso não é relatado para menores idades porque não é lembrado. A memória pode ser um elemento importante para explicar por que o relato de ASI aumenta com a idade.

Os autores da violência possuem de 30 a 39 anos em sua maioria, mesma idade observada por Fleming (1997) e Fanslow et al (2004), que relataram médias de idade de 34 anos e 30 anos, respectivamente. Em média, os agressores são de 21 a 24 anos mais velhos que suas vítimas (FLEMING, 1997; FANSLOW et al, 2004), o que também pode ser observado no presente estudo. A diferença de idade é um dos fatores importantes para que relações assimétricas sejam estabelecidas, conforme explicita a definição de ASI pela OMS (1999).

Para parcela substancial de mulheres, a primeira relação sexual não foi desejada, inclusive antes dos 15 anos, o que fere os direitos básicos à integridade corporal (GARCIA-MORENO et al, 2005) e os direitos sexuais e reprodutivos. O mesmo foi relatado para os demais países da pesquisa multicêntrica da OMS, embora tenha havido diferenças significativas nas proporções apresentadas. Iniciação sexual forçada antes dos 15 anos foi mais relatada por mulheres da ZMP do que as de SP. Essas discrepâncias podem ser decorrentes de concepções sociais distintas acerca da sexualidade feminina e do comportamento sexual, como fortes restrições sociais à expressão do desejo sexual por mulheres, ou ainda, podem refletir diferenças culturais na possibilidade de que elas controlem as circunstâncias de sua primeira experiência sexual (GARCIA-MORENO et al, 2005).

Primeira relação sexual antes dos 15 anos foi relatada por quase $10 \%$ das entrevistadas e a maior parte foi descrita como forçada, proporção semelhante à 
calculada com base na Pesquisa Nacional de Demografia e Saúde da Criança e da Mulher (12,66\%). Por outro prisma, o Código Penal brasileiro, lei $\mathrm{n}^{\mathrm{o}} 12.015$, de 7 de agosto de $2009,{ }^{4}$ considera estupro de vulnerável ter conjunção carnal ou praticar outro ato libidinoso com menor de 14 anos (artigo 217-A) e crime sexual contra passivo induzir alguém menor de 14 anos a satisfazer a lascívia de outrem (artigo 218). Não importa se há consentimento ao realizar o ato, o crime de estupro vulnerável está consumado quando se pratica qualquer ato com esse sujeito considerado passivo. Isso porque se acredita que tais sujeitos não possuem condições de consentir o ato sexual em função de sua idade ou condição de desenvolvimento. Diante disso, a partir desse artigo, os índices de ASI no Brasil poderiam ser maiores.

\section{Explorando as causas do ASI}

Características socioeconômicas não estiveram associadas ao abuso, sugerindo que o ASI possui ampla distribuição social, atingindo pessoas de diferentes condições socioeconômicas, ao contrário do que permeia o imaginário social, que liga a violência à pobreza. Segundo Neves e Romanelli (2006), a violência está presente nas diversas classes sociais. Entretanto, entre as classes mais favorecidas, essa violência torna-se camuflada pelos baixos índices de denúncia e por diferentes mecanismos utilizados para mascarar a realidade. Entre as classes populares, a violência vem mais facilmente à tona, uma vez que estão sob maior foco de atenção e intervenção de órgãos públicos.

Para variáveis temporamente próximas ao desfecho, a violência física por parceiro íntimo sofrida pela mãe na infância das mulheres mostrou-se importante fator de risco para a ocorrência de ASI, como observado em outros estudos (PAVEZA, 1989; RUMM et al, 2000; KRUG et al, 2002; AYALA et al, 2009). A violência conjugal é descrita pela literatura como fator de risco para o desenvolvimento de patologias e de transtornos de ajustamento infantis (BOOTH, CROUTER e CLEMENTS, 2001) e o testemunho dessa violência chega a ser comparável à experiência da violência em si quanto às suas conseqüências (RAVAZZOLA, 2005). Ademais, crianças expostas à violência entre os pais/parceiros íntimos tornam-se mais propensas a serem também vítimas de maus tratos (SANI, 2006). Os dados do presente estudo apontam que o risco

\footnotetext{
${ }^{4}$ Disponível em: http://www.planalto.gov.br/ccivil_03/_ato2007-2010/2009/lei/112015.htm [Acesso em 02 Mai 2011].
} 
aumentado de meninas sofrerem abuso sexual em lares em que há violência entre parceiros íntimos, mesmo que não seja relatada como vista ou ouvida. Isso porque, mesmo que a criança não presencie a cena violenta, ela afeta as relações da família como um todo. Mães agredidas fisicamente podem desenvolver transtornos, como depressão e ansiedade, que podem interferir significativamente no cuidado e na proteção dos filhos (ESFANDYARI, BAHARUDIN e NOWZARI, 2009). Entre os fatores que influenciam a não denúncia de abuso sexual sofrido por meninas, por exemplo, estão as violências vividas por mães em sua família de origem quando crianças, assim como a falta de uma família protetora (NARVAZ, 2005). Claro está que o agressor de mães e filhas pode ser o mesmo. Isso sugere a existência de um ciclo da violência, que deve ser rompido para que também o seja o ASI.

Pais serem separados esteve associado à ocorrência do abuso. Muitas separações conjugais são marcadas por agressividade e ocorrem de forma violenta ou para cessar a violência nos relacionamentos (D’OLIVEIRA et al, 2009). Isso pode explicar a associação encontrada entre as variáveis.

\section{Identificando marcadores do ASI}

O modelo sem restrição de temporalidade estimou associação entre características da respondente com a experiência de abuso sexual na infância. Os fatores associados foram entendidos como marcadores de risco. Os marcadores indicam a probabilidade de que a mulher adulta que relate um ou mais fatores tenha vivido o abuso na infância. Marcadores são úteis para identificação retrospectiva de casos para fins de cuidado psicossocial, além de possibilitar o combate policial e jurídico da violência, a partir da detecção de áreas de maior ocorrência de ASI. Equidade de gênero. Social e político.

Aspectos relacionados a questões de gênero, características de saúde e experiências familiares de violência compuseram os principais marcadores de risco ao ASI tanto para a área de características urbanas, quanto para a de características urbanorurais. Entre os fatores, as violências foram ponto comum para a maioria.

Um desses marcadores seria o abuso sexual após os 15 anos para as duas regiões. A literatura aponta que pessoas que sofrem o abuso na infância estão mais 
propensas a sofrerem essa violência também na idade adulta (COID et al, 2009). A ocorrência dessa violência poderia ser indicativa de possível abuso na infância.

Primeira relação sexual antes dos 15 anos também se associou ao desfecho em SP e na ZMP, conforme descrito em relatório da OMS (ELLSBERG e HEISE, 2005). Segundo o estudo, em todos os países com exceção da Etiópia, quanto menor a idade da mulher na primeira relação sexual, maior a probabilidade de que sua iniciação sexual tenha sido forçada.

O ASI é freqüentemente associado a transtornos como depressão (HALL et al, 1993), transtornos de ansiedade (GOLDING, COOPER e GEORGE, 1999) e transtorno de estresse pós-traumático (HARRIET et al, 2001), embora a associação com transtorno mental comum não tenha se mantido na análise múltipla. Por outro lado, a associação com o uso de medicamentos para dor, tristeza ou sono em SP pode ser indicativa da presença de psicopatologias, conforme descreve a literatura (HARRIET et al, 2001). Em sentido oposto, tais psicopatologias podem representar indícios de ASI.

Apesar de observada associação entre a presença de ideação/tentativa de suicídio e ASI na análise univariada, essa associação deixou de ser significativa na análise múltipla. Ideação/tentativa de suicídio é comumente associada à ocorrência de ASI (HABIGZANG et al, 2006; HABIGZANG et al, 2008). Entretanto, grande parte dos estudos destaca sua presença entre crianças e adolescentes que sofreram o abuso, como uma conseqüência imediata da violência. Isso poderia explicar a ausência de associação no presente estudo, haja vista que o instrumento usado aborda retrospectivamente o abuso e as tentativas/ideações suicidas foram relatadas nas últimas quatro semanas pelas mulheres.

Marido/companheiro ter sofrido violência física por familiar na infância esteve associado ao desfecho na análise múltipla para SP. Crianças que crescem em lares violentos podem desenvolver comportamentos agressivos, inclusive na vida adulta (HABIGZANG e CAMINHA, 2004). Além disso, as relações violentas vivenciadas tendem a ser reproduzidas em relacionamentos futuros, seja como perpetrador, seja como vítima (KRUG et al, 2002; NEVES, 2009).

A violência por parceiro íntimo esteve associada à ocorrência do abuso nas duas regiões. Em SP, a violência exclusivamente física e na ZMP, violências física, psicológica e sexual combinadas ou violência exclusivamente sexual perpetrada por parceiro íntimo apresentaram associação. Isso reforça os dados de Fanslow et al (2007), 
COID et al (2009) e de SCHRAIBER et al (2009) e sugere que pessoas vítimas de violência por parceiro íntimo, principalmente mulheres, podem também apresentar história de abusos sexuais na infância.

Uso diário de álcool associou-se ao abuso na ZMP. WINDLE et al (1995) e MONCRIEFF et al (1996) descreveram associações entre o abuso sofrido na infância e o uso de abuso de álcool. Esse uso diário sugere dependência alcoólica pela mulher, o que pode levar a conseqüências negativas em diversas esferas de sua vida. Deste modo, frente a uma mulher adulta com uso problemático de álcool, o ASI deve ser lembrado e pode ser abordado com vistas ao cuidado integral.

Mãe sofrer violência por parceiro íntimo, a mulher não se lembrar dessa violência ou os pais não morarem juntos apresentaram associação com o desfecho também no modelo múltiplo para a ZMP. Mais uma vez, a reprodução da violência é demarcada. Mulheres com história de violência por parceiro íntimo deveriam receber maior acompanhamento familiar, pois as crianças presentes em seus lares podem estar em risco de sofrer abuso sexual.

Como vimos na Introdução, o estudo das causas do ASI ainda está incompleto. Adotar apenas variáveis anteriores ou próximas cronologicamente ao desfecho foi um esforço para contornar a dificuldade metodológica de inferir sobre causas do ASI a partir de entrevistas com mulheres adultas.

O instrumento utilizado não foi desenvolvido com o objetivo de estudar o ASI como desfecho principal, mas como exposição à violência entre mulheres adultas. Em função disso, variáveis possivelmente associadas ao desfecho não puderam ser testadas, como abuso físico sofrido pela mulher em sua infância, uso/abuso de álcool e/ou outras drogas pelos pais. Daí a dificuldade de testar mais variáveis anteriores ao abuso. Apesar disso, as questões abordadas contribuem significativamente para o estudo da violência sexual infantil, pois permitem a análise de associações em estudo populacional. Os modelos estatísticos alcançaram acurácia considerável $(62,11 \%$ para o modelo com restrição de temporalidade), o que sugere que as variáveis disponíveis possuem influência significativa e devem ser consideradas. O percentual não explicado pelo modelo deve ser mais bem explorado em outros estudos que desenvolvam instrumentos específicos sobre o tema e que contemplem mais variáveis possivelmente associadas ao abuso. 
Apesar das peculiaridades culturais e regionais, os fatores que influenciam a sua ocorrência do abuso são semelhantes para as duas regiões estudadas. Isso, somado à ampla distribuição social do abuso, sugere que é possível a elaboração de programas nacionais de prevenção ao ASI e de intervenção nacionais, que abranjam pessoas das diferentes classes sociais.

Neste estudo, a identificação bem sucedida dos marcadores de risco (modelos com acurácia de 75,19\% para SP e 74,73\% para a ZMP) pode contribuir para a identificação e interrupção da violência e, principalmente para prevenir que o abuso sexual aconteça e/ou cuidar das repercussões na saúde de mulheres adultas.

Os dados apontam que, para que os índices de ASI diminuam, é necessária a interrupção das diversas formas de violência a que a família possa estar submetida. Assim, políticas públicas de saúde, educação, assistência social e outros que visem à prevenção do ASI devem incluir em suas estratégias o trabalho com a família e o fortalecimento de seus vínculos.

O ASI esteve associado principalmente com a violência contra a mulher por parceiro íntimo. Na infância, crianças expostas à violência física sofrida pela mãe e perpetrada pelo pai/companheiro possuem maior risco de sofrerem abuso sexual. Por outro lado, mulheres que sofrem violências por seus parceiros possuem probabilidade maior de terem sido abusadas, conseqüentemente as crianças que vivem em seus lares também estão em risco. A saúde e os direitos da mulher, portanto, devem ser os principais focos de ação, com vistas ao combate à violência sexual infantil.

Reduzir a prevalência de ASI, elevada em áreas urbanas e rurais brasileiras, requer principalmente a interrupção das violências sofridas pela mulher, principalmente por parceiro íntimo, em áreas urbanas brasileiras. 


\section{5 - REFERÊNCIAS}

ABRAPIA. Abuso sexual contra crianças e adolescentes. Rio de Janeiro: Autores \& Agentes \& Associados, 1997.

ARIÉS, P. História social da criança e da família. Tradução de Dora Flaksman. 2 ed. Rio de Janeiro: Guanabara, 1986.

BASSANI, D.G. et al. Child sexual abuse in southern Brazil and associated factors: a population-based study. BMC Public Health, 2009, 9:133.

BONTEMPO, D., BOSETTI, E., CÉSAR, M.A. e LEAL, M.L.P. (1995) Exploração Sexual de Meninas e Adolescentes no Brasil. Brasília: UNESCO/CECRIA.

BOOTH, A., CROUTER, A. e CLEMENTS, M. Couples in conflict. United States: Lawrence Erlbaum Associates, 2001.

BOUVIER, P et al. Typology and correlates of sexual abuse in children and youth: multivariate analyses in a prevalence study in Geneva. Abuse-Negl. Aug; 23(8): 77990, 1999.

BRASIL. Lei $\mathbf{n}^{\mathbf{0}}$ 12.015, de 7 de agosto de 2009. Altera o Título VI da Parte Especial do Decreto-Lei $n^{0} 2.848$, de 7 de dezembro de 1940 - Código Penal, e o art. $1^{\circ}$ da Lei ${ }^{\circ}$ 8.072, de 25 de julho de 1990, que dispõe sobre os crimes hediondos, nos termos do inciso XLIII do art. $5^{\circ}$ da Constituição Federal e revoga a Lei ${ }^{\circ} 2.252$, de $1^{\circ}$ de julho de 1954, que trata de corrupção de menores.

BREIRE, J. RUNTZ, M. Childhood Sexual Abuse. Long-Term Sequelae and Implications for Psychological Assessment. J Interpers Violence September 1993 vol. 8 no. 3 312-330 doi: 10.1177/088626093008003002.

CASEY,-E-A; NURIUS,-P-S. Trends in the prevalence and characteristics of sexual violence: a cohort analysis. Violence-Vict. Oct; 21(5): 629-44, 2006.

CHAUÍ, M. Participando do debate sobre mulher e violência. Em Perspectivas Antropológicas da Mulher. Rio de Janeiro: Zahar, 1985. 
COID, J., PETRUCKEVITCH, A, FEDER, G., CHUNG, W., RICHARDSON, J. e MOOREY, S. Relation between childhood sexual and physical abuse and risk of revictimisation in women: a cross-sectional survey. The Lancet, v. 358, n. 9280, 450454, 2009.

CONNORS, M. E. and MORSE, W. Sexual abuse and eating disorders: A review. International, Journal of Eating Disorders, 13: 1-11, 1993. doi: 10.1002/1098108X(199301)13:1<1::AID-EAT2260130102>3.0.CO;2-P

Convenção sobre os Direitos da Criança. Disponível em: http://www.unicef.pt/docs/pdf_publicacoes/convencao_direitos_crianca2004.pdf, acesso em 20/01/2008.

D'OLIVEIRA, A.F.P.L. et al . Fatores associados à violência por parceiro íntimo em mulheres brasileiras. Rev. Saúde Pública, São Paulo, v. 43, n. 2, Apr. 2009.

ECHEBURÚA, E. et al. Secuelas emocionales en víctimas de abuso sexual en la infancia. Cuad Med Forense, 12(43-44), Enero-Abril 2006.

ELlsberG, M. e HEISE, L. Researching Violence Against Women: A Practical Guide for Researchers and Activists. Washington DC, United States: World Health Organization, PATH; 2005.

ESFANDYARI, B., BAHARUDIN, R. e NOWZARI, L. The relationship between inter-parental conflicts and externalizing behavior problems among adolescents. European Journal of Social Sciences, 12 (1), 120-125, 2009.

FANSLOW, JL, ROBINSON, EM, CRENGLE, S, PERESE, L. Prevalence of child sexual abuse reported by a cross-sectional sample of New Zealand women. Child Abuse Negl. Sep; 31(9):935-45, 2007.

FERGUSSON,-D-M; LYNSKEY,-M-T; HORWOOD,-L-J. Childhood sexual abuse and psychiatric disorder in young adulthood: I. Prevalence of sexual abuse and factors associated with sexual abuse. -Am-Acad-Child-Adolesc-Psychiatry. Oct; 35(10): 1355-64, 1996. 
FLEMING, J.M. Prevalence of childhood sexual abuse in a community sample of Australian women. MJA 1997; 166: 65-68.

FLEMING,-J; MULLEN,-P; BAMMER,-G. A study of potential risk factors for sexual abuse in childhood. Child-Abuse-Negl. Jan; 21(1): 49-58, 1997.

FRANÇA JUNIOR, I. Abuso sexual na infância: compreensão a partir da Epidemiologia e dos Direitos Humanos, Interface - Comunic, Saúde, Educ, v.7, n.12, p.23-38, 2003.

GARCIA-MORENO C, JANSEN HA, ELLSBERG M, WATTS CH. WHO multicountry study on women's health and domestic violence against women: initial results on prevalence, health outcomes and women's response. Geneva: World Health Organization; 2005.

GIMENO, S.G.A.; SOUZA, J.M.P. Utilização de estratificação e modelo de regressão logística na análise de dados de estudos caso-controle. Rev. Saúde Pública, São Paulo, v. 29, n. 4, Aug. 1995.

GUERRA, V.N. de A. Violência de pais contra filhos: a tragédia revisitada. 3.ed. São Paulo: Cortez, 1998.

GOLDING, J.M.; COOPER, M.L.; GEORGE, L.K. Sexual assault history and health perceptions: Seven general population studies. Health Psychology, Vol 16(5), Sep $1997,417-425$.

HABIGZANG, L.F. e CAMINHA, R.M. Abuso sexual contra crianças e adolescentes: conceituação e intervenção clínica. São Paulo: Casa do Psicólogo, 2004, 171 p.

HABIGZANG, L. F., AZEVEDO, G. A., KOLlER, S. H., MACHADO, P. X. Fatores de Risco e de Proteção na Rede de Atendimento a Crianças e Adolescentes Vítimas de Violência Sexual. Psicologia: Reflexão e Crítica, 19 (3), 2006, 379- 386.

HABIGZANG, L. F., DALA CORTE, F., HATZENBERGER, R., STROEHER, F. \& KOLLER, S. H. Avaliação psicológica em casos de abuso sexual na infância e adolescência. Psicologia: Reflexão e Crítica, 21(2), 2008, 338-344. 
HALL, L. A., SACHS, B., RAYENS, M. K. and LUTENBACHER, M., Childhood Physical and Sexual Abuse: Their Relationship with Depressive Symptoms in Adulthood. Journal of Nursing Scholarship, 25: 317-323, 1993. doi: 10.1111/j.15475069.1993.tb00266.x

HARDT, J, SIDOR, A, BRACKO, M, EGLE, UT. Reliability of retrospective assessments of childhood experiences in Germany. J Nerv Ment Dis. 2006 Sep;194(9):676-83.

HARRIET, L. et al. Childhood Abuse and Lifetime Psychopathology in a Community Sample. Am J Psychiatry 158:1878-1883, Nov. 2001.

JESSIE ANDERSON, M.B, et al. Prevalence of Childhood Sexual Abuse Experiences in a Community Sample of Women. Am J Psychiatry. v. 32, n. 5, 911-919, Sep. 1993.

KAUFMAN KANTOR, G. e JASINSKI, J.L.'Dynamics and Risk Factors in Partner Violence,' in Jasinski, J.L. \& Williams, L.M. Partner Violence: A Comprehensive Review of 20 Years of Research, London, SAGE, 1998.

KRUG, E.G., DAHLBER, L.L., MERCY, J.A., ZWI, A.B., LOZANO, R. World report on violence and health. Genebra: World Health Organization; 2002.

LAWS, A. Does a History of Sexual Abuse in Childhood Play a Role in Women's Medical Problems? A Review. Journal of Women's Health. January 1993, Vol. 2, No. 2: $165-172$.

JOHNSON, C. Child sexual abuse. The Lancet, 364: 9432, 462-470, 2009.

LENDERKING, W. R., WOLD, C., MAYER, K. H., GOLDSTEIN, R., LOSINA, E. and SEAGE, G. R. Childhood Sexual Abuse Among Homosexual Men. Journal of General Internal Medicine, 12:250-253, 1997. doi: 10.1046/j.15251497.1997.012004250.

LEROI, A.M. et al. Prevalence of sexual abuse among patients with functional disorders of the lower gastrointestinal tract. International Journal of Colorectal Disease,v. 10, n. 4, 200-206, 1995. DOI: 10.1007/BF00346219 
LESERMAN, J. Sexual Abuse History: Prevalence, Health Effects, Mediators, and Psychological Treatment. Psychosomatic Medicine 67:906-915, 2005.

LONDON, K et al. Review of the contemporary literature on how children report sexual abuse to others: findings, methodological issues, and implications for forensic interviewers. [PubMed - indexed for MEDLINE]3: Memory. Jan; 16(1):29-47, 2008.

LUO, Y; PARISH, W.L; LAUMANN, E.O. A population-based study of childhood sexual contact in China: prevalence and long-term consequences. Child- abuse-Negl. Jul; 32(7): 721-31, 2008.

MARK, H. et al. Gynaecological symptoms associated with physical and sexual violence.v Psychosom-Obstet-Gynaecol. Sep; 29(3): 164-72, 2008.

MARTIN, J; ANDERSON, J.; ROMANS, S.; MULLEN, P. and O'SHEA, M. Asking about child sexual abuse: Methodological implications of a two stage survey. Child Abuse \& Neglect. v. 17, n. 3, May-June 1993, 383-392.

MINAYO, M.C.S. e SOUZA, E.R. É possível prevenir a violência? Reflexões a partir do campo da saúde pública. Ciênc. Saúde coletiva; 4(1): 7-32, 1999.

MOLNAR, B.E.; BERKMAN, L.F. and BUKA, S.L. Psychopathology, childhood sexual abuse and other childhood adversities: relative links to subsequent suicidal behaviour in the US. Psychological Medicine, 31, pp 965-977, 2001. doi:10.1017/S0033291701004329

MONCRIEFF, J. et al. Sexual abuse in people with alcohol problems. A study of the prevalence of sexual abuse and its relationship to drinking behavior. The British Journal of Psychiatry; 169: 355-360 (1996).

MORALES, A.E.; SCHRAMM, F.R. A moralidade do abuso sexual intrafamiliar em menores. Ciênc. saúde coletiva, São Paulo, v. 7, n. 2, 2002 . Available from $<$ http://www.scielo.br/scielo.php?script=sci_arttext\&pid=S1413-

81232002000200007\&lng=en\&nrm=iso $>$. access on 07 Mar. 2011. doi: 10.1590/S1413-81232002000200007. 
NARVAZ, M.G. Submissão e resistência: explodindo o discurso patriarcal da dominação feminina. Dissertação de Mestrado, Universidade Federal do Rio Grande do Sul, Porto Alegre.

NARVAZ, M.G.; KOLLER, S.H. O feminino, o incesto e a sedução: problematizando os discursos de culpabilização das mulheres e das meninas diante da violação sexual. Revista Ártemis, v. VI, p. 77-84, 2007.

NEVES, A. S. Família no singular, histórias no plural: a violência física de pais e mães contra filhos. 1. ed. Uberlândia: Edufu - Editora da Universidade Federal de Uberlândia, 2009.

NEVES, A.S. e ROMANELLI, G. A violência doméstica e os desafios da compreensão interdisciplinar. Estud. Psicol. (Campinas), vol. 23, no. 3 pp. 299-306, 2006.

NOLL, J.G.; TRICKETT, P.K.; PUTNAM, F.W. A prospective investigation of the impact of childhood sexual abuse on the development of sexuality Journal of Consulting and Clinical Psychology, Vol 71(3), Jun 2003, 575-586.

PAVEZA, G.J. Risk factors in father-daughter in child sexual abuse: a case-control study. Journal of Interpersonal Violence, vol 3, n.3, September, 1989, 290-306.

PLICHTA, S.B e FALIK, M. Prevalence of violence and its implications for women's health. Womens-Health-Issues. May-Jun; 11(3): 244-58, 2001.

PRIBOR, E.F. e DINWIDDIE, S.H. Psychiatric correlates of incest in childhood. Am J Psychiatry; 149:52-56, 1992

RAGHAVAN, R; Sexual victimization among a national probability sample of adolescent women. Perspect-Sex-Reprod-Health. Nov-Dec; 36(6): 225-32, 2004

RAVAZZOLA, M.C. Historias infames: los maltratos en las relaciones. Buenos Aires: Padiós, 2005.

RESENDE, A.C.C.; OLIVEIRA, A.M.H.C. Avaliando resultados de um programa de transferência de renda: o impacto do Bolsa-Escola sobre os gastos das famílias brasileiras. Estud. Econ., São Paulo, v. 38, n. 2, 2008. 
RICKERT,-V-I et al. Rates and risk factors for sexual violence among an ethnically diverse sample of adolescents. Arch-Pediatr-Adolesc-Med. Dec; 158(12): 1132-9, 2004.

RIBEIRO, M.A.; FERRIANI, M.G.C.; REIS, J.N. Sexual abuse of children and adolescents: characteristics of sexual victimization in family relations. Cad. Saúde Pública, Rio de Janeiro, v. 20, n. 2, 2004.

ROMANS, S.E., MARTIN, J.L., ANDERSON, J.C., HERBISON, G.P. and MULLEN, P.E. Sexual abuse in childhood and deliberate self-harm. Am J Psychiatry 1995; 152:1336-1342.

RUMM, P. et al. Identified spouse abuse as a risk factor for child abuse. Child Abuse \& Neglect, Vol. 24, No. 11, pp. 1375-1381, 2000.

SAFFIOTI, H.I.B. No Fio da Navalha: Violência Contra Crianças e Adolescentes no Brasil Atual. Em F.R. Madeira (Org.), Quem Mandou Nascer Mulher? (pp. 134-211). São Paulo: Editora Rosa dos Tempos, 1997.

SAFFIOTI, H.I.B. Circuito cerrado: abuso sexual incestuoso. In: Vigiladas y Castigadas. Lima, Peru: CLADEM, 1993. Este livro foi traduzido para o português com o título Mulheres: Vigiadas e Castigadas. São Paulo: CLADEM, 1995.

SANI, A.I. Vitimação indirecta de crianças em contexto familiar. Análise Social, 16 (180), 849-864.

SÁNCHEZ, E.M. e MARTÍN, I. Características de una muestra de niños com sospecha de abuso sexual en un dispositivo especializado andaluz. Intervención Psicosocial, 2007, Vol. 16 N. 3 Págs. 339-359. ISSN: 1132-0559.

SCHRAIBER, L.B., D’OLIVEIRA, A.F.P.L, FALCÃO, M.T.C. E FIGUEIREDO, W.S. Violência dói e não é direito. A violência contra a mulher, a saúde e os direitos humanos. São Paulo: Editora UNESP, 2005.

SCHRAIBER, L.B. et al. Prevalência da violência contra a mulher por parceiro íntimo em regiões do Brasil. Rev. Saúde Pública, São Paulo, v. 41, n. 5, out. 2007. 
SCHRAIBER, L.B.; D'OLIVEIRA, A.F.P.L; FRANÇA JUNIOR, I. Violência sexual por parceiro íntimo entre homens e mulheres no Brasil urbano, 2005. Rev. Saúde Pública, São Paulo, 2009.

SCHREINER, M.T. O Abuso sexual numa perspectiva de gênero: o processo de responsabilização da vítima. Fazendo Gênero 8 - Corpo, Violência e Poder. Florianópolis, 2008.

SPATARO, J. et al. Impact of child sexual abuse on mental health. Prospective study in males and females. The British Journal of Psychiatry 184: 416-42, 2004.

SPEIZER, I.S. et al. Dimensions of child sexual abuse before age 15 in three Central American countries: Honduras, El Salvador, and Guatemala. Child-Abuse-Negl. Apr; 32(4): 455-62, 2008.

UNICEF. Situação da infância brasileira. Editorial UNICEF: Rio de Janeiro, 2006.

WALKER, E.A. et al. Adult health status of women with histories of childhood abuse and neglect. Am J Medicine. v. 107, n. 4, 332-339, Oct. 1999.

WHO (World Health Organization). WHO Consultation on Child Abuse Prevention, Geneva, WHO, 1999.

WHO (World Health Organization). World Report on violence and Health. Geneva: World Health Organization, 2002. http://www5.who.int/violence_injury_prevention/, acesso em 01/10/2008.

WINDLE, M.; WINDLE, R.C.; SCHEIDT, D.M. and MILLER, G.B. Physical and sexual abuse and associated mental disorders among alcoholic inpatients. Am J Psychiatry 1995; 152:1322-1328.

YEN, C.F et al. Childhood physical and sexual abuse: prevalence and correlates among adolescents living in rural Taiwan. Child-Abuse-Negl. Mar; 32(3): 429-38, 2008. 
ANEXO 


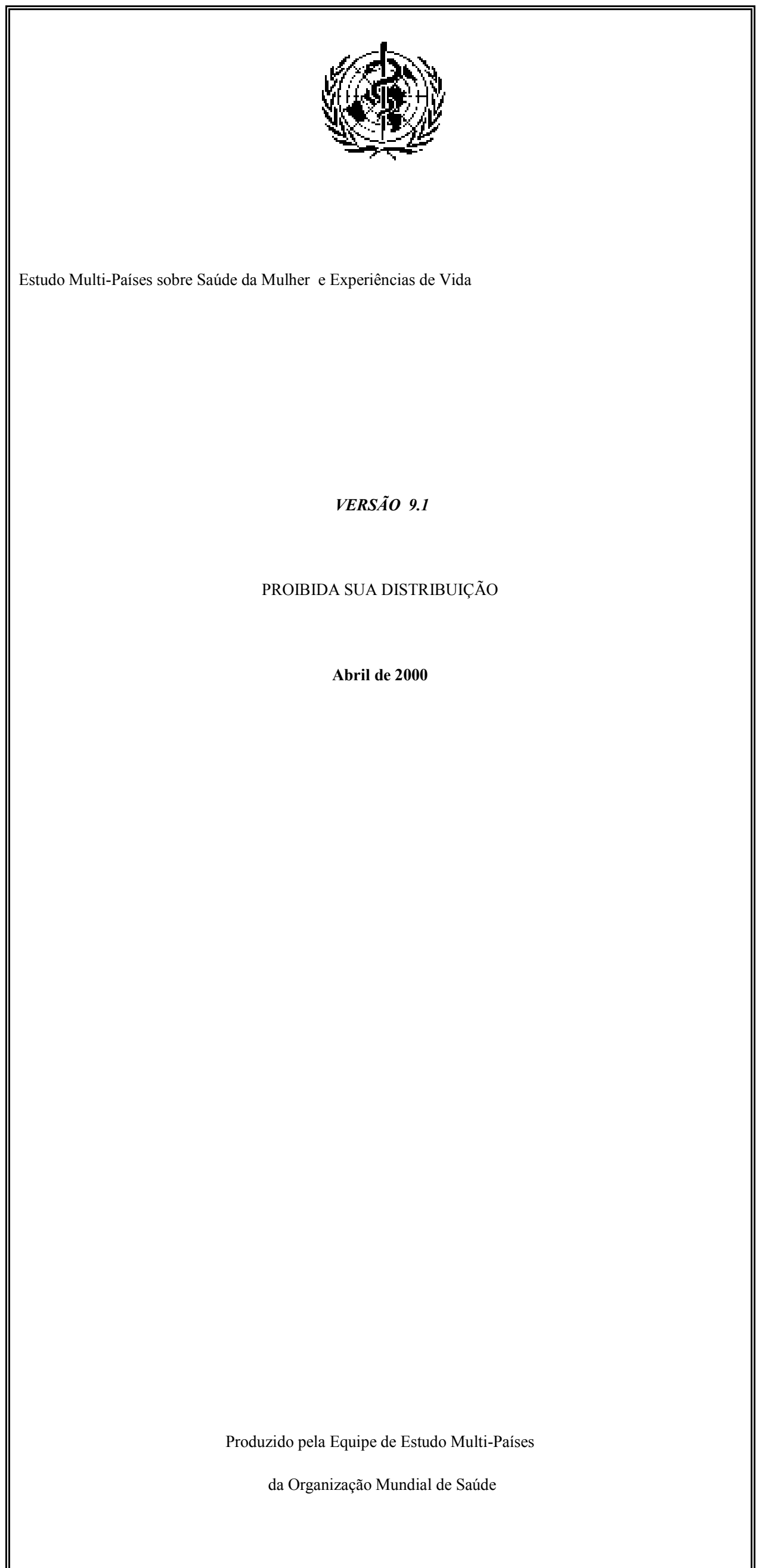


Inquérito sobre Saúde da Mulher e Experiências de Vida em SÃo PAULO

ADMINISTRAÇÃO

FORMULÁRIO DE SELEÇão DE RESIDÊNCIAS

QUESTIONÁRIO SOBRE A RESIDÊNCIA 
ADMINISTRAÇÃO

\begin{tabular}{|c|c|}
\hline "IDENTIFICAÇÃO & \\
\hline CÓDIGO DO PAÍS & BRA \\
\hline LOCAL (SÃO PAULO = 1, ZONA DA MATA = 2) & [ ] $]$ \\
\hline 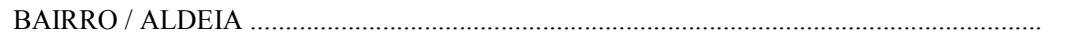 & {$\left[\begin{array}{ll}{[} & ]\end{array}\right]$} \\
\hline 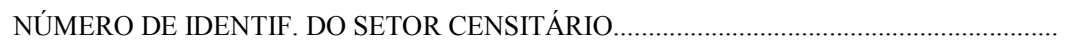 & {$\left[\begin{array}{ll}{[} & ]\end{array}\right]$} \\
\hline NÚMERO DE IDENTIF. DA RESIDÊNCIA & {$[\quad]\left[\begin{array}{ll}{[} & 0\end{array}\right]$} \\
\hline NOME DO (A) CHEFE DA FAMÍLIA (nome e apelido) & \\
\hline
\end{tabular}

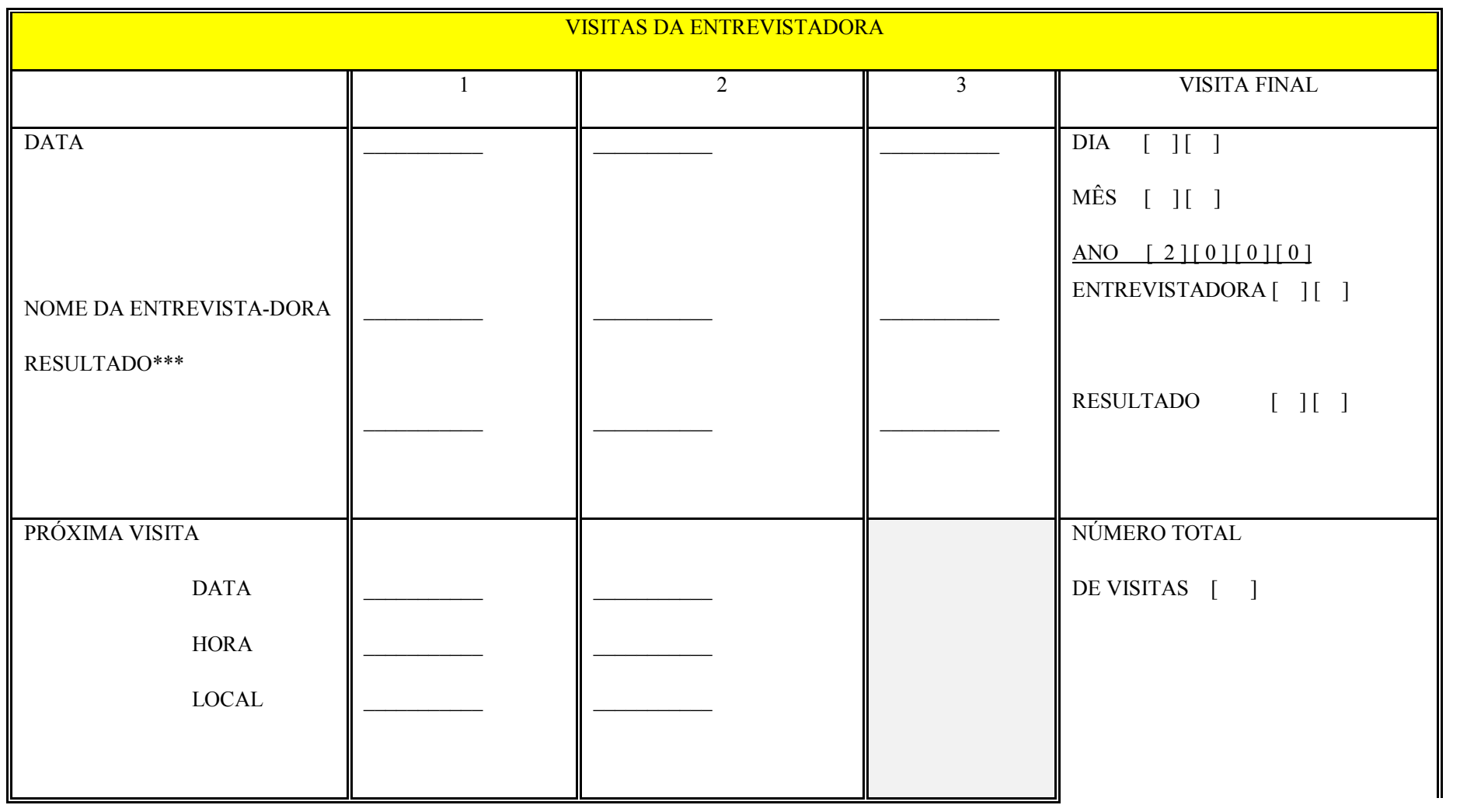




\begin{tabular}{|c|c|c|c|}
\hline $\begin{array}{l}\text { QUESTIIONÁRIO } \\
\text { COMPLETADO? }\end{array}$ & 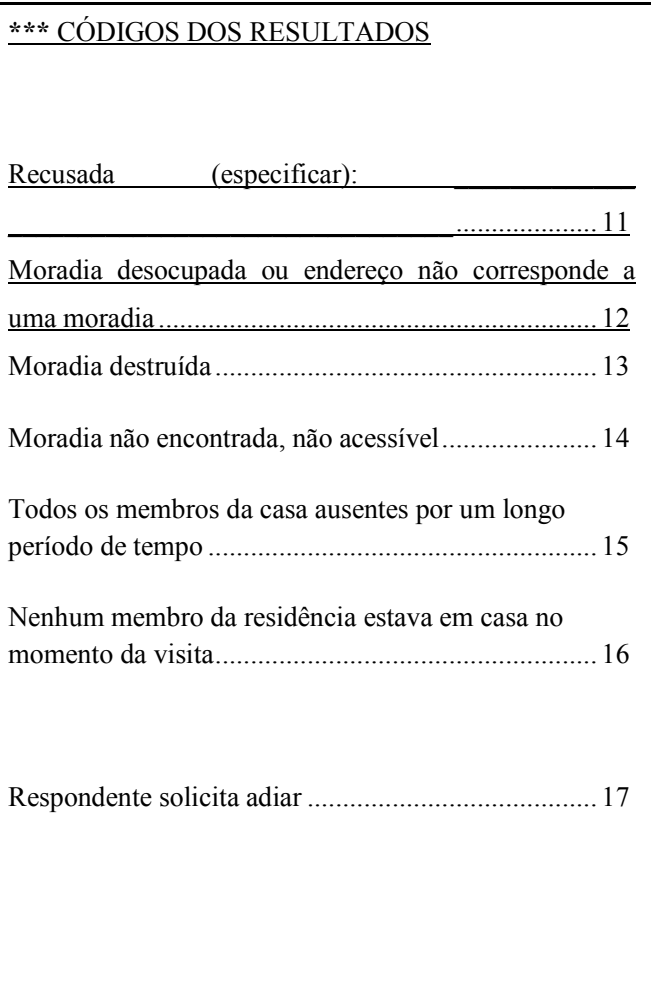 & $\begin{array}{l} \\
\Rightarrow \quad \text { Necessida-de } \\
\text { de Retorno } \\
\Rightarrow \quad \text { Necessida-de } \\
\text { de Retorno }\end{array}$ & 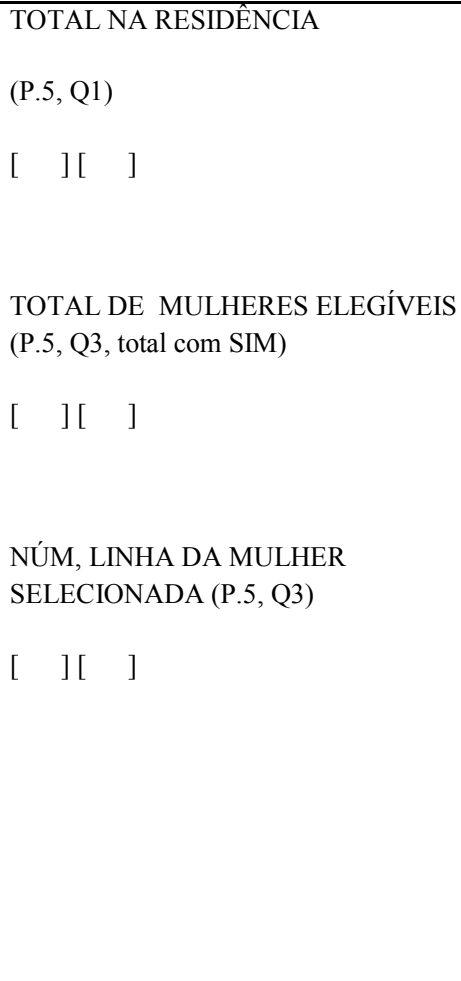 \\
\hline $\begin{array}{l}{[\text { ] } 2 \text {. Somente o questioná-rio da }} \\
\text { moradia } \Rightarrow\end{array}$ & 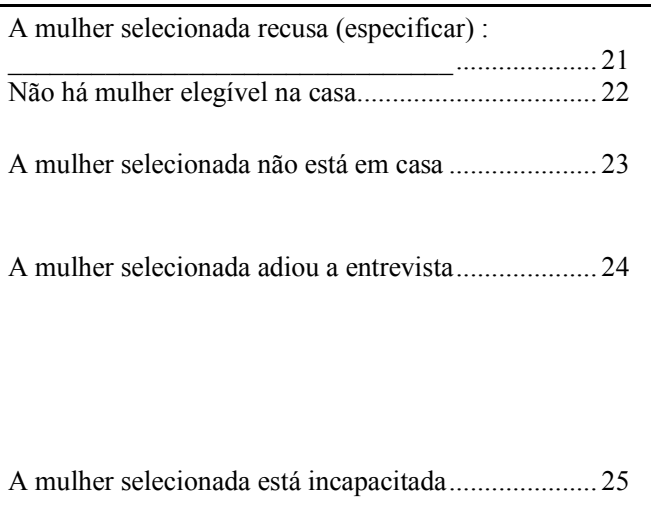 & $\begin{array}{l} \\
\Rightarrow \quad \text { Necessida-de } \\
\text { de Retorno } \\
\Rightarrow \quad \text { Necessida-de } \\
\text { de Retorno }\end{array}$ & \\
\hline $\begin{array}{l}\text { [ ] 3. O questionário parcialmente } \\
\text { completo } \Rightarrow\end{array}$ & 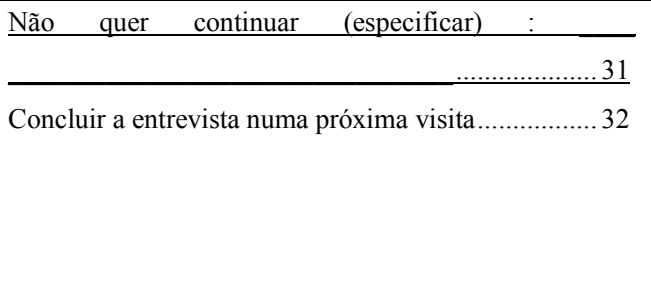 & $\begin{array}{l}\text { क Necessida-de } \\
\Rightarrow \quad \text { de Retorno }\end{array}$ & \\
\hline [ ] 4. O questionário completo $\Rightarrow$ & 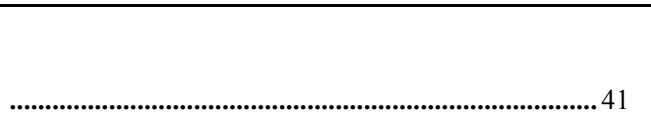 & & \\
\hline
\end{tabular}




\begin{tabular}{|c|c|c|c|}
\hline \multicolumn{3}{|c|}{ IDIOMA NO QUAL A ENTREVISTA FOI REALIZADA } & $\begin{array}{l}{\left[\begin{array}{l}0 \\
{[}\end{array}\left[\begin{array}{l}3 \\
{[}\end{array}\right]\right.} \\
{\left[\begin{array}{ll}3 & ]\end{array}\right.}\end{array}$ \\
\hline \multicolumn{3}{|c|}{ ENTREVISTA REALIZADA COM CONTROLE DE QUALIDADE ( 1 = sim, 2 = não $)$} & [ ] \\
\hline "SUPERVISORA & " QUESTIONÁRIO & $\overline{\text { CODIFICADORA }}$ & $\overline{\overline{\text { ENTRADA DADA }}}$ \\
\hline DE CAMPO & VERIFICADO POR & DO ESCRITÓRIO & POR \\
\hline NOME [ ] [ ] & NOME [ ] ] [ ] & NOME [ ] ] [ ] & DIGITADOR 1 \\
\hline DIA $[$ ] $[$ ] & DIA $\quad[\quad]\left[\begin{array}{l}{[} \\
\text { D }\end{array}\right.$ & & DIGITADOR 2 \\
\hline MÊS [ ] [ ] & MÊS $\quad[\quad][\quad]$ & & \\
\hline ANO [ ] ] ] [ ] ] ] & ANO [ ] [ ] [ ] ] ] & & \\
\hline
\end{tabular}

Tabela de Códigos:

\begin{tabular}{|c|c|c|}
\hline Supervisoras & - & 01 \\
\hline & & 02 \\
\hline & & 03 \\
\hline & & 04 \\
\hline & & 05 \\
\hline Codificadoras & - & 06 \\
\hline & & 07 \\
\hline & & 08 \\
\hline & & 09 \\
\hline & & 10 \\
\hline Entrevistadoras & - & 11 \\
\hline & & 12 \\
\hline & & 13 \\
\hline & & 14 \\
\hline & & 15 \\
\hline & & 16 \\
\hline & & 17 \\
\hline & & 18 \\
\hline & & 19 \\
\hline & & 20 \\
\hline Digitadoras & - & 31 \\
\hline & & 32 \\
\hline & & 33 \\
\hline & & 34 \\
\hline
\end{tabular}

21
22
23
24
25
26
27
28
29
30


FORMULÁRIO PARA SELEÇÃo DE RESIDÊNCIAS

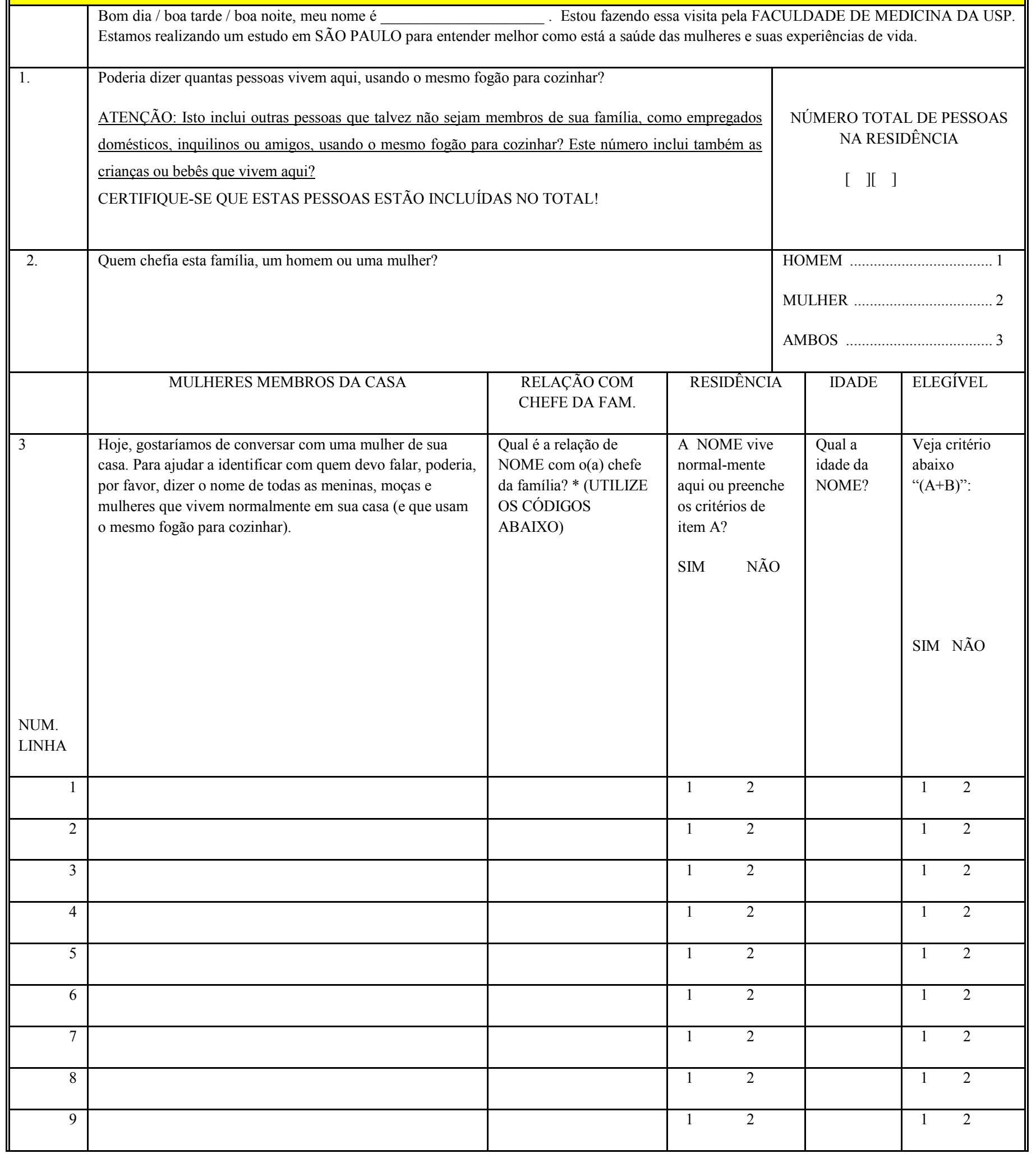




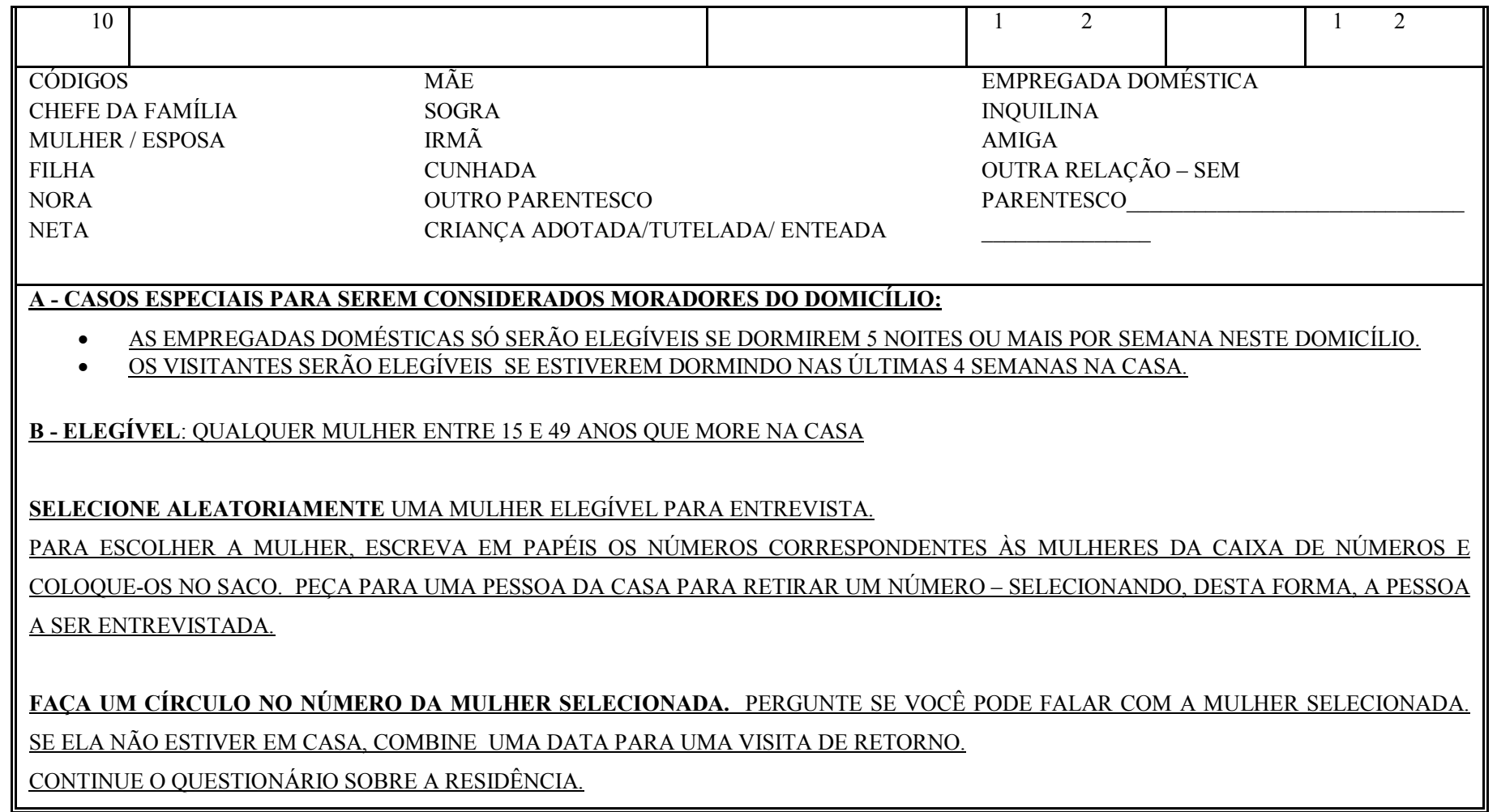

* se tanto o homem quanto a mulher são os chefes da família, relacione o grau de parentesco com o homem. 
PODE SER RESPONDIDO POR QUALQUER ADULTO RESPONSÁVEL NO DOMICÍLIO

\begin{tabular}{|c|c|c|}
\hline \multicolumn{3}{|c|}{ QUESTIONÁRIO SOBRE A RESIDÊNCIA } \\
\hline & PERGUNTAS E FILTROS & CATEGORIAS DE CODIFICAÇÃO \\
\hline \multicolumn{3}{|c|}{ PERGUNTAS DE 1-6: INDICADORES SÓCIO-ECONÔMICOS ESPECÍFICOS DE CADA PAÍS } \\
\hline 1. & $\begin{array}{l}\text { Se você não se incomodar, gostaria de lhe fazer algumas perguntas } \\
\text { sobre sua casa. Qual a principal fonte de água potável (água para beber, } \\
\text { cozinhar, etc.) em sua casa? }\end{array}$ & 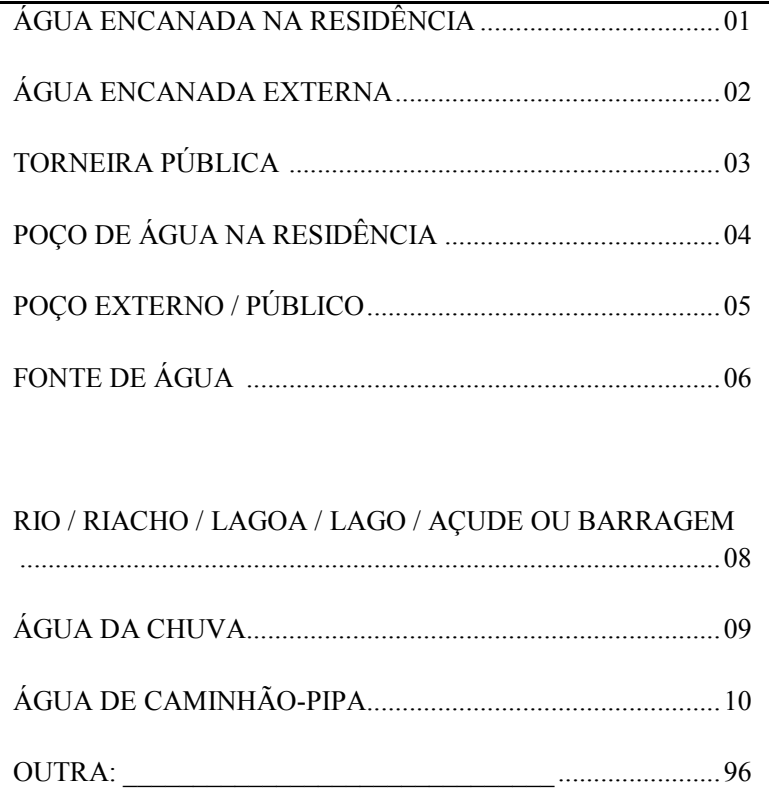 \\
\hline 2. & Que tipo de instalações sanitárias existem em sua casa? & 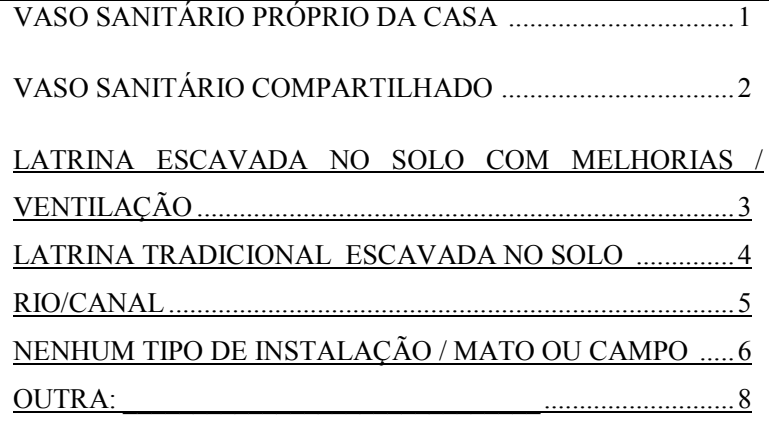 \\
\hline 3. & $\begin{array}{l}\text { Quais os principais materiais utilizados no telhado? } \\
\text { REGISTRAR O QUE SE OBSERVAR }\end{array}$ & 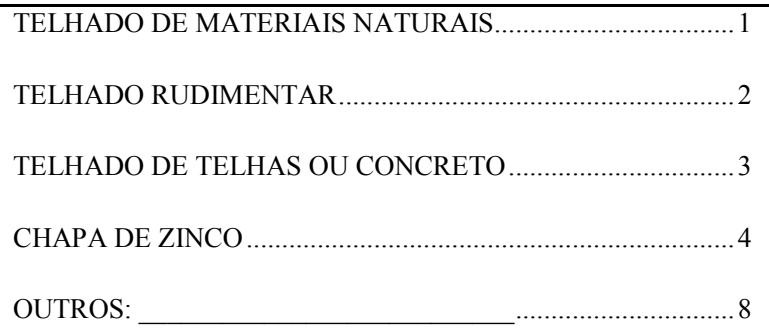 \\
\hline $4 \mathrm{a}$ & Nesta casa tem eletricidade? & SIM \\
\hline
\end{tabular}




\begin{tabular}{|c|c|c|c|c|c|}
\hline $\begin{array}{l}5 . \\
\text { BRA }\end{array}$ & $\begin{array}{l}\text { Nesta casa existem quantos destes ítens? } \\
\text { a) televisão colorida } \\
\text { b) vídeo-cassete } \\
\text { c) rádio } \\
\text { d) banheiro } \\
\text { e) automóvel de passeio } \\
\text { f empregada mensalista } \\
\text { g) aspirador de pó } \\
\text { h) maq. de lavar roupa } \\
\text { i) geladeira } \\
\text { j) freezer (isolado ou em geladeira duplex) }\end{array}$ & $\begin{array}{l}\text { a) } \\
\text { b) } \\
\text { c) } \\
\text { d) } \\
\text { e) } \\
\text { f) } \\
\text { g) } \\
\text { h) } \\
\text { i) } \\
\text { j) }\end{array}$ & 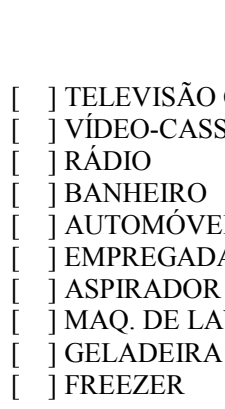 & & \\
\hline $\begin{array}{l}6 . \\
\text { BRA }\end{array}$ & $\begin{array}{l}\text { Alguma pessoa desta casa possui: } \\
\text { a) terreno } \\
\text { b) casa } \\
\text { c) apartamento } \\
\text { d) terra }\end{array}$ & $\begin{array}{l}\text { a) } \\
\text { b) } \\
\text { c) } \\
\text { d) }\end{array}$ & $\begin{array}{l}\text { TERRENO } \\
\text { CASA } \\
\text { APARTAMENTO } \\
\text { TERRA }\end{array}$ & $\begin{array}{c}\text { SIM } \\
1 \\
1 \\
1 \\
1 \\
1\end{array}$ & $\begin{array}{c}\text { NÃO } \\
2 \\
2 \\
2 \\
2 \\
2\end{array}$ \\
\hline 7. & Quantos cômodos em sua casa são usados para dormir? & & E CÔMODOS ........... & $\ldots$ & ][ ] \\
\hline
\end{tabular}




\begin{tabular}{|c|c|c|}
\hline 8. & $\begin{array}{l}\text { Você está preocupada/o com a criminalidade em sua vizinhança (como } \\
\text { roubos ou assaltos)? } \\
\text { Você diria que não está preocupada/o, está um pouco preocupada/o, ou } \\
\text { está muito preocupada/o? }\end{array}$ & 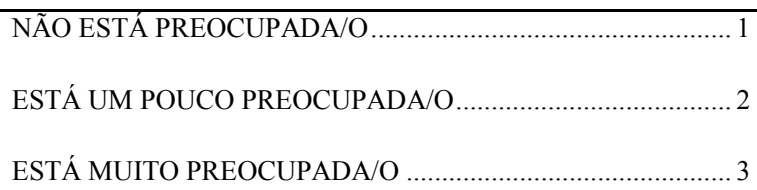 \\
\hline 9. & $\begin{array}{l}\text { Nas últimas } 4 \text { semanas alguém de sua casa foi vítima de um crime } \\
\text { nesta vizinhança, tais como roubo ou assalto? }\end{array}$ & 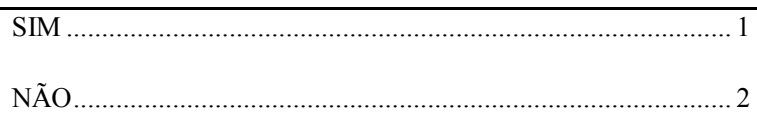 \\
\hline 10 . & ANOTE O SEXO DA/O ENTREVISTADA/O & MASCULINO \\
\hline
\end{tabular}

Muito obrigada por sua ajuda. 
Pesquisa sobre a saúde e experiências de vida em SÃO PAULO

QUESTIONÁRIO DA MULHER

ESTUDO REALIZADO PELA

FACULDADE DE MEDICINA DA USP 
Confidencial uma vez preenchido 
FORMULÁRIO DE CONSENTIMENTO INDIVIDUAL

Bom dia / boa tarde / boa noite, meu nome é Trabalho para a FACULDADE DE MEDICINA DA USP. Nós estamos realizando uma pesquisa em SÃO PAULO para saber mais sobre a saúde das mulheres e suas experiências de vida. Você (sua casa) foi sorteada para participar desta pesquisa.

Posso garantir para você que tudo o que você responder vai ser guardado em segredo total. Eu não vou deixar escrito seu nome completo ou o seu endereço. Você tem o direito de parar a entrevista na hora em que quiser, ou de pular alguma pergunta se não quiser respondê-la. Nesta pesquisa não existem respostas certas ou erradas. Alguns dos assuntos são muito pessoais ou difíceis de conversar, muitas mulheres acharam que foi útil ter tido a oportunidade de falar sobre eles.

Você só participa se quiser, mas as suas experiências podem ser muito úteis para ajudar outras mulheres aqui no Brasil.

Quer fazer alguma pergunta?

A entrevista dura mais ou menos 45 minutos. Você concorda em ser entrevistada?

ANOTE SE A ENTREVISTADA CONCORDA OU NÃO EM SER ENTREVISTADA

[ ] NÃO CONCORDA EM SER ENTREVISTADA

AGRADEÇA PELO TEMPO DELA

[ ] CONCORDA EM SER ENTREVISTADA

AGORAÉUA BOA HORA PARA CONVERSAR?

É muito importante que a gente converse a sós. Aqui é um lugar bom para fazer a entrevista, ou há algum outro lugar onde você gostaria de ir? 


\section{PARA A ENTREVISTADORA COMPLETAR}

Declaro que li o consentimento acima e a entrevistada está de acordo em participar.

Pesquisador responsável: Lilia Blima Schraiber

Nome e Assinatura da entrevistadora

RG: 3945405 (SSP-SP)

Endereço: Av. Dr. Arnaldo, $4552^{\circ}$ andar

Departamento de Medicina Preventiva - FMUSP 
DATA: DIA [ ] ] ]MÊS [ ][ ]

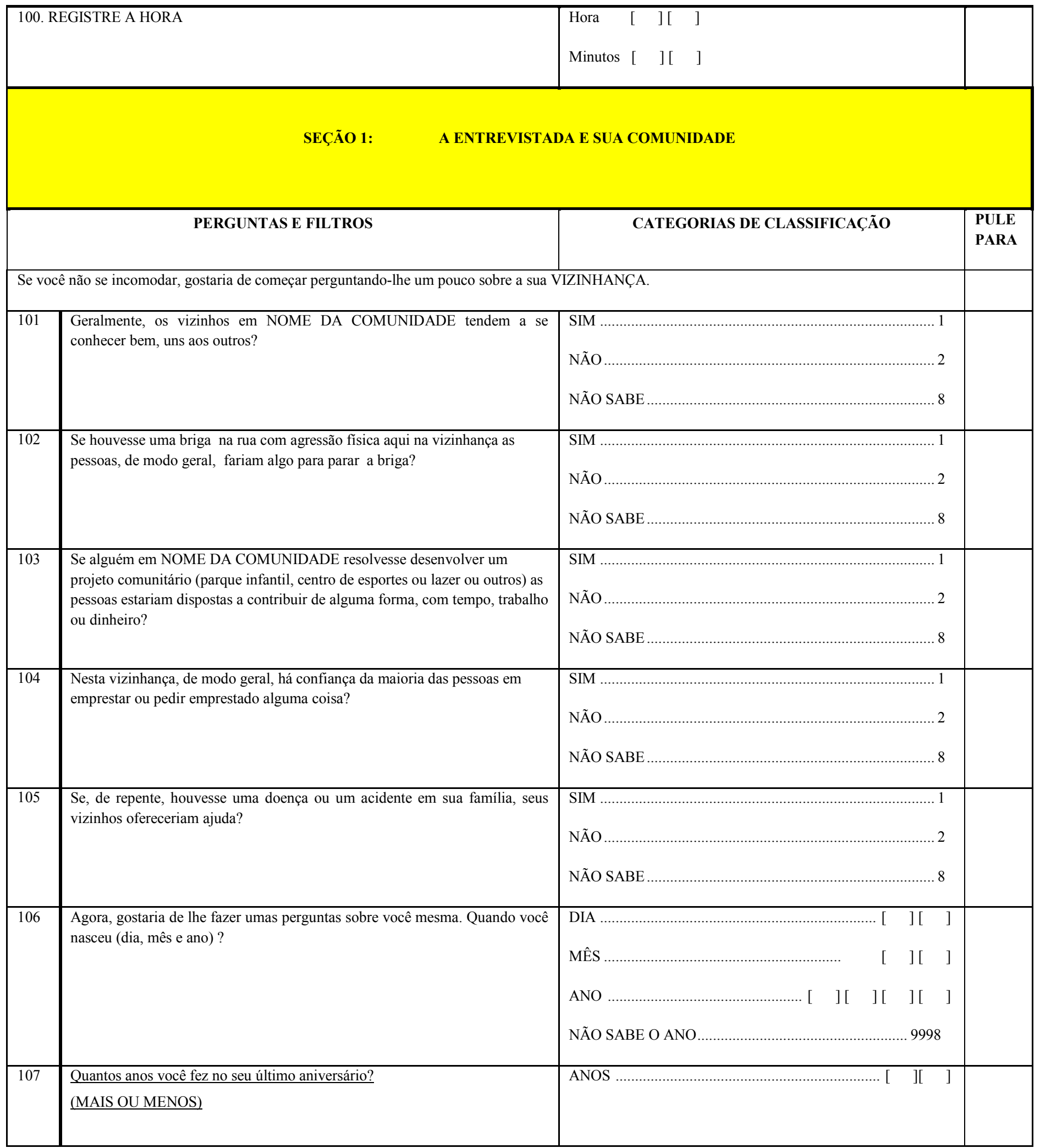




\begin{tabular}{|c|c|c|c|c|}
\hline 108 & $\begin{array}{l}\text { Quanto tempo faz que você mora em NOME DA COMUNIDADE sem } \\
\text { interrupção? }\end{array}$ & \multicolumn{2}{|c|}{ 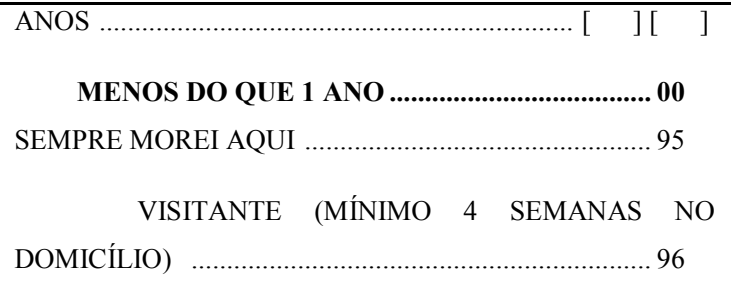 } & \\
\hline 109 & Você sabe ler e escrever? & 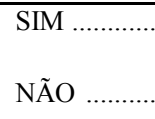 & . & \\
\hline 110 & Você já frequentou a escola? & 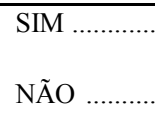 & 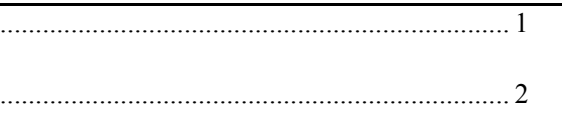 & $\Rightarrow 112$ \\
\hline 111 & $\begin{array}{l}\text { Qual é o grau mais alto de instrução que você cursou? MARQUE O GRAU } \\
\text { MAIS ELEVADO. } \\
\text { CONVERTA OS ANOS DE ESCOLARIDADE DE ACORDO COM OS } \\
\text { CÓDIGOS DA TABELA. }\end{array}$ & $\begin{array}{l}\text { PRIMÁRIO } \\
\text { SECUNDÁF } \\
\text { UNIV. COM } \\
\text { UNIV.INCO } \\
\mathrm{N}^{\circ} \text { DE ANO } \\
][\quad]\end{array}$ & 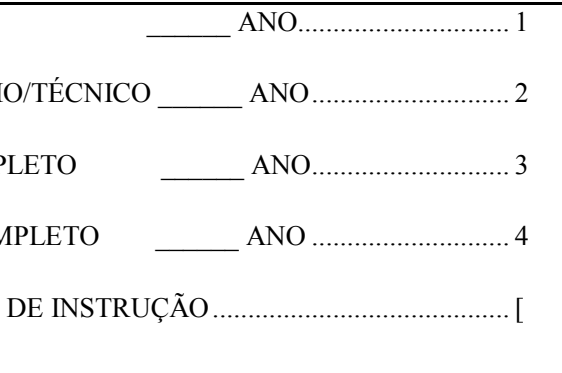 & \\
\hline 112 & Onde você foi criada? & $\begin{array}{l}\text { NESTA COI } \\
\text { EM OUTRA } \\
\text { EM OUTRA } \\
\text { EM OUTRO }\end{array}$ & IUNIDADE/CIDADE & \\
\hline 113 & $\begin{array}{l}\text { Você tem parentes morando perto o suficiente para que você possa vê- } \\
\text { los/visitá-los com facilidade? }\end{array}$ & 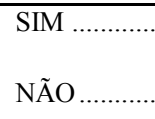 & 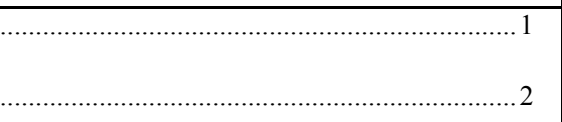 & \\
\hline 114 & $\begin{array}{l}\text { Com que freqüência você conversa ou se encontra com algum parente da } \\
\text { família na qual você nasceu? Você diria que isso acontece pelo menos uma } \\
\text { vez por semana, uma vez por mês, uma vez por ano, ou nunca (quase nunca)? }\end{array}$ & $\begin{array}{l}\text { PELO MEN } \\
\text { PELO MEN } \\
\text { PELO MEN } \\
\text { NUNCA (Q }\end{array}$ & 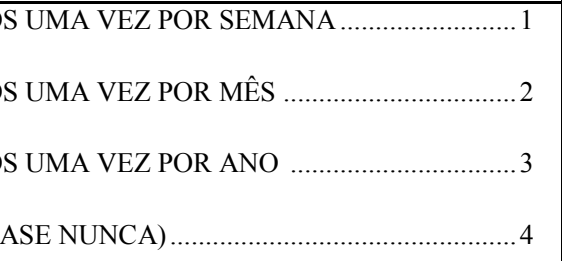 & \\
\hline 115 & $\begin{array}{l}\text { Quando você precisa de ajuda ou tem algum problema, você pode contar com } \\
\text { seus parentes para lhe dar apoio? }\end{array}$ & 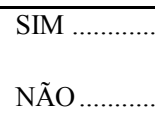 & . & \\
\hline $116 \mathrm{a}$ & $\begin{array}{l}\text { Você freqüenta regularmente algum } \\
\text { grupo ou organização? }\end{array}$ & .................. A & $\begin{array}{l}\Rightarrow \text { SE NENHUM, PULE PARA } 118 \\
\text { 116b. Com que freqüência você participa? (PEI } \\
\text { E ANOTE DE ACORDO COM CADA } \\
\text { ASSINALADA NA 116a) }\end{array}$ & $\begin{array}{r}\text { ITEM } \\
\text { ITUNE }\end{array}$ \\
\hline
\end{tabular}




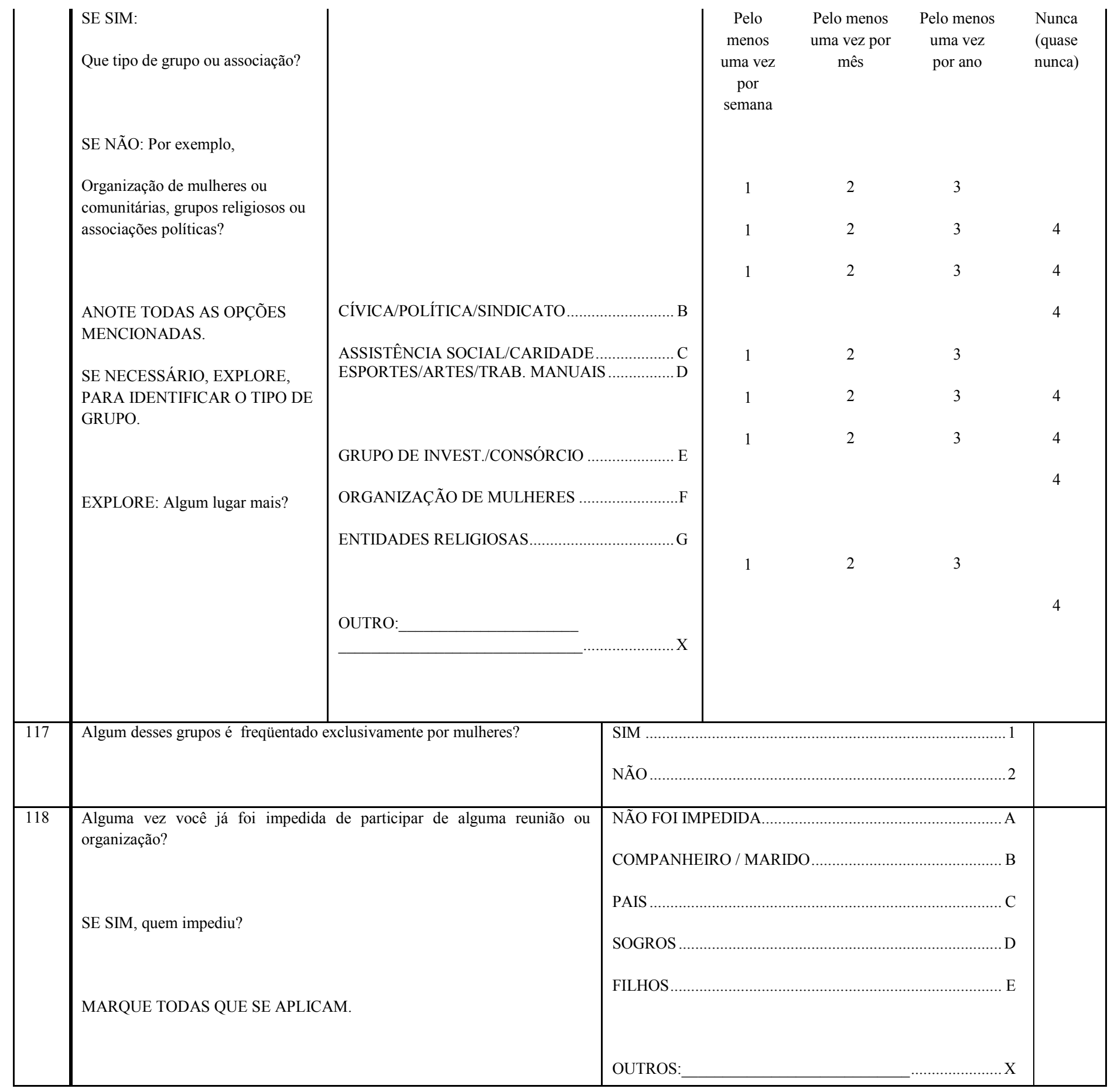




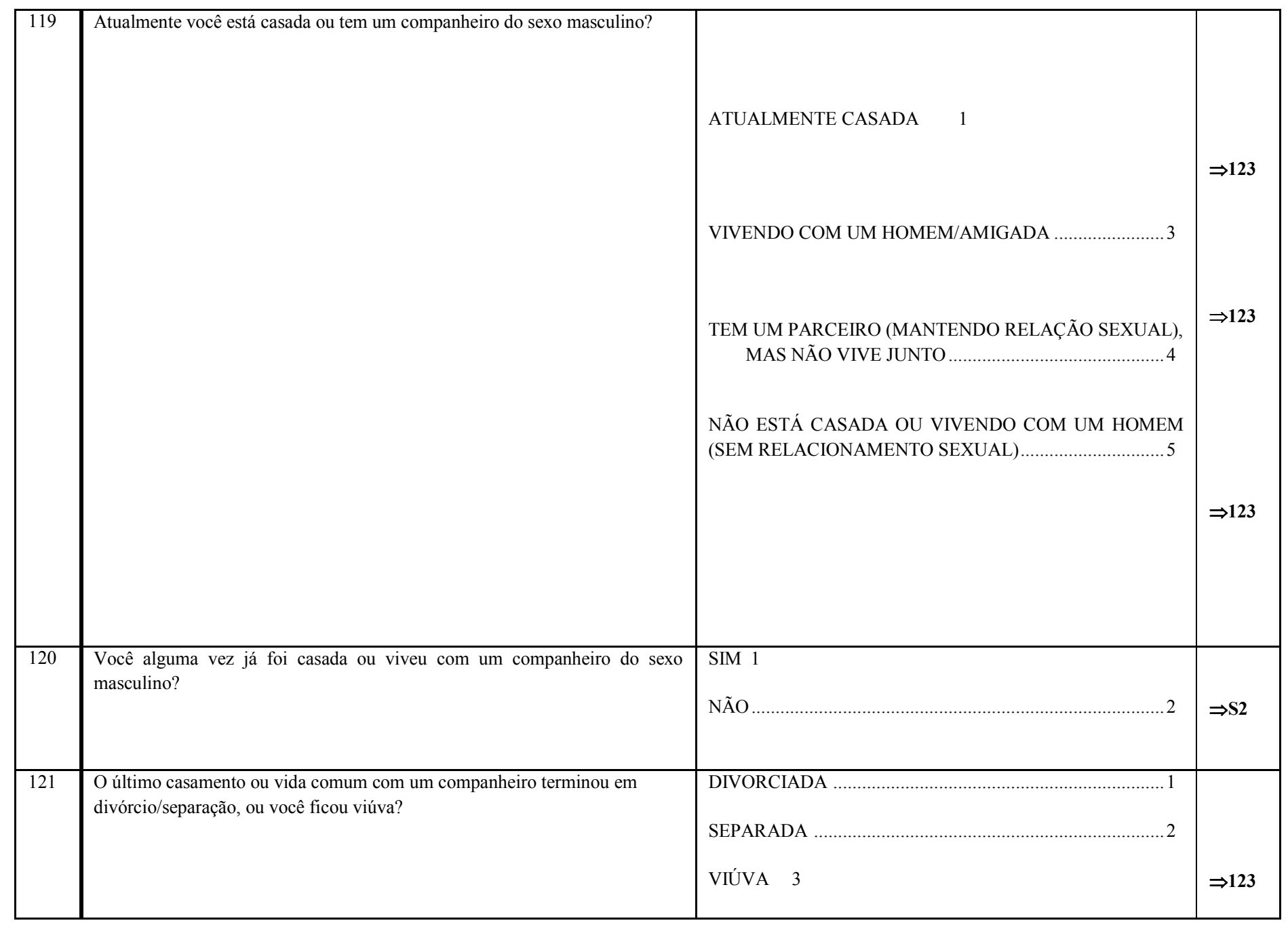




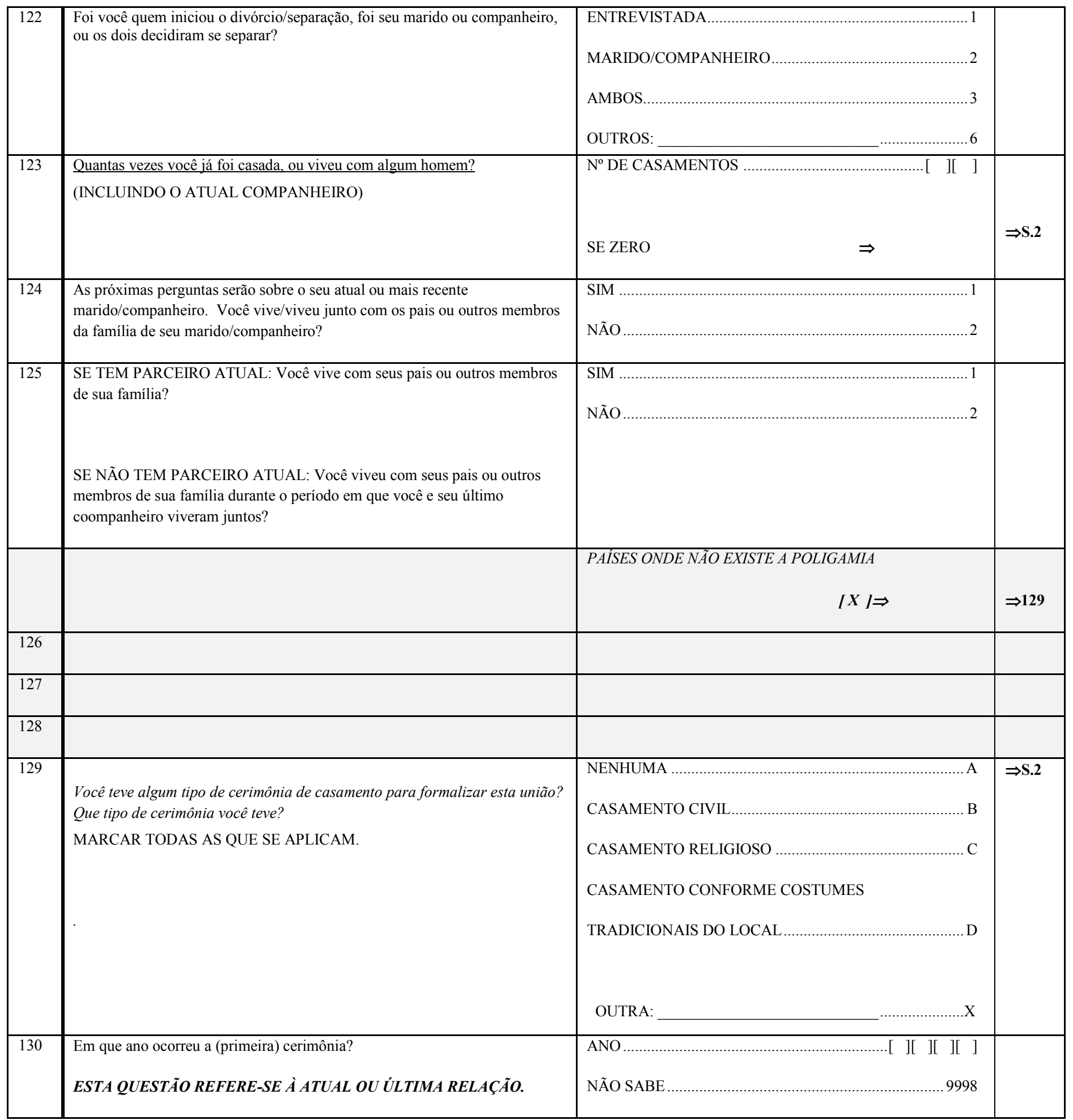




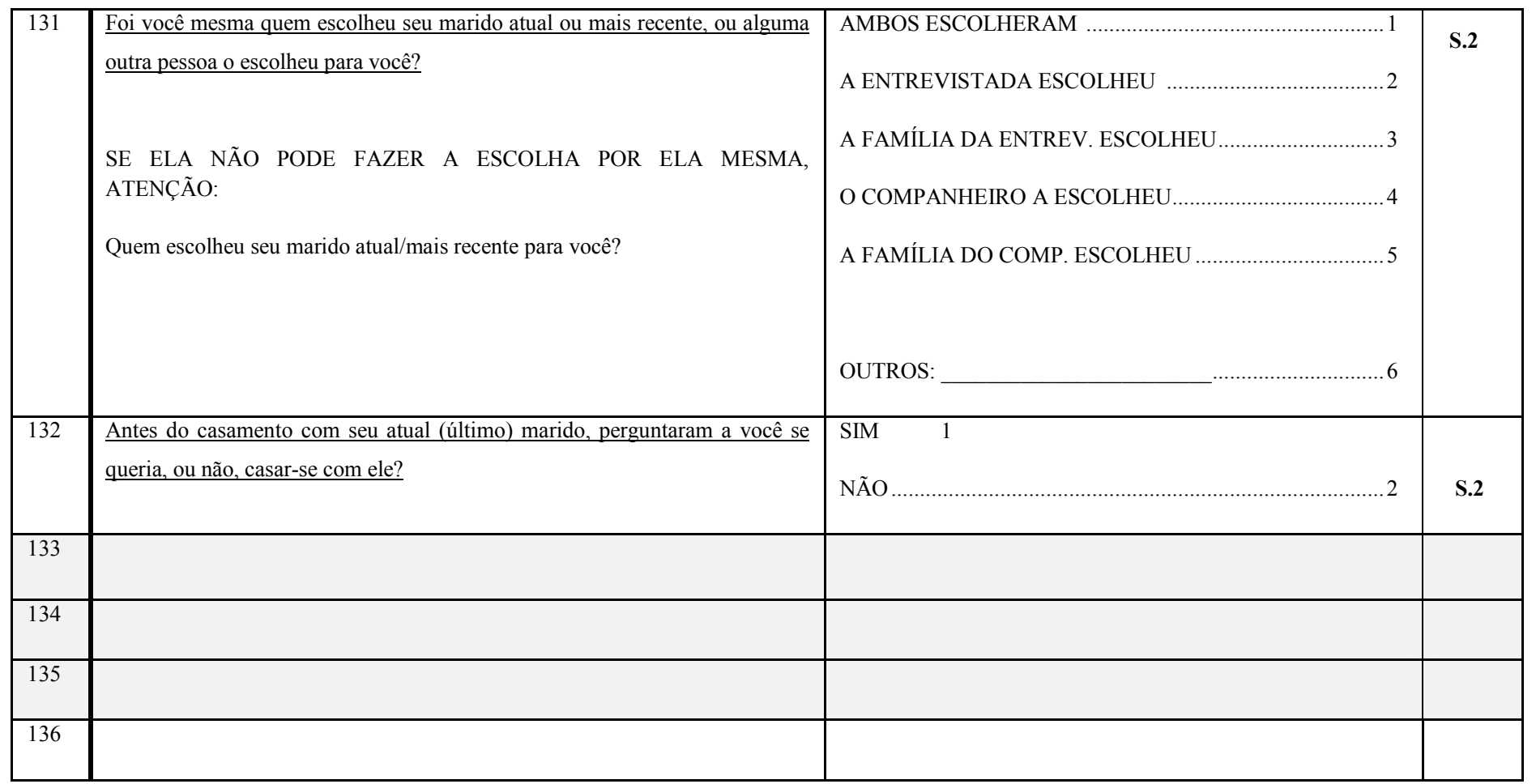


SEÇÃO 2 - QUESTÕES GERAIS DE SAÚDE

ANTES DE COMEÇAR COM A SEÇÃO 2:

VERIFIQUE AS RESPOSTAS NA SEÇÃO 1 E MARQUE O ESTADO MARITAL NA FOLHA DE REFERÊNCIA, BOX A.

\begin{tabular}{|c|c|c|}
\hline 201 & $\begin{array}{l}\text { Agora, poderíamos falar sobre sua saúde e o uso que você faz de } \\
\text { serviços de saúde? } \\
\text { Em termos gerais, você acha que a sua saúde é excelente, boa, } \\
\text { regular, fraca ou muito fraca? }\end{array}$ & EXCELENTE \\
\hline 202 & $\begin{array}{l}\text { Agora gostaria de perguntar sobre a sua saúde nas últimas } 4 \\
\text { semanas. Como você descreveria sua capacidade de locomoção? } \\
\text { Você diria que não teve problema, teve muito pouco, alguns, } \\
\text { muitos problemas ou ficou incapacitada de locomover-se? }\end{array}$ & MŨO TEVE PROBLEMA POUCO PROBLEMA \\
\hline 203 & $\begin{array}{l}\text { Nas últimas } 4 \text { semanas você teve dificuldade em desenvolver suas } \\
\text { atividades diárias, como o trabalho, estudo, trabalhos domésticos, } \\
\text { família e atividades sociais? Você diria que não teve problema, } \\
\text { teve muito pouco, alguns, muitos problemas ou ficou incapacitada? }\end{array}$ & NÃO TEVE PROBLEMA \\
\hline 204 & $\begin{array}{l}\text { Nas últimas } 4 \text { semanas você sentiu alguma dor ou desconforto? } \\
\text { Você diria que não sentiu dor e desconforto, sentiu dor e } \\
\text { desconforto leves, moderados, sérios ou graves? }\end{array}$ & DEM DOR OU DESCONFORTO \\
\hline
\end{tabular}




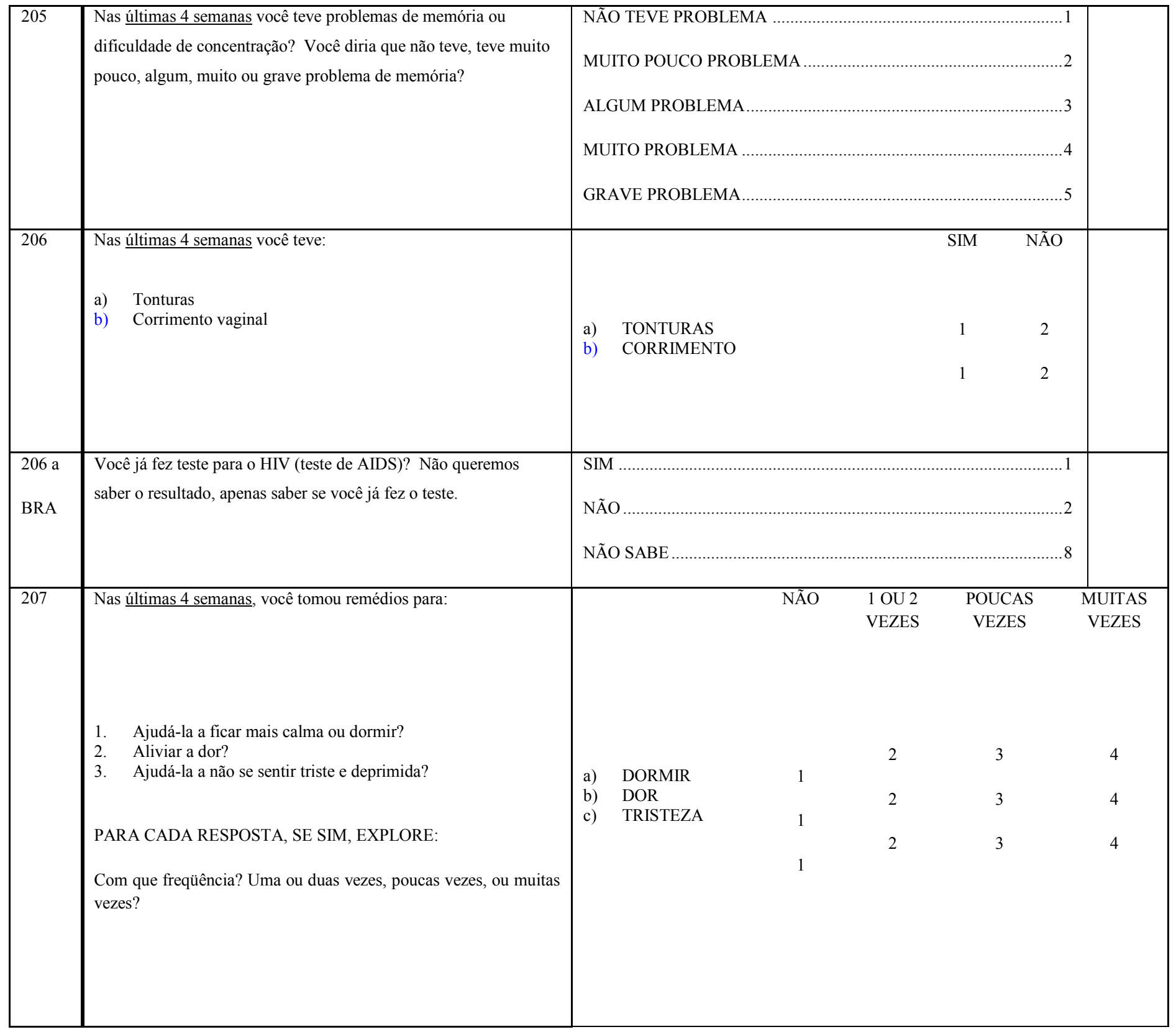




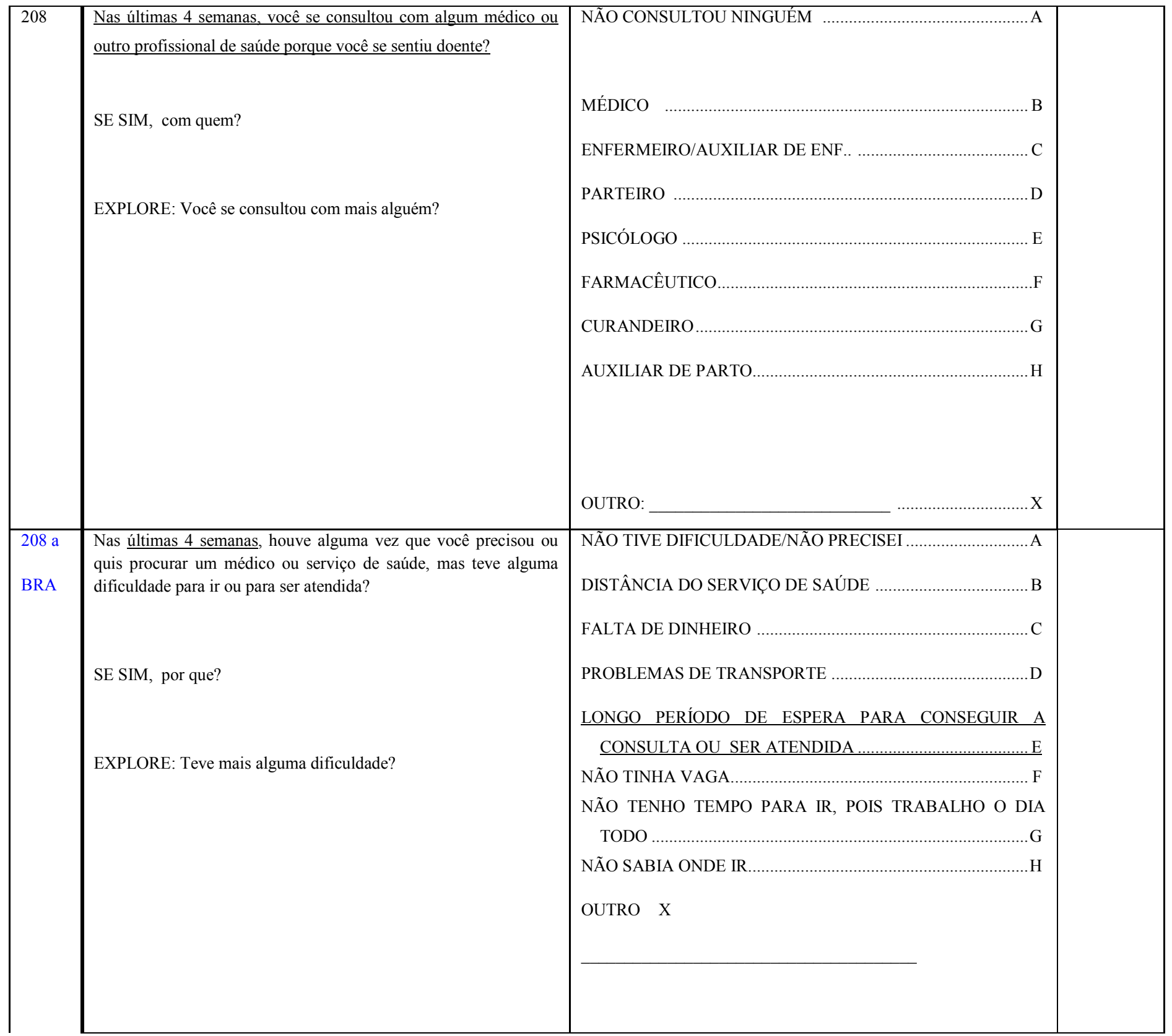




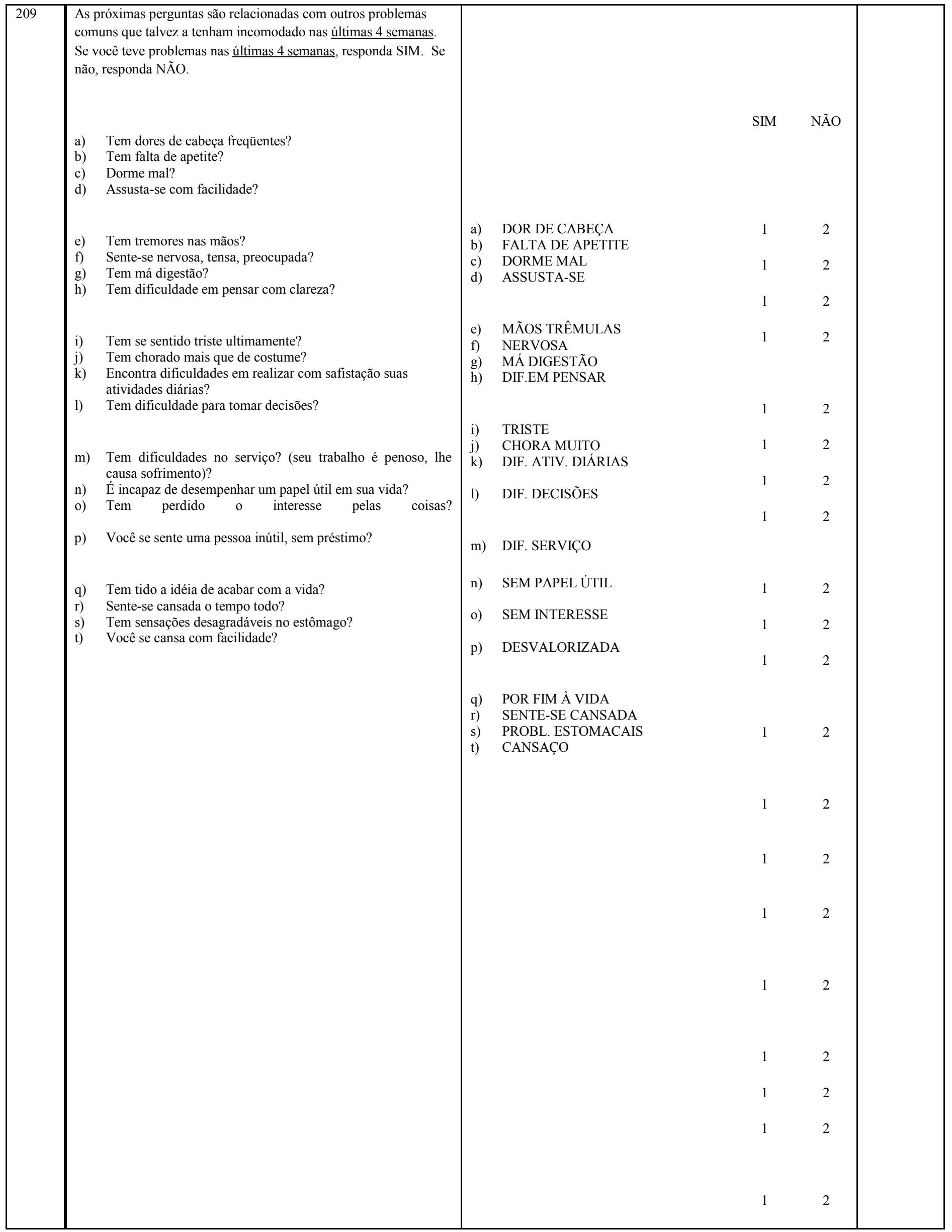




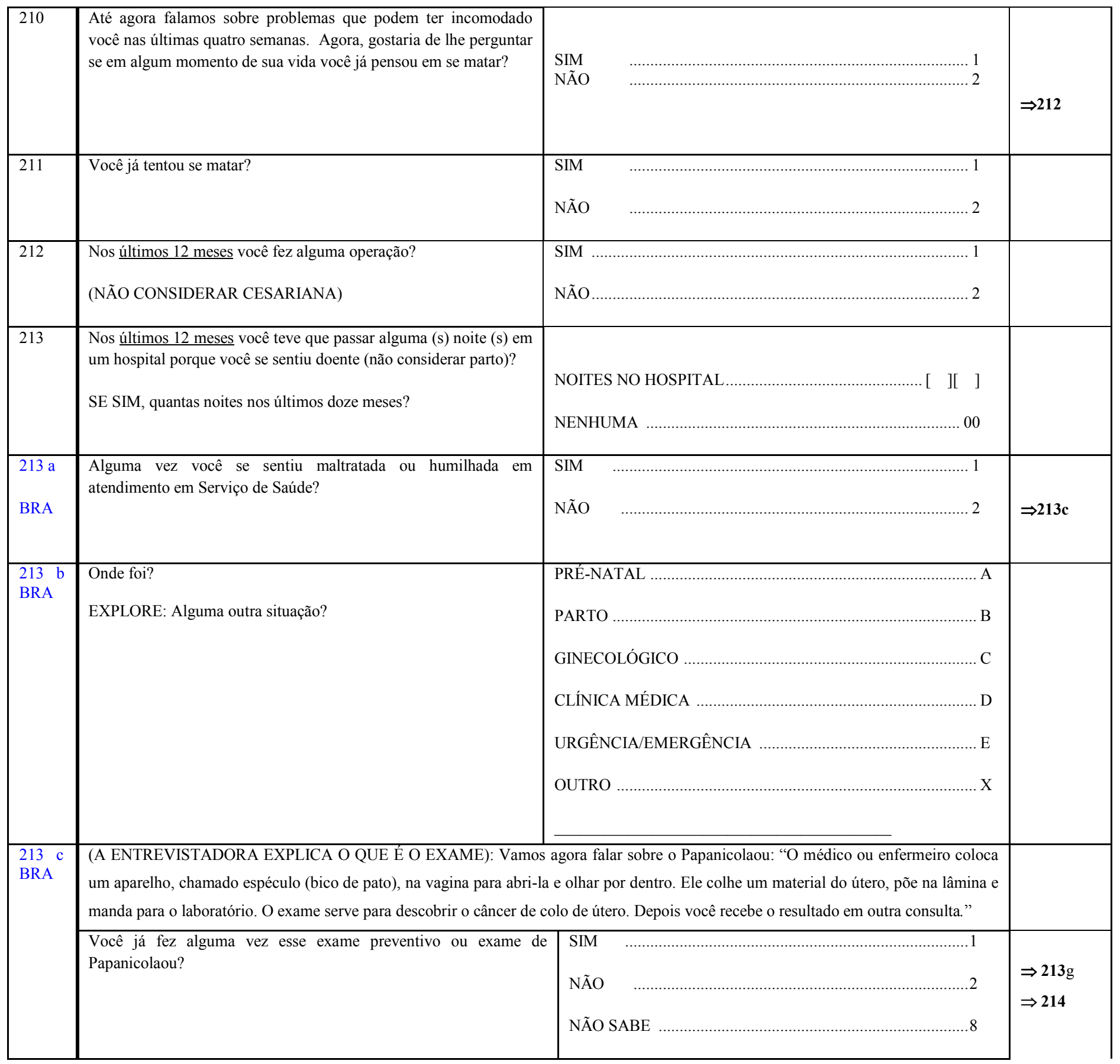




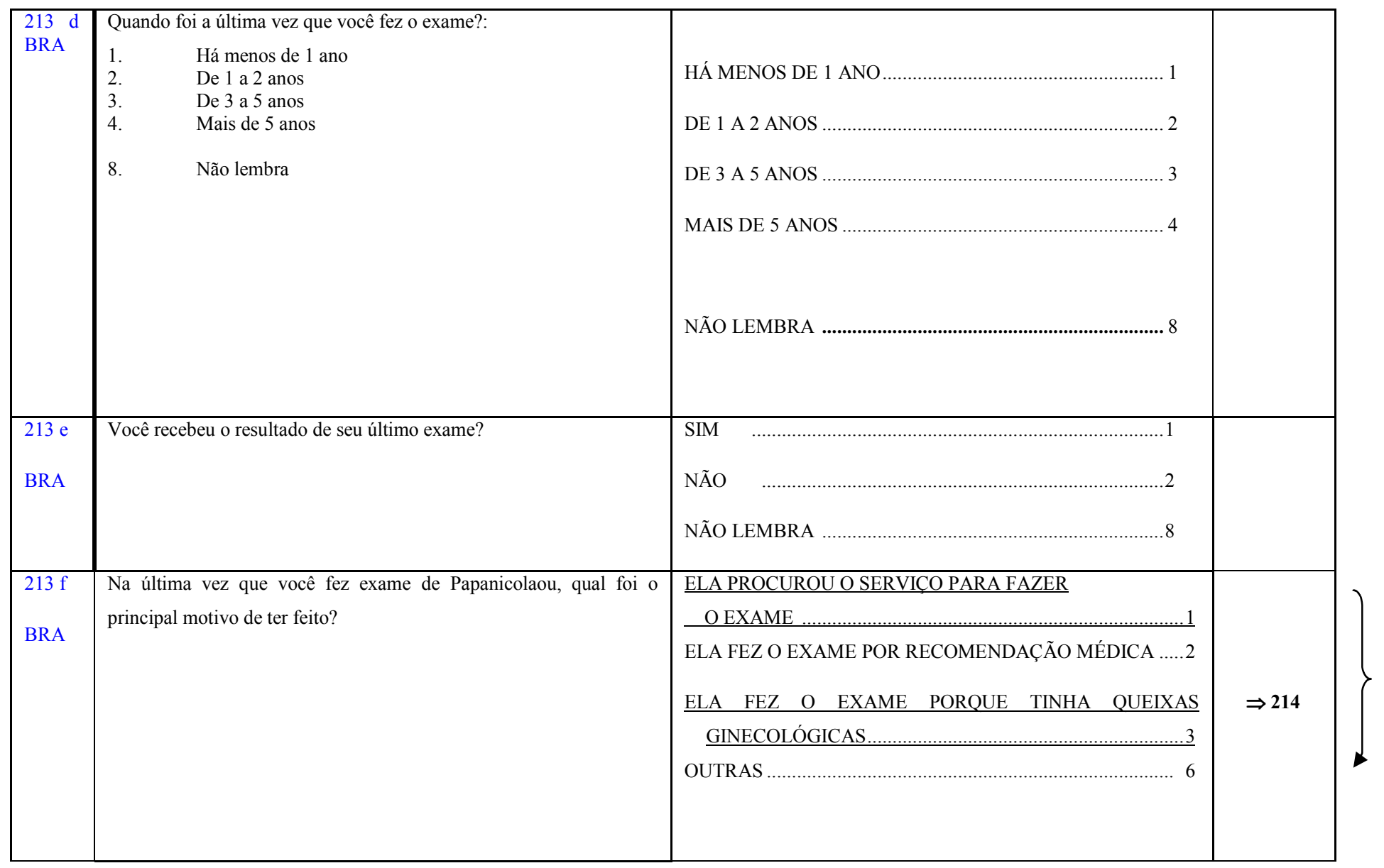




\begin{tabular}{|c|c|c|c|}
\hline $\begin{array}{l}213 \mathrm{~g} \\
\text { BRA }\end{array}$ & $\begin{array}{l}\text { Algumas mulheres não fazem o exame preventivo ou nunca o } \\
\text { fizeram por vários motivos. No seu caso, porque não fez ou não pôde } \\
\text { fazer o exame? }\end{array}$ & 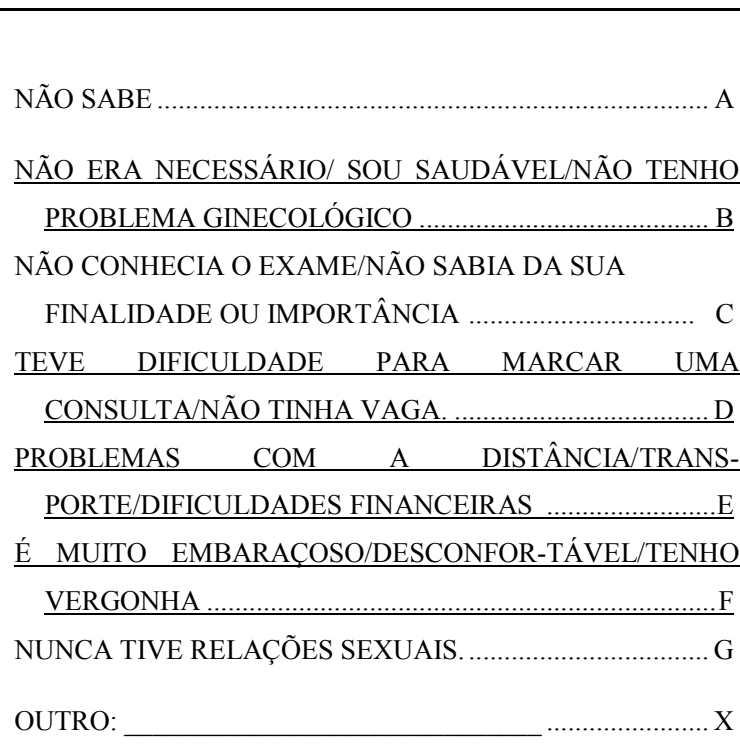 & \\
\hline 214 & $\begin{array}{l}\text { Atualmente você fuma ... } \\
\text { 1. Diariamente (pelo menos um cigarro por dia)? } \\
\text { 2. Ocasionalmente (menos de um cigarro por dia)? } \\
\text { 3. De modo algum? }\end{array}$ & DIARIAMENTE & $\begin{array}{l}\Rightarrow 216 \\
\Rightarrow 216\end{array}$ \\
\hline 215 & $\begin{array}{l}\text { Você já fumou alguma vez em sua vida? Você fumava... } \\
\text { 1. Diariamente? (pelo menos um cigarro por dia) } \\
\text { 2. Ocasionalmente? (pelo menos } 100 \text { cigarros, mas nunca } \\
\text { diariamente) } \\
\text { 3. De modo algum? (ou menos que } 100 \text { cigarros durante todas sua } \\
\text { vida) }\end{array}$ & DIARIAMENTE & \\
\hline 216 & 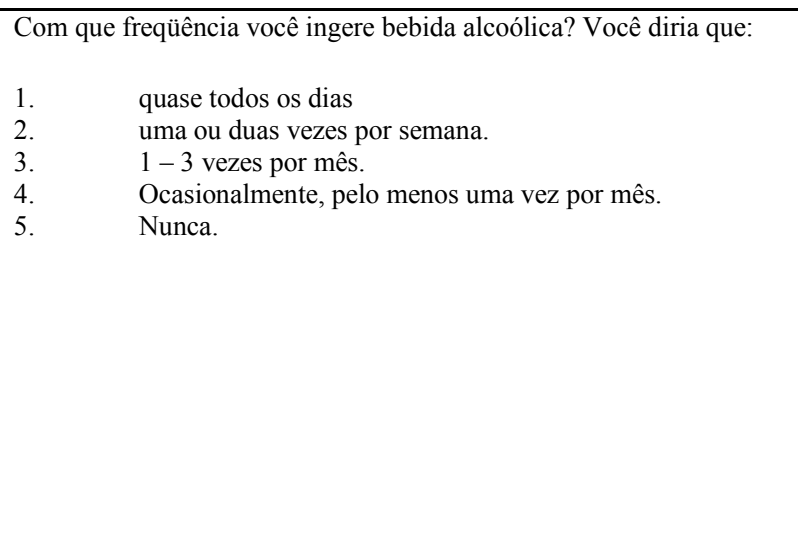 & QUASE TODOS OS DIAS & $\Rightarrow \mathrm{S} .3$ \\
\hline
\end{tabular}




\begin{tabular}{|c|c|c|c|c|}
\hline 217 & $\begin{array}{l}\text { Nos dias em que você tomou bebida alcoólica, nas últimas quatro } \\
\text { semanas, qual foi o seu consumo diário (em doses)? }\end{array}$ & \multicolumn{3}{|c|}{ 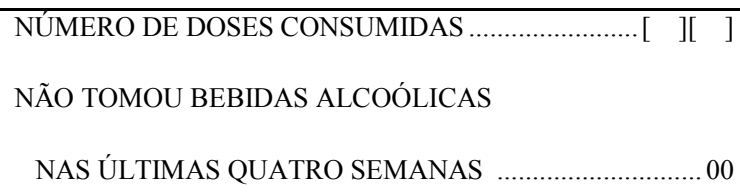 } \\
\hline 218 & $\begin{array}{l}\text { Nos últimos } 12 \text { meses, você teve algum dos seguintes problemas, } \\
\text { relacionados com a bebida? } \\
\text { a) Problemas com dinheiro } \\
\text { b) Problemas de saúde } \\
\text { c) Conflitos familiares ou com amigos. } \\
\text { d) Problemas com autoridades (dono de bar/polícia, etc) } \\
\text { x) Outros, especifique }\end{array}$ & $\begin{array}{l}\text { a) PROBL. COM DINHEIRO } \\
\text { b) PROBL. DE SAÚDE } \\
\text { c) CONFLITOS FAMILIARES } \\
\text { d) PROBL. COM AUTORIDADES } \\
\text { x) OUTROS: }\end{array}$ & $\begin{array}{l}1 \\
1 \\
1\end{array}$ & $\begin{array}{l}2 \\
2 \\
2 \\
2\end{array}$ \\
\hline
\end{tabular}


SEÇÃO 3 - SAÚDE REPRODUTIVA

\begin{tabular}{|c|c|c|c|}
\hline 301 & $\begin{array}{l}\text { Agora eu gostaria de perguntar sobre todos os partos que você já teve } \\
\text { durante a sua vida. Você já deu à luz a quantas crianças vivas? (ESTA } \\
\text { QUESTÃO DIZ RESPEITO AOS NASCIDOS VIVOS) }\end{array}$ & No DE NASCIMENTOS …............................ [ ] ] ] & $\Rightarrow 303$ \\
\hline 302 & Você já engravidou alguma vez? & SIM & $\begin{array}{l}\Rightarrow 304 \\
\Rightarrow 310 \\
\Rightarrow 310\end{array}$ \\
\hline 303 & $\begin{array}{l}\text { Quantos filhos você tem, que estejam vivos atualmente? } \\
\text { REGISTRE O NÚMERO }\end{array}$ & FILHOS & \\
\hline 304 & $\begin{array}{l}\text { Você já teve um menino ou uma menina que tenha nascido vivo (a), mas } \\
\text { morrido depois, em qualquer idade? } \\
\text { SE NÃO, explore: nenhum bebê que tenha chorado ou dado algum sinal de } \\
\text { vida, mas que tenha vivido somente algumas horas ou dias? }\end{array}$ & 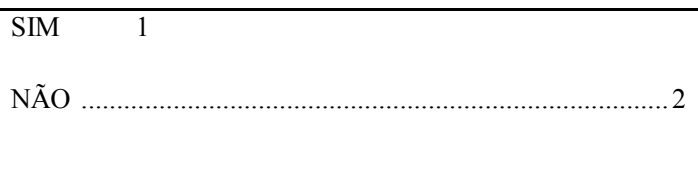 & $\Rightarrow 306$ \\
\hline 305 & $\begin{array}{l}\text { a) Quantos filhos morreram? } \\
\text { b) Quantos filhas morreram? } \\
\text { (ESTA QUESTÃO DIZ RESPEITO A TODAS AS IDADES) }\end{array}$ & 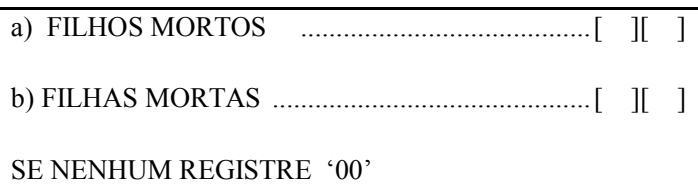 & \\
\hline 306 & $\begin{array}{l}\text { Os seus filhos são todos do mesmo pai biológico ou você tem filhos com } \\
\text { mais de um pai? }\end{array}$ & 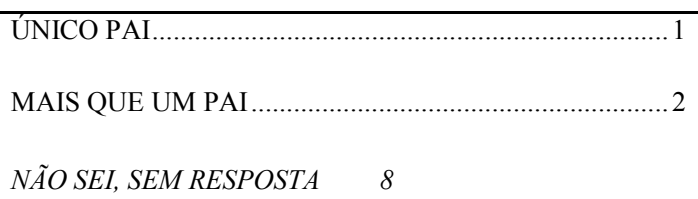 & \\
\hline 307 & $\begin{array}{l}\text { Quantos dos seus filhos recebem apoio financeiro dos pais deles? Você } \\
\text { diria que nenhum, alguns ou todos? }\end{array}$ & NENHUM & \\
\hline 308 & $\begin{array}{l}\text { Quantas vezes você já ficou grávida? Considere, inclusive, qualquer } \\
\text { gravidez mesmo que não tenha tido uma criança viva. } \\
\text { EXPLORE: quantas gestações foram gêmeos ou trigêmeos? }\end{array}$ & $\begin{array}{l}\text { a) NÚMERO TOTAL DE VEZES ........................ [ ] ] ] } \\
\text { QUE ENGRAVIDOU } \\
\text { b) GESTAÇÕES COM GÊMEOS ............................ [ ] } \\
\text { c) GESTAÇÕES COM TRIGÊMEOS ........................ [ ] }\end{array}$ & \\
\hline
\end{tabular}




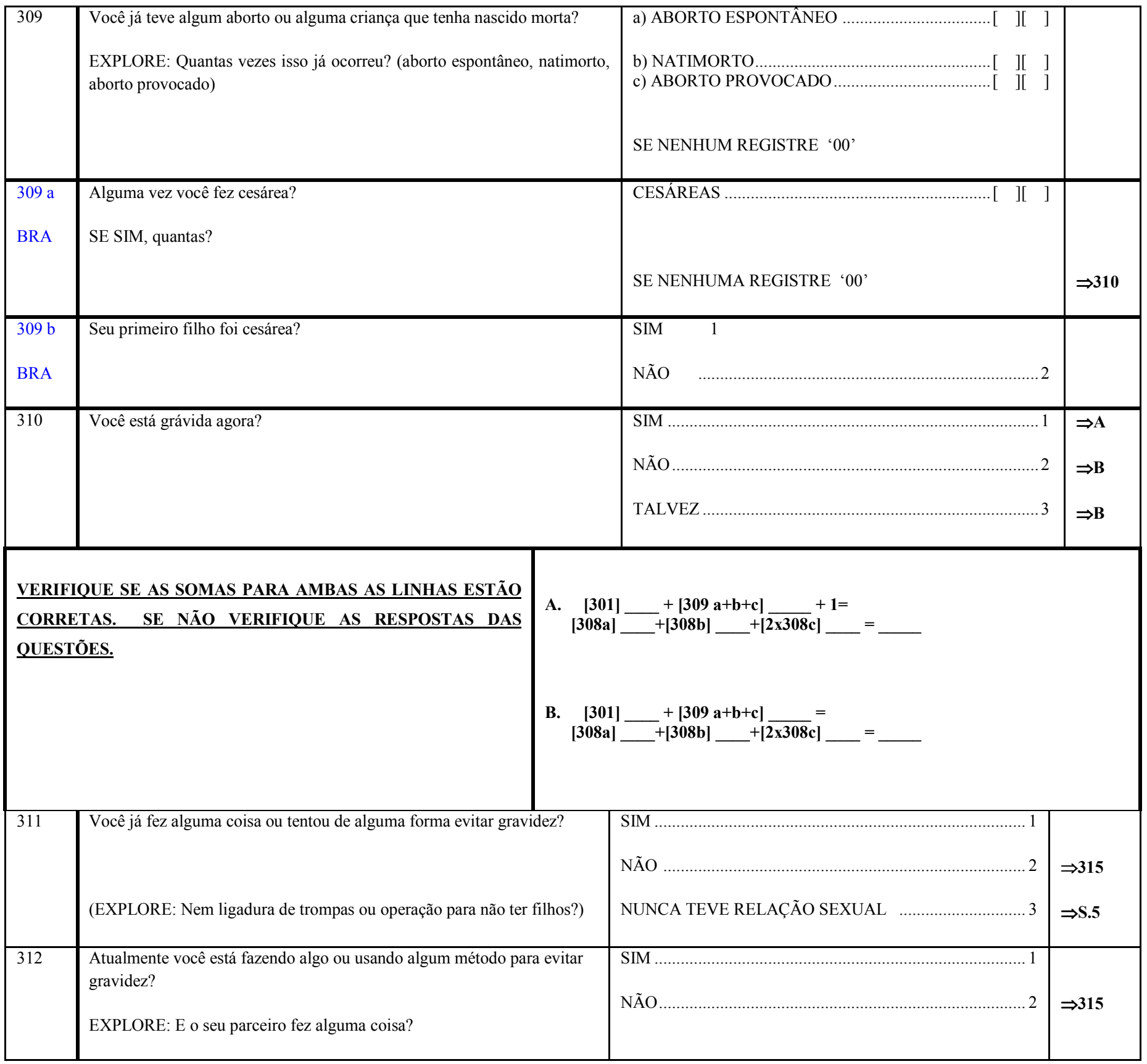




\begin{tabular}{|c|c|c|c|}
\hline 313 & SE MAIS QUE UM, MARQUE APENAS O PRINCIPAL. & INIEÇÕES & $\begin{array}{l}\Rightarrow 315 \\
\Rightarrow 315 \\
\Rightarrow 315\end{array}$ \\
\hline 314 & $\begin{array}{l}\text { Seu marido/companheiro atual sabe que você está usando um método } \\
\text { para planejamento familiar? }\end{array}$ & SIM & \\
\hline 315 & $\begin{array}{l}\text { Alguma vez seu marido/companheiro mais recente/atual já recusou ou } \\
\text { tentou impedi-la de usar algum método para evitar a gravidez? }\end{array}$ & SIM & $\Rightarrow 317$ \\
\hline 316 & $\begin{array}{l}\text { De que maneira ele demonstrou que não aprovava que você usava algum } \\
\text { método para evitar a gravidez? } \\
\text { MARQUE TODAS AS QUE SE APLICAM }\end{array}$ & 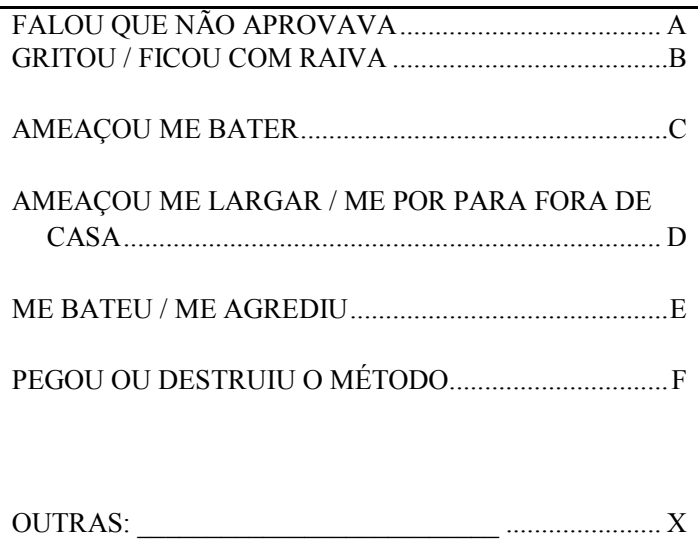 & \\
\hline 317 & $\begin{array}{l}\text { Você alguma vez usou camisinha com seu parceiro mais recente/atual } \\
\text { para se proteger de alguma doença? }\end{array}$ & SIM & $\Rightarrow \mathrm{S} .4$ \\
\hline 318 & $\begin{array}{l}\text { Você alguma vez pediu para que seu parceiro mais recente/atual usasse } \\
\text { camisinha? }\end{array}$ & SIM & $\Rightarrow \mathrm{S} .4$ \\
\hline
\end{tabular}




\begin{tabular}{|c|c|c|c|}
\hline 319 & $\begin{array}{l}\text { Alguma vez seu marido/companheiro mais recente/atual já se recusou a } \\
\text { usar camisinha para prevenir alguma doença? }\end{array}$ & SIM & $\Rightarrow$ S.4 \\
\hline 320 & $\begin{array}{l}\text { De que maneiras ele demonstrou para você que não aprovava o uso de } \\
\text { camisinha? }\end{array}$ & $\begin{array}{l}\text { FALOU QUE NÃO APROVAVA } \\
\text { GRITOU / FICOU COM RAIVA } \\
\text { AMEAÇOU ME BATER } \\
\text { AMEAÇOU ME LARGAR / ME POR PARA FORA DE } \\
\text { PEGOU OU DESTRUIU O MÉTODO BCUSOU VOCÊ DE SER INFIEL/ DE NÃO SER UMA } \\
\text { BOA MULHER } \\
\text { RIU DE MIM/ NÃO ME LEVOU A SÉRIO } \\
\text { DISSE QUE NÃO ERA NECESSÁRIO }\end{array}$ & \\
\hline
\end{tabular}


SEÇÃO 4 - FILHOS

ANTES DE COMEÇAR A SEÇÃO 4:

REVISE AS RESPOSTAS E MARQUE A HISTÓRIA REPRODUTIVA NA FOLHA DE REFERÊNCIA, BOX B.

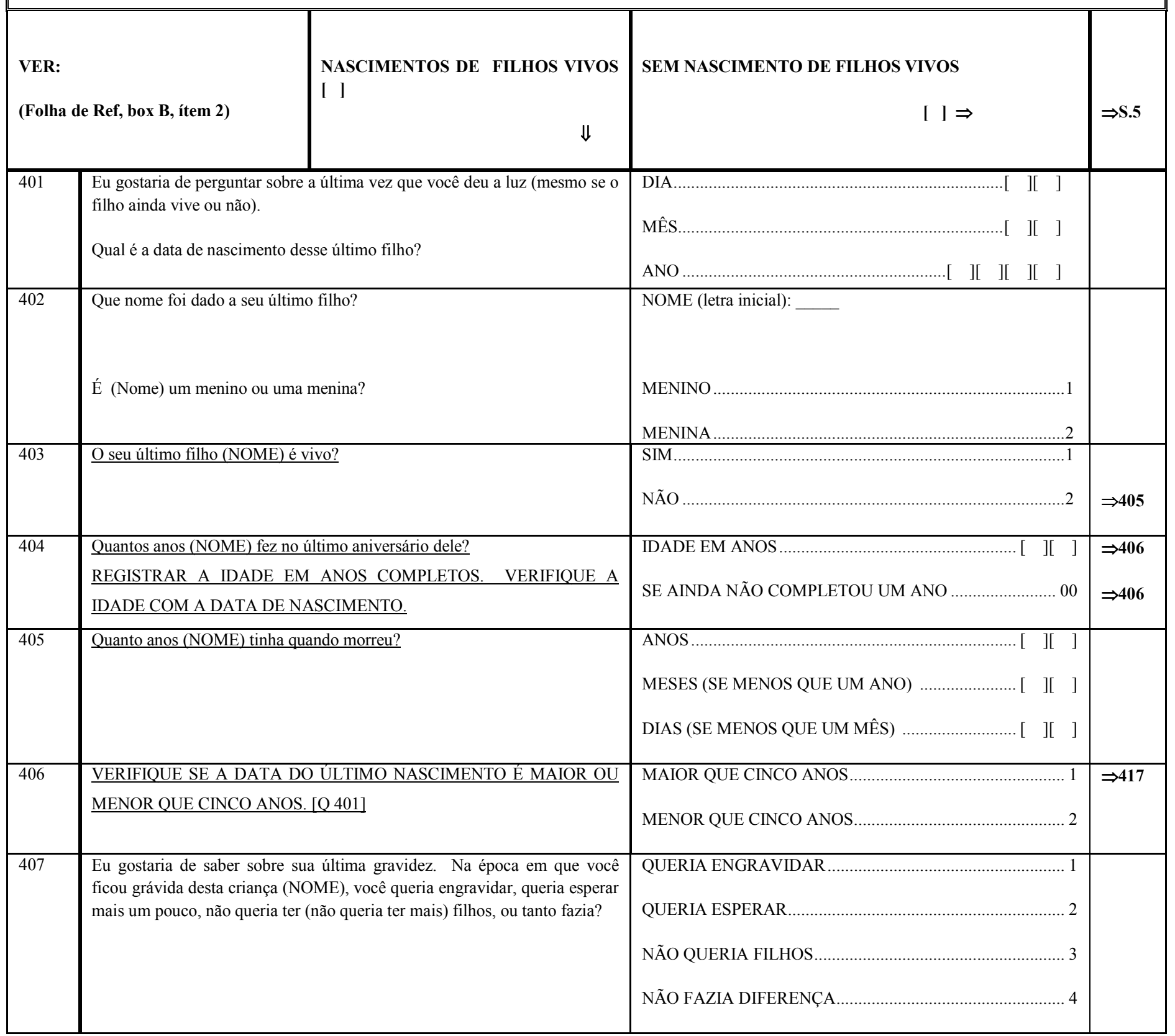




\begin{tabular}{|c|c|c|}
\hline 408 & $\begin{array}{l}\text { Na época em que você ficou grávida desta criança (NOME), seu marido / } \\
\text { companheiro queria que você engravidasse, queria esperar mais um pouco, } \\
\text { não queria ter (não queria ter mais) fillhos, ou tanto fazia? }\end{array}$ & QUERIA A GRAVIDEZ \\
\hline 409 & $\begin{array}{l}\text { Quando você estava grávida desta criança (NOME), você fez } \\
\text { acompanhamento pré-natal? } \\
\text { Se sim, com quem? } \\
\text { MARQUE TODAS AS RESPOSTAS QUE SE APLICAM }\end{array}$ & 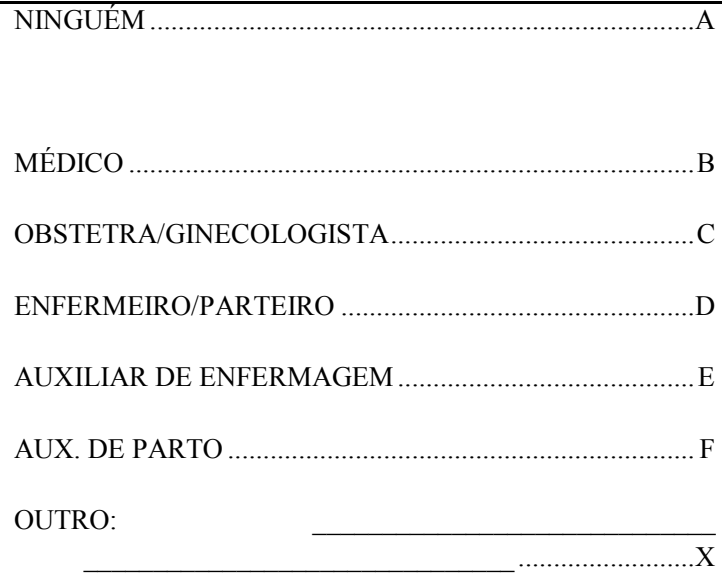 \\
\hline 410 & $\begin{array}{l}\text { Seu marido/companheiro impediu, encorajou, ou não demonstrou qualquer } \\
\text { interesse que você recebesse cuidados durante a gravidez (pré-natal)? }\end{array}$ & IMPEDIU \\
\hline 411 & $\begin{array}{l}\text { Quando você estava grávida desta criança, seu marido/companheiro tinha } \\
\text { preferência por um filho, uma filha, ou não se importou se seria um menino } \\
\text { ou uma menina? }\end{array}$ & FILHO \\
\hline 412 & Durante esta gravidez, você consumiu algum tipo de bebida alcoólica? & NĨO \\
\hline
\end{tabular}




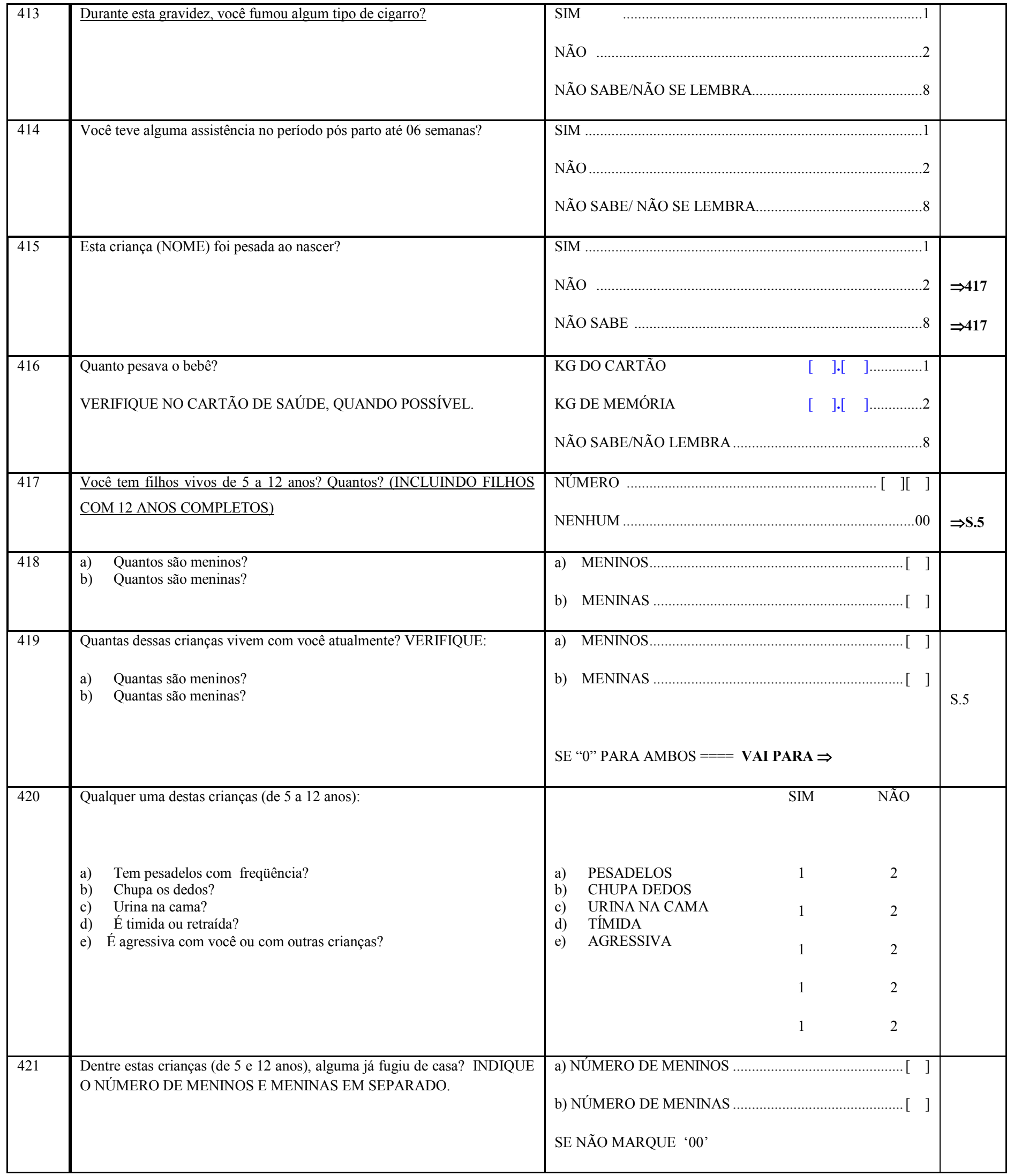




\begin{tabular}{|c|c|c|c|}
\hline 422 & $\begin{array}{l}\text { Dentre estas crianças (de } 5 \text { e } 12 \text { anos), quantas frequentam a escola? } \\
\text { INDIQUE O NÚMERO DE MENINOS E MENINAS EM SEPARADO. }\end{array}$ & b) MENINAS & $\Rightarrow$ S.5 \\
\hline 423 & $\begin{array}{l}\text { Alguma destas crianças repetiu de ano na escola? } \\
\text { CERTIFIQUE-SE QUE SÃO APENAS OS FILHOS DE } 5 \text { A } 12 \text { ANOS }\end{array}$ & SIM & \\
\hline 424 & $\begin{array}{l}\text { Alguma destas crianças parou de ir à escola por algum período ou } \\
\text { abandonou os estudos completamente? } \\
\text { CERTIFIQUE-SE QUE SÃO APENAS OS FILHOS DE } 5 \text { A } 12 \text { ANOS }\end{array}$ & SIM & \\
\hline
\end{tabular}


SEÇÃO 5 - PARCEIRO ATUAL OU MAIS RECENTE

ANTES DE COMEÇAR A SEÇÃO 5:

VEJA O ESTADO MARITAL NA FOLHA DE REFERÊNCIA, BOX A, E MARQUE ABAIXO.

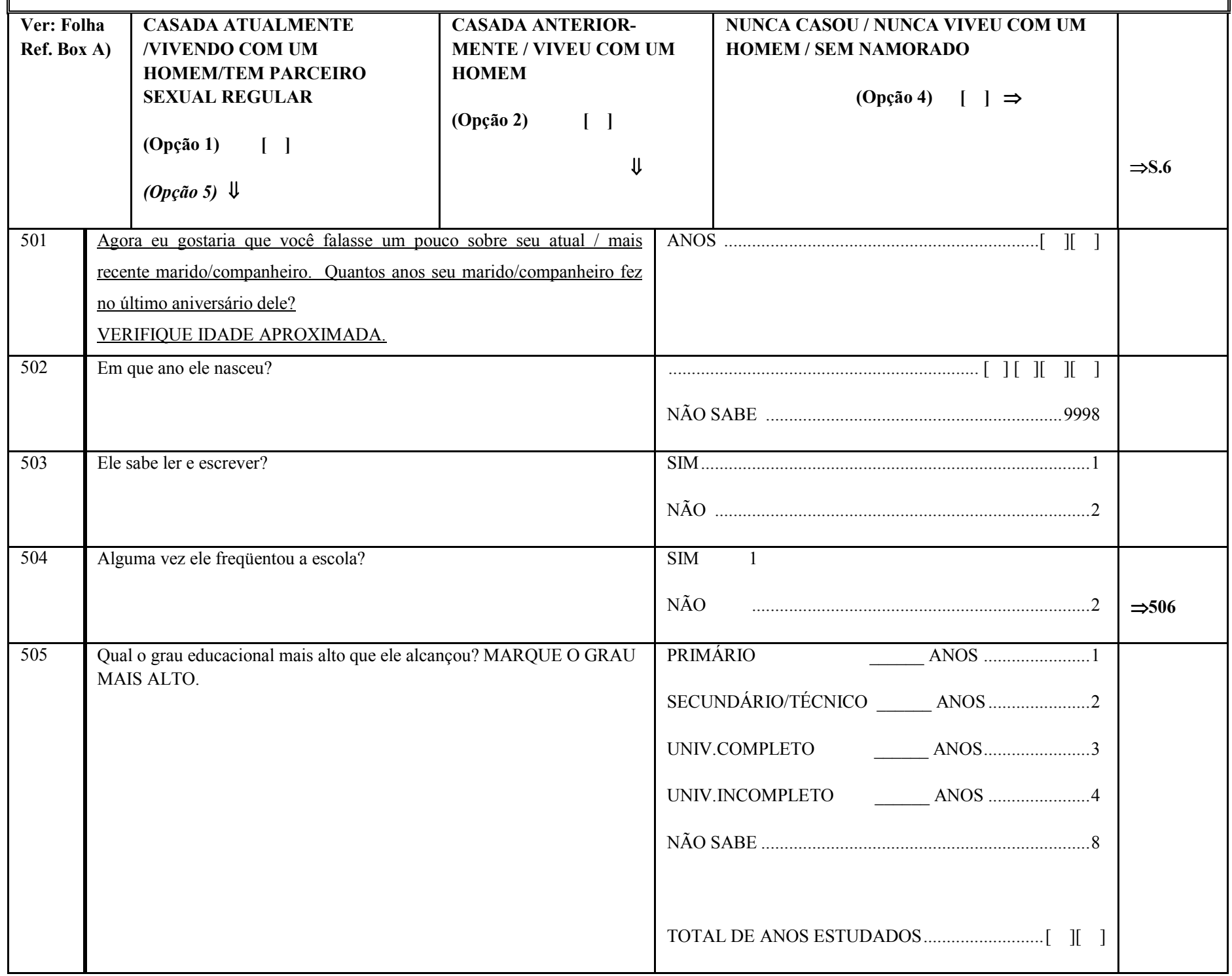




\begin{tabular}{|c|c|c|c|}
\hline 506 & $\begin{array}{l}\text { Atualmente seu marido/companheiro está trabalhando, procurando } \\
\text { emprego ou desempregado, aposentado ou estudando? } \\
\text { (PARA O CASO DE PARCEIRO MAIS RECENTE: Durante o } \\
\text { relacionamento de vocês ele estava trabalhando ....?) }\end{array}$ & TRABALHANDO & $\begin{array}{l}\Rightarrow \mathbf{5 0 8} \\
\Rightarrow \mathbf{5 0 8} \\
\Rightarrow \mathbf{5 0 9}\end{array}$ \\
\hline 507 & $\begin{array}{l}\text { Quando ele saiu do seu último emprego? Nas últimas quatro semanas, } \\
\text { entre } 4 \text { semanas e últimos doze meses, ou depois disso? } \\
\text { (PARA O CASO DE PARCEIRO MAIS RECENTE: nas últimas quatro } \\
\text { semanas ou nos últimos doze meses de seu relacionamento?) }\end{array}$ & 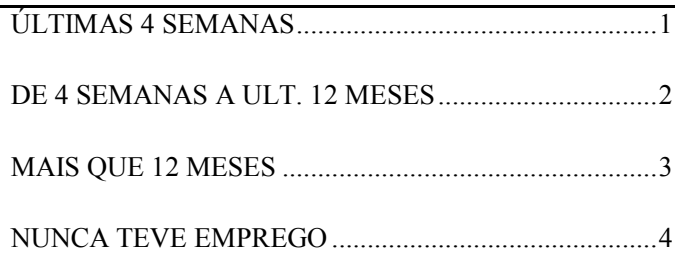 & $\Rightarrow 509$ \\
\hline 508 & ESPECIFIQUE O TIPO DE TRABALHO & $\begin{array}{l}\text { PROFISSIONAL: } \\
\text { TÉCNICO: } \\
\text { NÃO ESPECIALIZADO: } \\
\text { MILITAR/POLICIAL: } \\
\text { OUTRO: }\end{array}$ & \\
\hline 509 & $\begin{array}{l}\text { Com que freqüência seu marido/companheiro toma/tomava bebidas } \\
\text { alcoólicas? } \\
\text { 1. Todos os dias ou quase todos os dias } \\
\text { 2. Uma ou duas vezes por semana } \\
\text { 3. } 1-3 \text { vezes por mês } \\
\text { 4. Ocasionalmente, menos de uma vez por mês } \\
\text { 5. Nunca }\end{array}$ & TODOS OU QUASE TODOS OS DIAS & $\Rightarrow 512$ \\
\hline
\end{tabular}




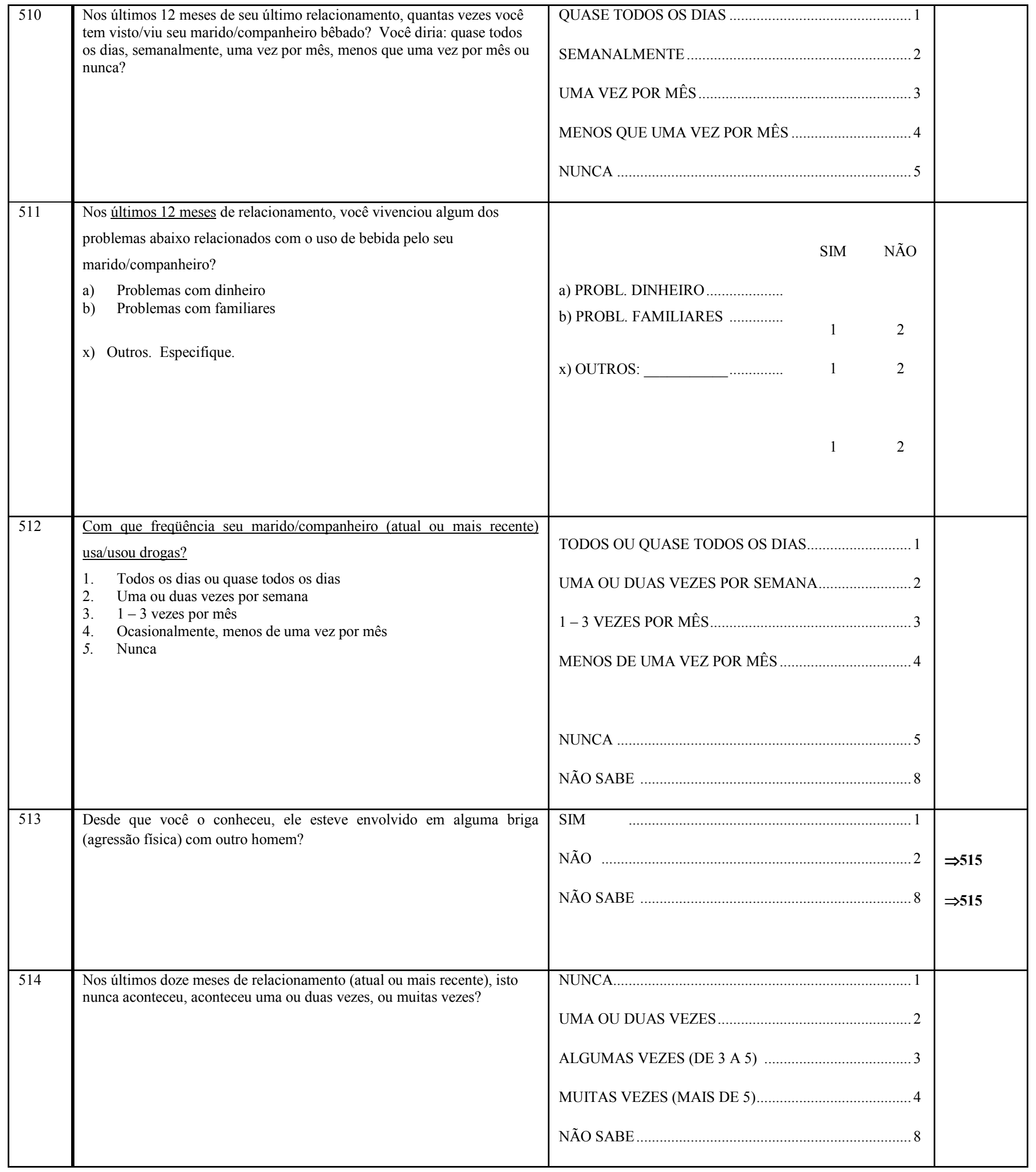




\begin{tabular}{|c|c|c|c|}
\hline 515 & $\begin{array}{l}\text { O seu marido/companheiro (atual ou mais recente) teve outras mulheres } \\
\text { durante o relacionamento com você? }\end{array}$ & SIM ÃO & $\begin{array}{l}\Rightarrow \text { S.6 } \\
\Rightarrow \text { S.6 }\end{array}$ \\
\hline 516 & $\begin{array}{l}\text { O seu marido/companheiro (atual ou mais recente) teve filhos com outra } \\
\text { mulher durante o relacionamento com você? }\end{array}$ & SIM NÃO & \\
\hline
\end{tabular}


SEÇÃO 6 - ATITUDES COM RELAÇÃO AOS PAPÉIS DE GÊNERO

\begin{tabular}{|c|c|c|}
\hline & \multicolumn{2}{|c|}{$\begin{array}{l}\text { Nesta comunidade e em outros locais, as pessoas têm idéias diferentes sobre as famílias e sobre o que constitui um comportamento aceitável } \\
\text { para homens e mulheres em casa. Vou ler uma lista de afirmações e gostaria que você me dissesse se você concorda ou discorda das } \\
\text { afirmações. Não há respostas certas ou erradas. }\end{array}$} \\
\hline 601 & Uma boa esposa obedece a seu marido mesmo que discorde dele & CONCORDA. \\
\hline 602 & $\begin{array}{l}\text { Os problemas familiares devem ser discutidos apenas com pessoas } \\
\text { da família. }\end{array}$ & 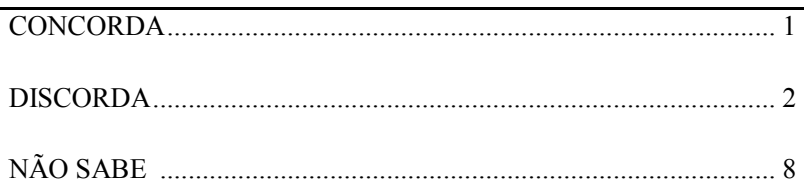 \\
\hline 603 & $\begin{array}{l}\text { É importante para o homem mostrar à sua esposa/companheira } \\
\text { quem é que manda. }\end{array}$ & CONCORDA. \\
\hline 604 & $\begin{array}{l}\text { Uma mulher deve escolher seus próprios amigos mesmo quando } \\
\text { seu marido não concorda. }\end{array}$ & CONCORDA. \\
\hline 605 & $\begin{array}{l}\text { É obrigação da esposa manter relações sexuais com seu marido } \\
\text { mesmo quando não estiver com vontade. }\end{array}$ & CONCORDA \\
\hline 606 & $\begin{array}{l}\text { Se um homem maltrata sua esposa, outras pessoas de fora da } \\
\text { família deveriam intervir. }\end{array}$ & CONCORDA. \\
\hline
\end{tabular}




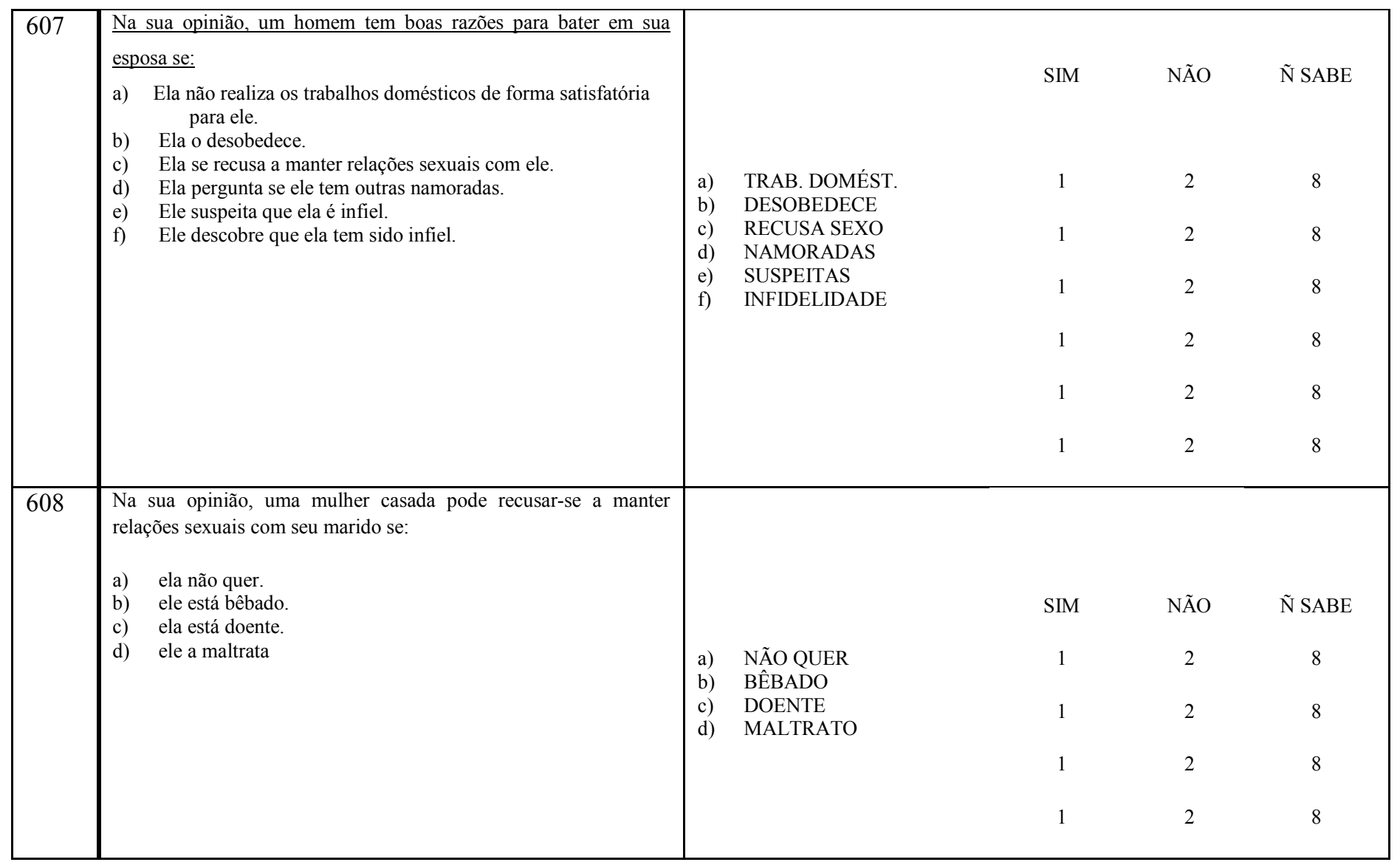


ANTES DE COMEÇAR A SEÇÃO 7:

VEJA O ESTADO MARITAL DA FOLHA DE REFERÊNCIA, BOX A, E MARQUE ABAIXO.

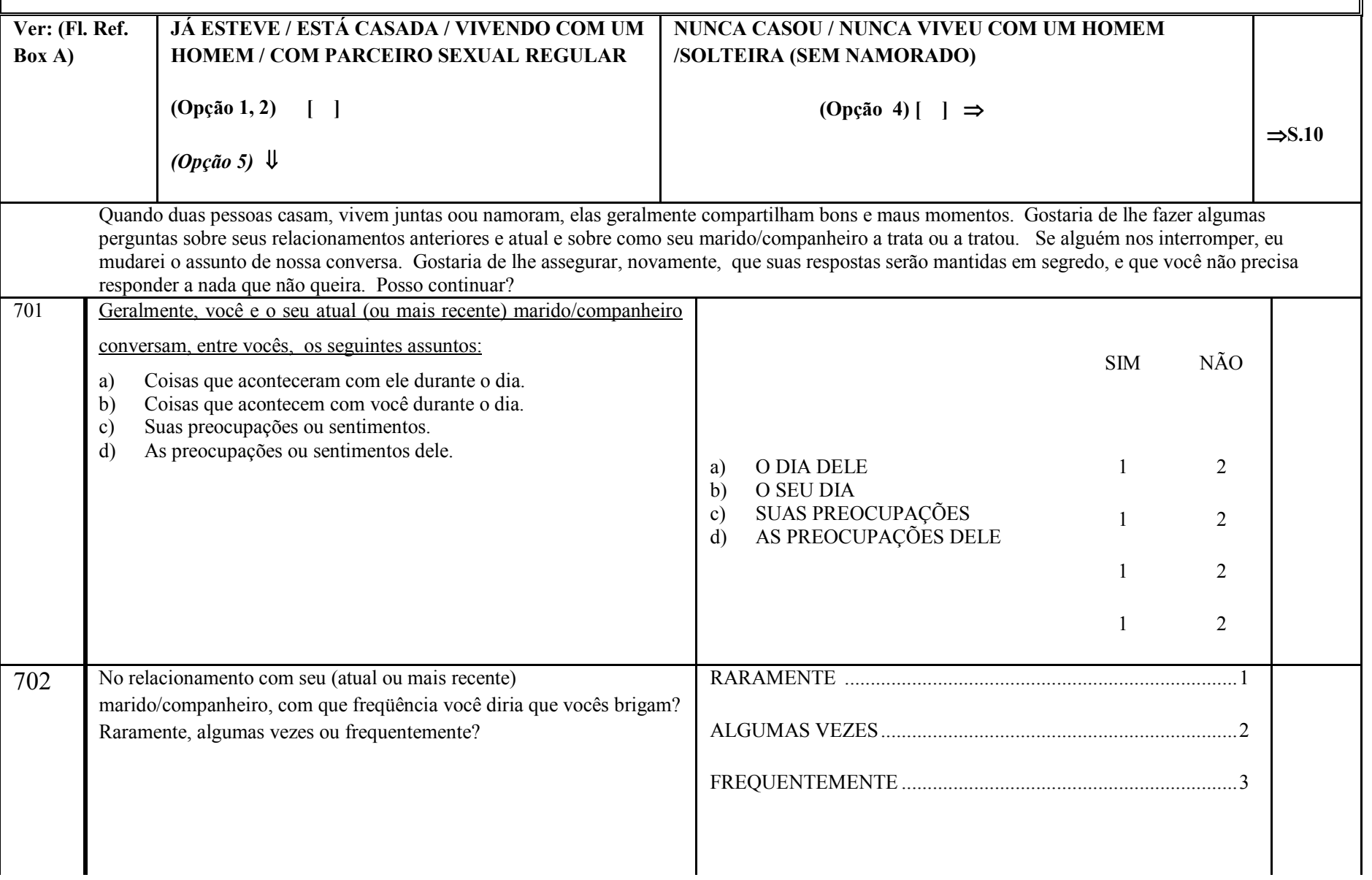




\begin{tabular}{|c|c|c|c|c|}
\hline 703 & $\begin{array}{l}\text { Agora vou lhe colocar algumas situações que são verdadeiras para } \\
\text { muitas mulheres. Pensando sobre seu marido/companheiro (atual ou } \\
\text { mais recente), você diria que geralmente ele: } \\
\text { a) tenta evitar que você visite/veja seus amigos. } \\
\text { b) Procura restringir o seu contato com sua família. } \\
\text { c) Insiste em saber onde você está o tempo todo. } \\
\text { d) Lhe ignora e a trata com indiferença. } \\
\text { e) Fica zangado se você conversa com outro homem. } \\
\text { f) Está frequentemente suspeitando que você é infiel. } \\
\text { g) Espera que você peça permissão a ele antes de procurar um } \\
\text { serviço de saúde para você mesma. }\end{array}$ & $\begin{array}{ll} & \\
\text { a) } & \text { VER AMIGOS } \\
\text { b) } & \text { CONTATOS FAMILIARES } \\
\text { c) } & \text { SABER ONDE ESTÁ } \\
\text { d) } & \text { A IGNORA } \\
\text { e) } & \text { FICA ZANGADO } \\
\text { f) } & \text { SUSPEITA } \\
\text { g) } & \text { SERVIÇO DE SAÚDE }\end{array}$ & $\begin{array}{l}1 \\
1 \\
1 \\
1 \\
1 \\
1\end{array}$ & $\begin{array}{l}2 \\
2 \\
2 \\
2 \\
2 \\
2 \\
2\end{array}$ \\
\hline
\end{tabular}




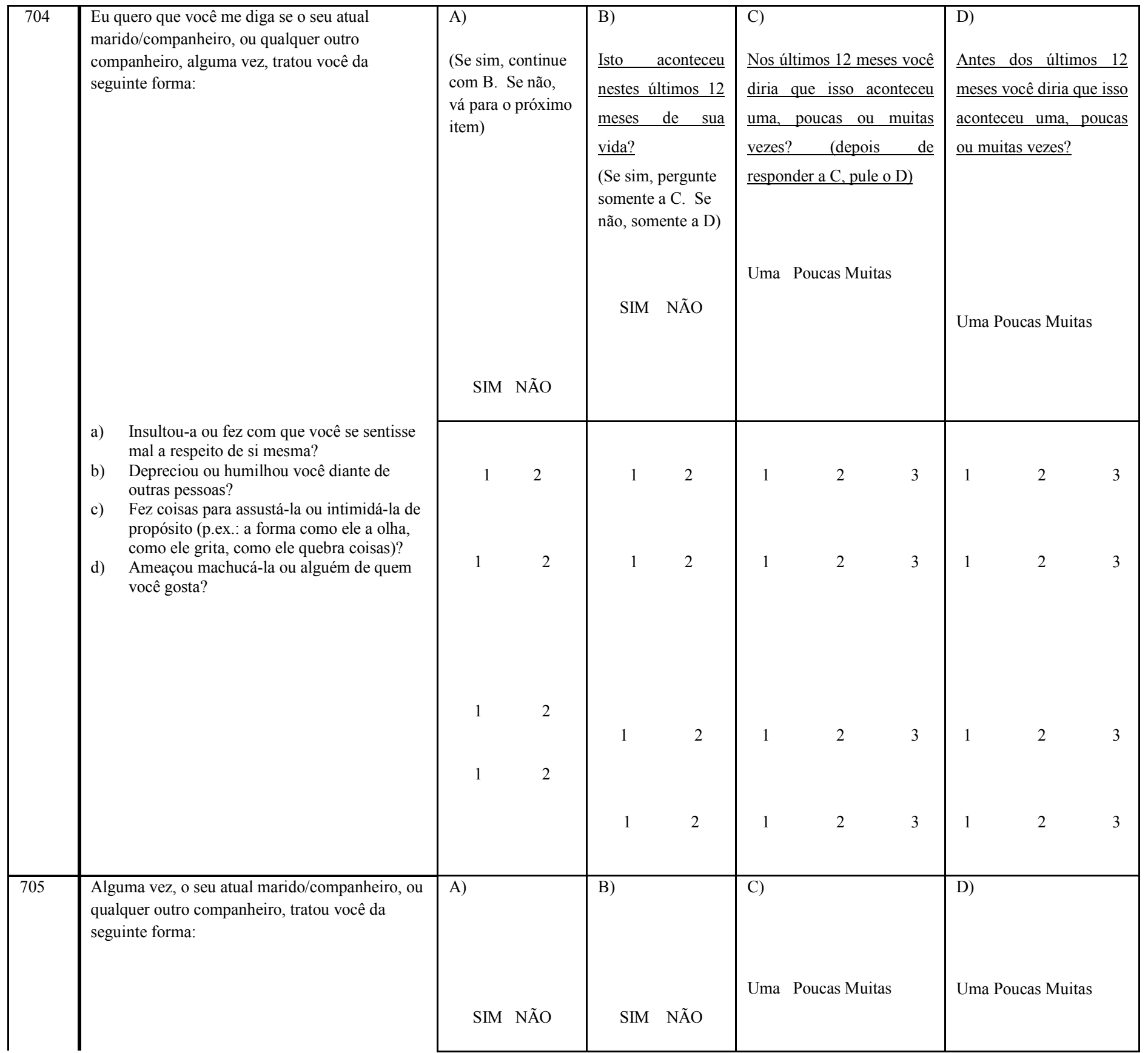




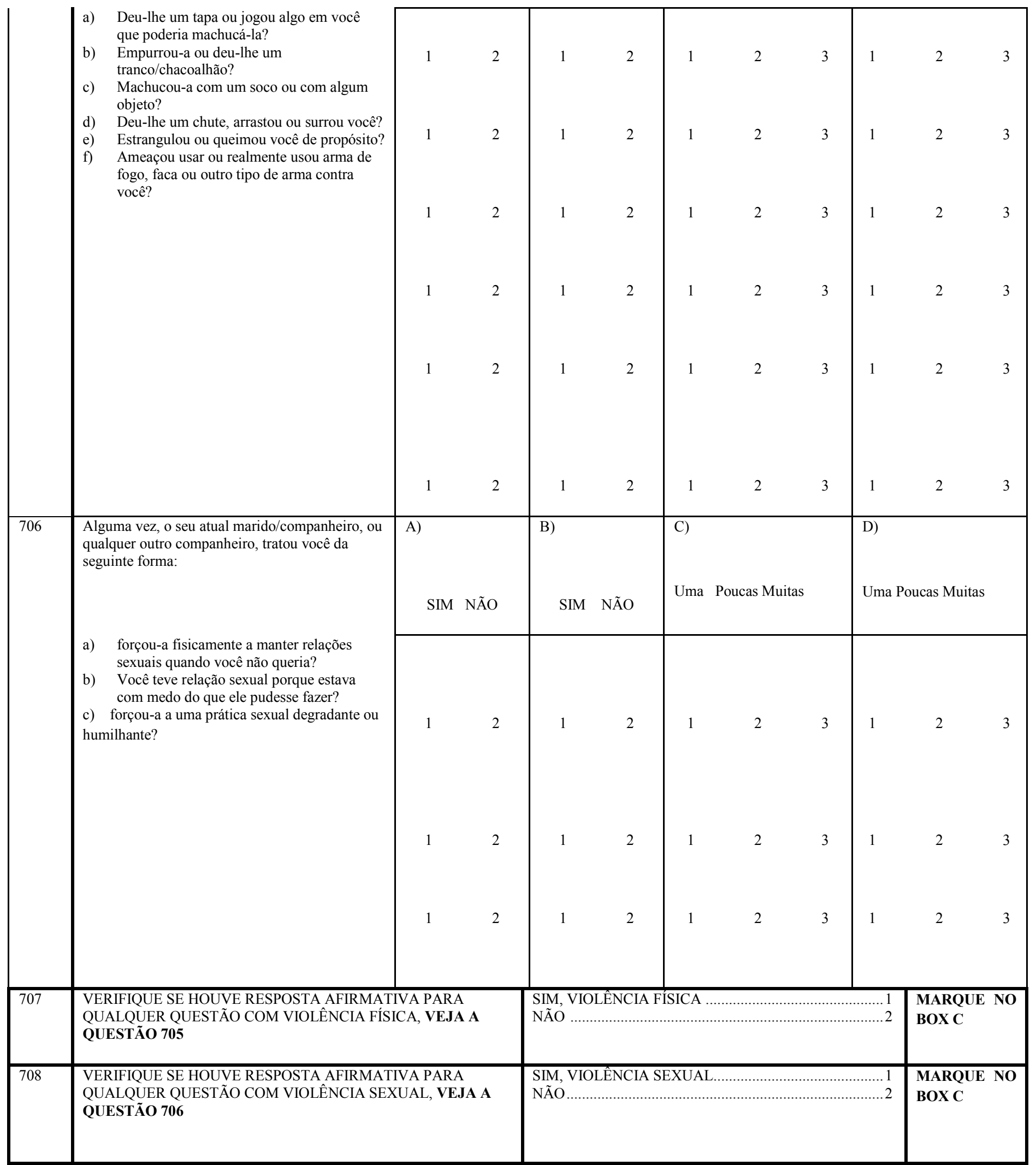




\begin{tabular}{|c|c|c|c|c|c|}
\hline \multicolumn{2}{|c|}{$\begin{array}{l}\text { Ver (Fl. Ref. Box } \\
\text { B opção 1) }\end{array}$} & \multicolumn{2}{|l|}{ 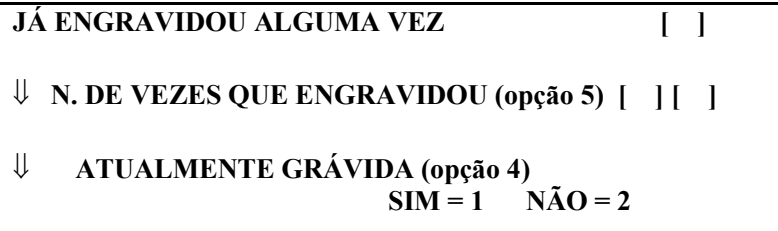 } & NUNCA ENGRAVIDOU [ ] $\Rightarrow$ & $\Rightarrow 716^{*}$ \\
\hline 709 & $\begin{array}{l}\text { Você diss } \\
\text { alguma oc } \\
\text { outra form } \\
\text { estava grá }\end{array}$ & $\begin{array}{l}\text { á ter engravidado NÚMERO TOTAL de vezes. Houve } \\
\text { ião na sua vida em que você foi espancada ou, de alguma } \\
\text { agredida fisicamente por um companheiro quando você } \\
\text { da? }\end{array}$ & $\begin{array}{l}\mathrm{SIM} . \\
\mathrm{NÃO}\end{array}$ & . & $\Rightarrow 716^{*}$ \\
\hline 710 & $\begin{array}{l}\text { Isto ocorr } \\
\text { SE EM M } \\
\text { Em quant }\end{array}$ & $\begin{array}{l}\text { em uma gravidez, ou em mais de uma? } \\
\text { IS DE UMA: } \\
\text { delas você foi agredida fisicamente? }\end{array}$ & $\begin{array}{l}\mathrm{N}^{\circ} \mathrm{Dl} \\
\text { FÍSIC }\end{array}$ & ES COM AGRESSÃO & \\
\hline \multicolumn{5}{|c|}{$\begin{array}{l}\text { SE A VIOLÊNCIA FOI RELATADA EM MAIS DO QUE UMA GRAVIDEZ, AS PERGUNTAS SEGUINTES IRÃO SE REFERIR À ÚLTIMA OU } \\
\text { MAIS RECENTE GRAVIDEZ COM VIOLÊNCIA REPORTADA. }\end{array}$} & \\
\hline 712 & $\begin{array}{l}\text { Durante a } \\
\text { a agrediu }\end{array}$ & $\begin{array}{l}\text { ais recente gravidez, na qual você foi agredida, a pessoa que } \\
\text { a o pai da criança? }\end{array}$ & $\begin{array}{l}\text { SIM } \\
\text { NÃO } \\
\text { NÃO }\end{array}$ & 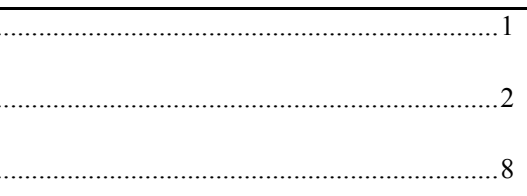 & \\
\hline 713 & Você esta & vivendo com esta pessoa quando isto aconteceu? & $\begin{array}{l}\text { SIM } \\
\text { NÃO } \\
\text { NÃO }\end{array}$ & +2 & \\
\hline 714 & $\begin{array}{l}\text { Você já } \\
\text { grávida? }\end{array}$ & ivia sido agredida por esta mesma pessoa antes de ficar & $\begin{array}{l}\mathrm{SIM} \\
\mathrm{NÃO}\end{array}$ & 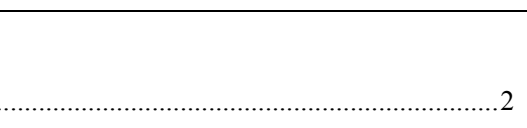 & $\Rightarrow 716^{*}$ \\
\hline 715 & $\begin{array}{l}\text { Comparan } \\
\text { violência }\end{array}$ & $\begin{array}{l}\text { o sua situação antes da gravidez, você diria que a situação de } \\
\text { minuiu, não se alterou ou aumentou durante a gravidez? }\end{array}$ & $\begin{array}{l}\text { DIMI } \\
\text { NÃO } \\
\text { AUM } \\
\text { NÃO }\end{array}$ & Und & \\
\hline
\end{tabular}




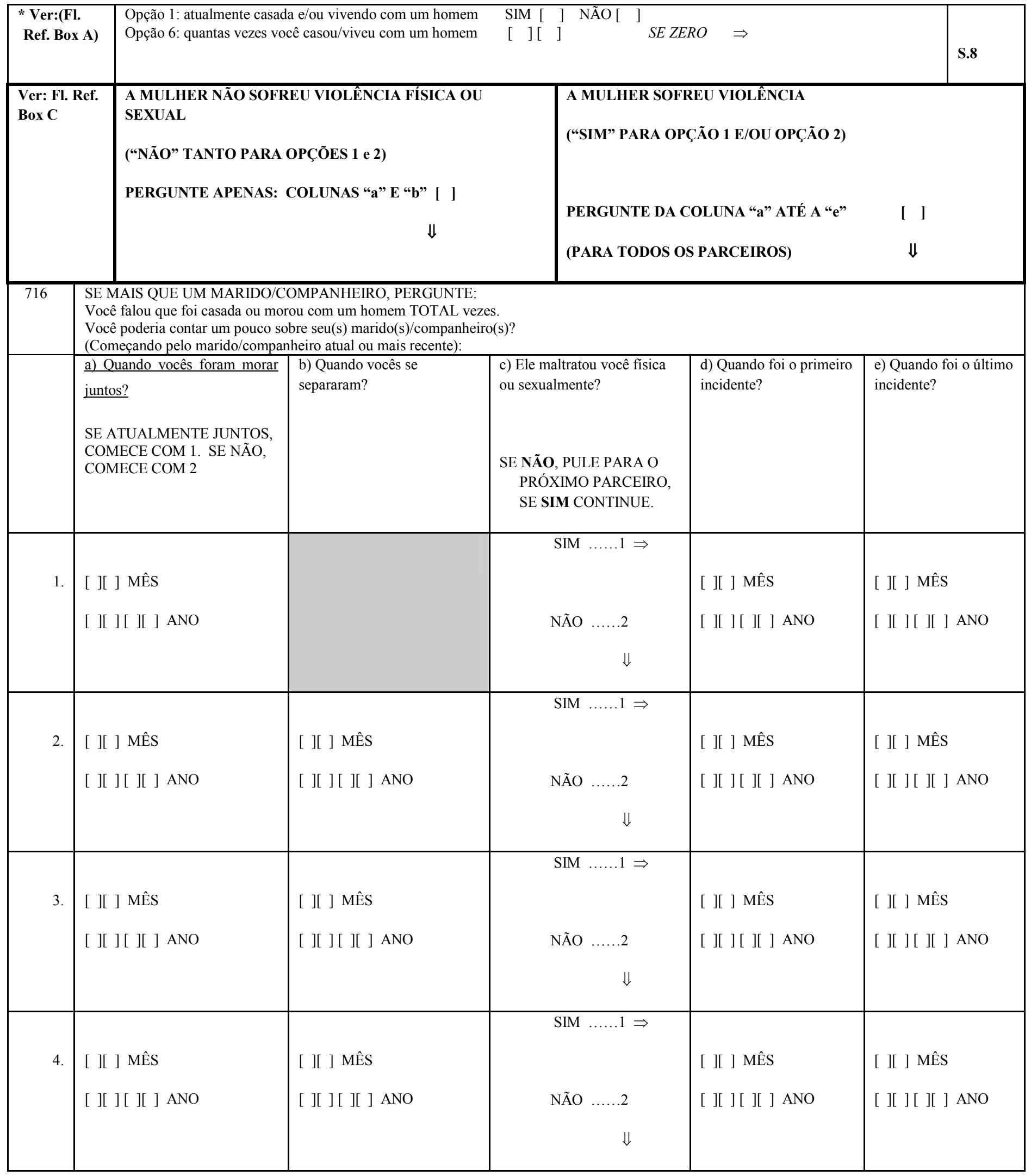




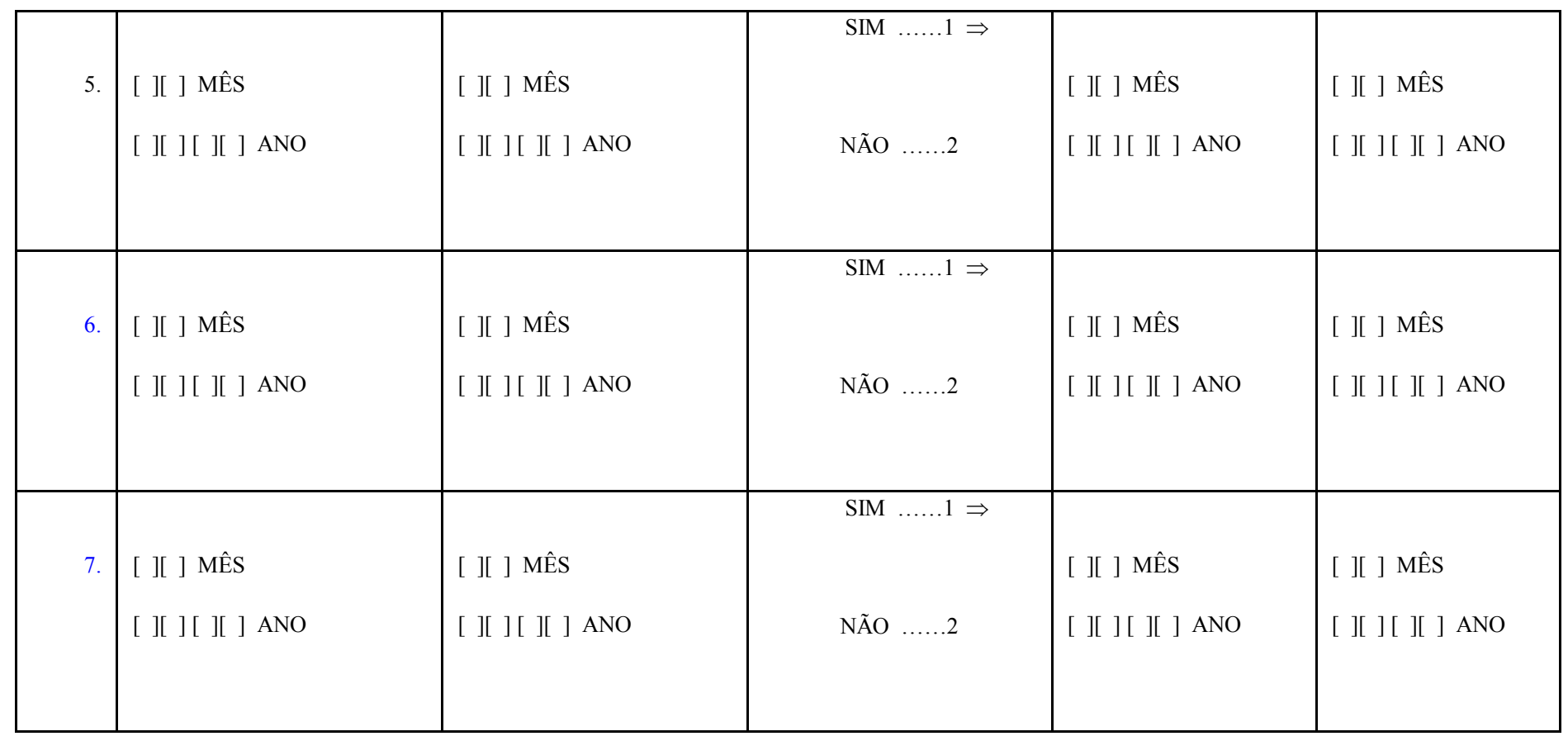

VERIFIQUE SE TODOS OS PARCEIROS ESTÃO INCLUIDOS. 
SEÇÃO 8 - LESÕES

ANTES DE COMEÇAR A SEÇÃO 8:

VEJA A SITUAÇÃO DE VIOLÊNCIA E LESÕES DA FOLHA DE REFERÊNCIA, BOX C, E MARQUE ABAIXO.

\begin{tabular}{|c|c|c|c|c|c|c|}
\hline \multicolumn{2}{|c|}{$\begin{array}{l}\text { Ver: Fl. Ref. } \\
\text { Box C }\end{array}$} & $\begin{array}{l}\text { A MULHER SOFREU VIOLÊNCIA F } \\
\text { (“SIM” VÁ PARA OPÇÃO 1) }\end{array}$ & $\begin{array}{lll}\text { SICA } & & \\
& 1 & \\
& & \\
& & \downarrow\end{array}$ & (“NÃO” VÁ PARA OPÇÃO 1) & 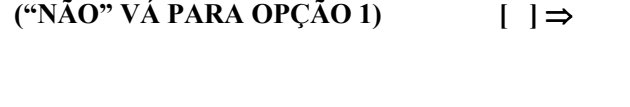 & $\Rightarrow \mathrm{S} .10$ \\
\hline & \multicolumn{6}{|c|}{$\begin{array}{l}\text { Agora, gostaria de saber mais sobre as lesões que você sofreu em decorrência da violência de seu marido/companheiro. Por violência, refiro-me a } \\
\text { qualquer forma de dano físico, como cortes, torções, ossos ou dentes quebrados, ou outras coisas desse gênero. }\end{array}$} \\
\hline $802 \mathrm{a}$ & \multicolumn{2}{|c|}{$\begin{array}{l}\text { Na sua vida, quantas vezes você já sofreu } \\
\text { lesões por seu marido/companheiro (atual ou } \\
\text { anteriores? } \\
\text { Você diria uma ou duas vezes, algumas vezes, } \\
\text { ou muitas vezes? }\end{array}$} & \multicolumn{3}{|c|}{ 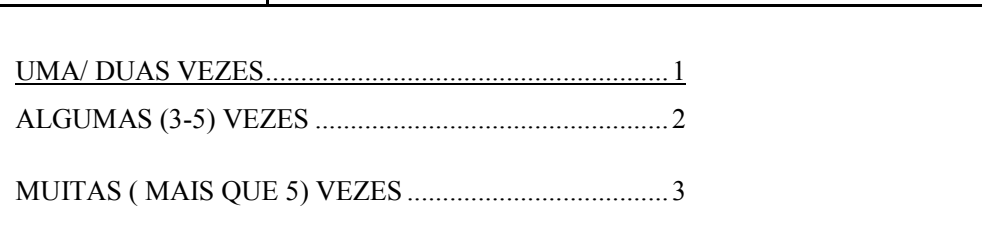 } & \\
\hline $803 \mathrm{a}$ & & & & & $\begin{array}{l}\text { b) SOMENTE } \\
\text { PERGUNTE PARA } \\
\text { AS RESPOSTAS } \\
\text { ASSINALADAS NA } \\
803 \text { a. Isto aconteceu } \\
\text { nos últimos } 12 \text { meses? } \\
\text { SIM NÃO }\end{array}$ & \\
\hline
\end{tabular}




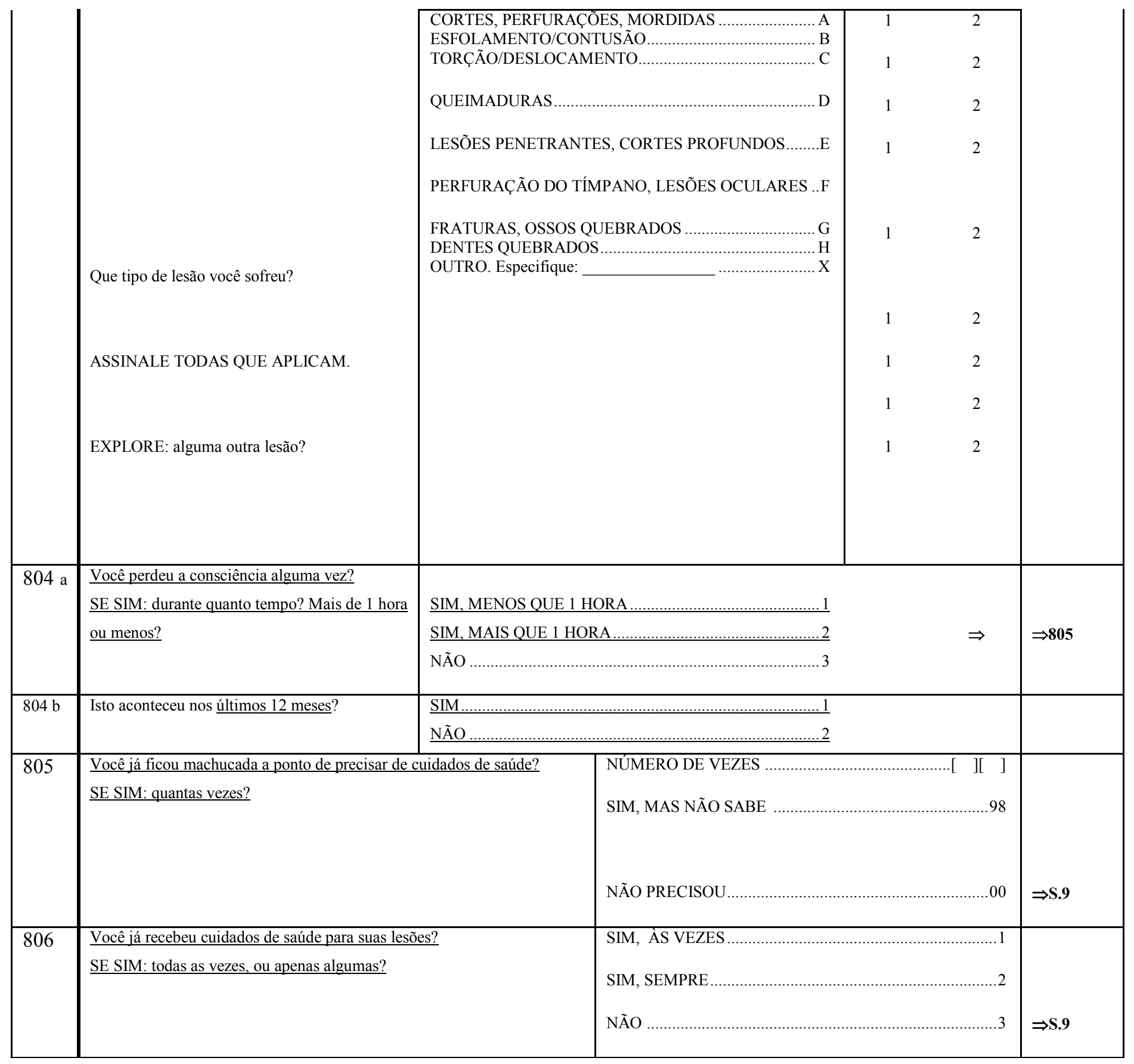




\begin{tabular}{|c|c|c|}
\hline 807 & $\begin{array}{l}\text { Você precisou passar alguma noite hospitalizada por causa de suas lesões? } \\
\text { SE SIM: quantas noites? }\end{array}$ & 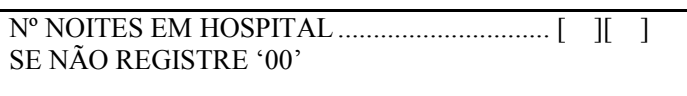 \\
\hline 808 & $\begin{array}{l}\text { Você contou ao profissional de saúde que a atendeu a verdadeira causa de } \\
\text { suas lesões? }\end{array}$ & SIM \\
\hline
\end{tabular}


SEÇÃO 9 - IMPACTO E ENFRENTAMENTO

Agora eu gostaria de fazer perguntas sobre o que geralmente acontecia quando seu marido/companheiro era violento.

CASO TENHA RELATADO MAIS QUE UM PARCEIRO VIOLENTO, ACRESCENTAR: AS QUESTÕES REFEREM-SE AO ÚLTIMO OU MAIS RECENTE PARCEIRO QUE USOU VIOLÊNCIA.

\begin{tabular}{|c|c|c|}
\hline 901 & $\begin{array}{l}\text { Existem situações particulares que costumam levar seu companheiro } \\
\text { à violência? } \\
\text { EXPLORE: alguma outra situação? } \\
\text { ASSINALE TODAS AS QUE FOREM MENCIONADAS. }\end{array}$ & QUANDO BÊBADO \\
\hline
\end{tabular}

ANTES DE CONTINUAR A SEÇÃO 9:

VEJA A HISTÓRIA REPRODUTIVA DA FOLHA DE REFERÊNCIA, BOX B, E MARQUE ABAIXO.

\begin{tabular}{|c|c|c|c|c|c|}
\hline \multicolumn{2}{|c|}{ Ver: (Fl. Ref., box B, ponto 3) } & \begin{tabular}{|l|} 
FILHOS VIVOS \\
\end{tabular} & \multicolumn{2}{|l|}{ SEM FILHOS VIVOS } & $\Rightarrow 903$ \\
\hline 902 & \multicolumn{2}{|c|}{$\begin{array}{l}\text { Seus filhos estavam presentes ou escutaram você sendo } \\
\text { agredida fisicamente em qualquer um desses episódios de } \\
\text { violência? } \\
\text { SE SIM: com que frequiência? Você diria que foram } 1 \text { ou } 2 \\
\text { vezes, algumas vezes ou muitas vezes/o tempo todo? }\end{array}$} & \multicolumn{2}{|c|}{ NUNCA OU 2 VEZES } & \\
\hline
\end{tabular}




\begin{tabular}{|c|c|c|}
\hline 903 & $\begin{array}{l}\text { Durante ou depois do episódio de violência física, ele } \\
\text { costuma/costumava forçar você a fazer sexo? } \\
\text { SE SIM: com que freqüência? Você diria que foram } 1 \text { ou } 2 \\
\text { vezes, algumas vezes ou muitas vezes/o tempo todo? }\end{array}$ & NUNCA \\
\hline 904 & $\begin{array}{l}\text { Durante as vezes em que você foi agredida, você alguma vez } \\
\text { revidou fisicamente ou reagiu para se defender? } \\
\text { SE SIM: com que freqüência? Você diria que foram } 1 \text { ou } 2 \\
\text { vezes, algumas vezes ou muitas vezes/o tempo todo? }\end{array}$ & NUNCA \\
\hline 905 & $\begin{array}{l}\text { Em alguma ocasião você bateu ou agrediu fisicamente seu } \\
\text { marido/companheiro quando ele não estava batendo em você ou } \\
\text { agredindo você fisicamente? } \\
\text { SE SIM: com que freqüência? Você diria que foram } 1 \text { ou } 2 \\
\text { vezes, algumas vezes ou muitas vezes? }\end{array}$ & NUNCA 1 OU 2 VEZES \\
\hline 906 & $\begin{array}{l}\text { Você diria que a violência do seu marido / compa-nheiro contra } \\
\text { você afetou / está afetando sua saúde física ou mental? } \\
\text { EXPLORE: afetou sua saúde um pouco ou muito? }\end{array}$ & NÃO AFETOU \\
\hline
\end{tabular}




\begin{tabular}{|c|c|c|}
\hline 907 & $\begin{array}{l}\text { De que forma a violência prejudicou seu emprego ou outras } \\
\text { atividades geradoras de renda? Se é que prejudicou. } \\
\text { ASSINALE TODAS AS RESPOSTAS QUE SE APLICAM. }\end{array}$ & 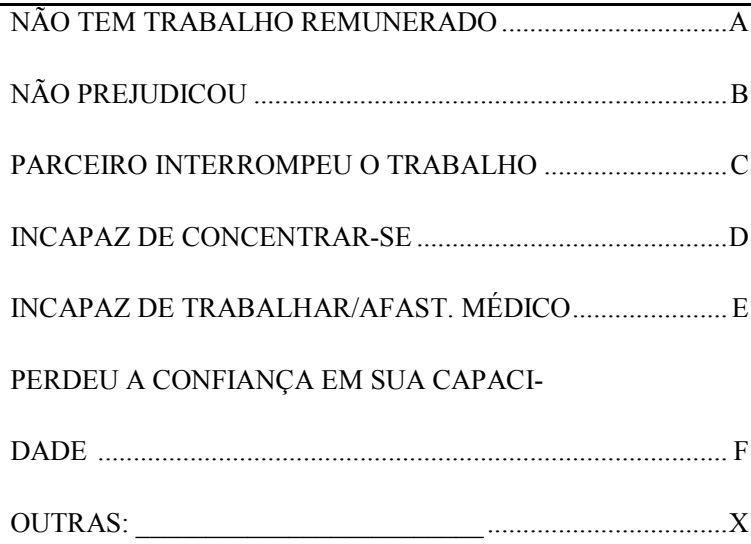 \\
\hline 908 & $\begin{array}{l}\text { Com quem você conversou sobre a violência física sofrida? } \\
\text { ASSINALE TODOS QUE SE APLICAM. }\end{array}$ & AMIGOS \\
\hline
\end{tabular}




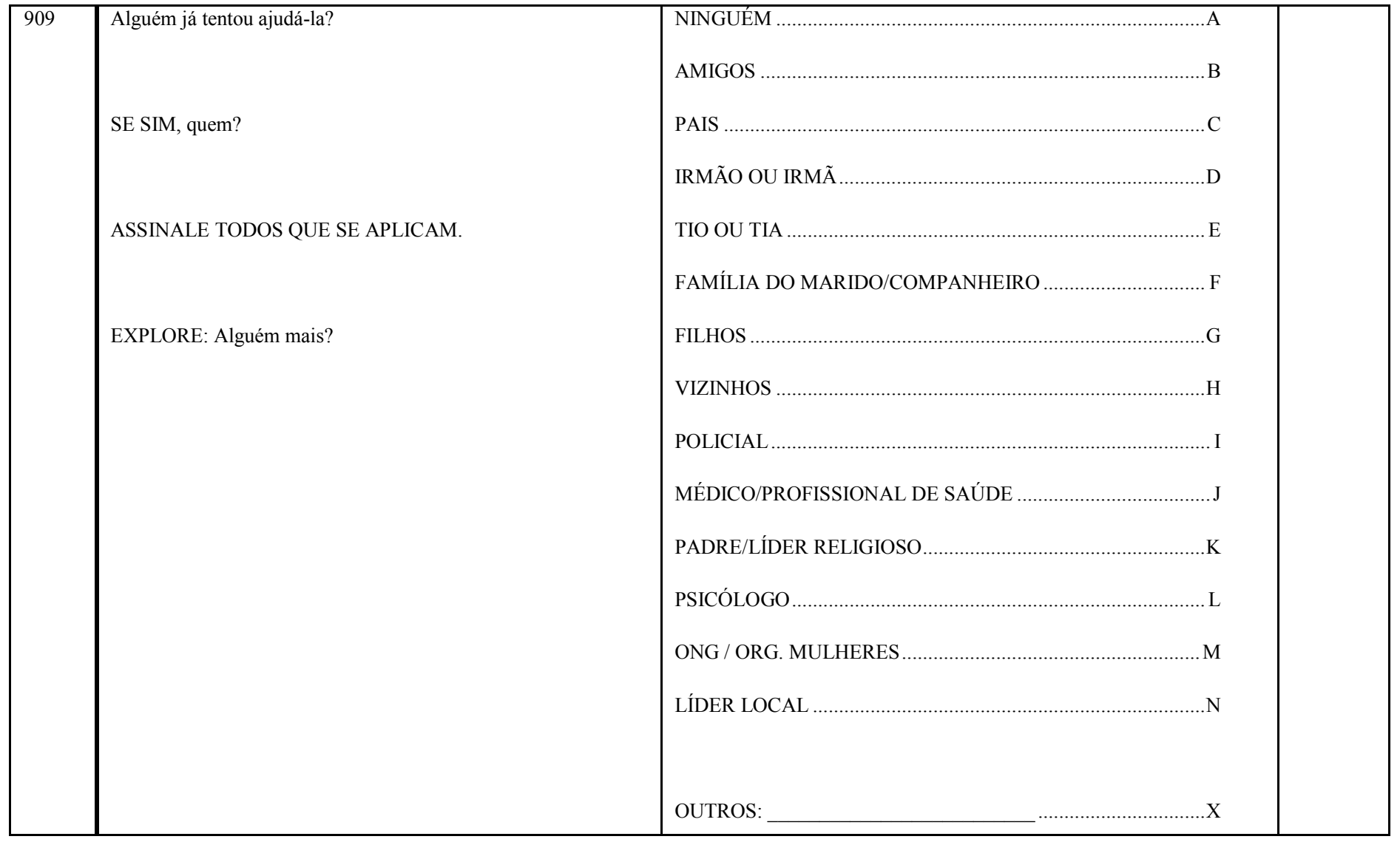




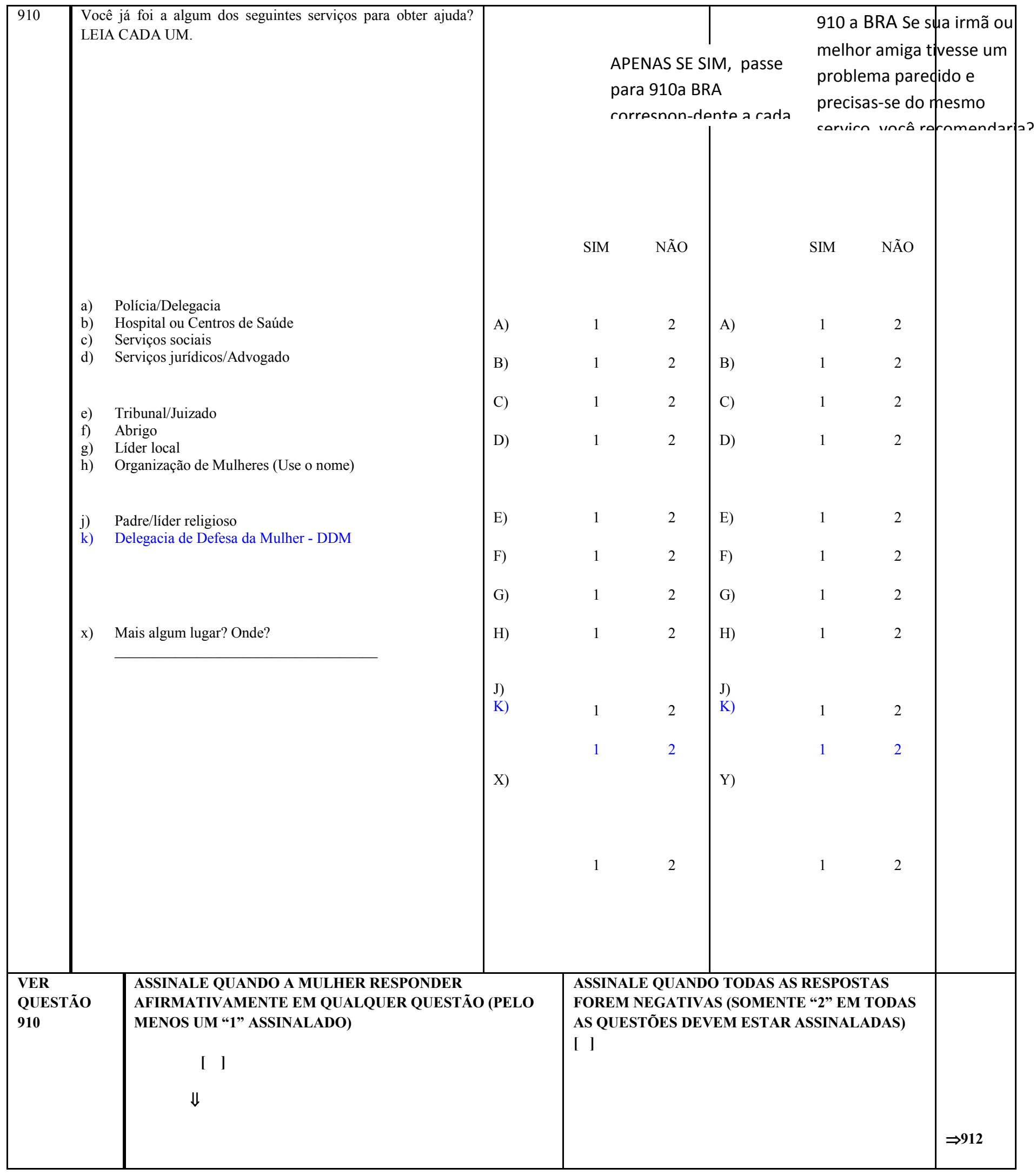




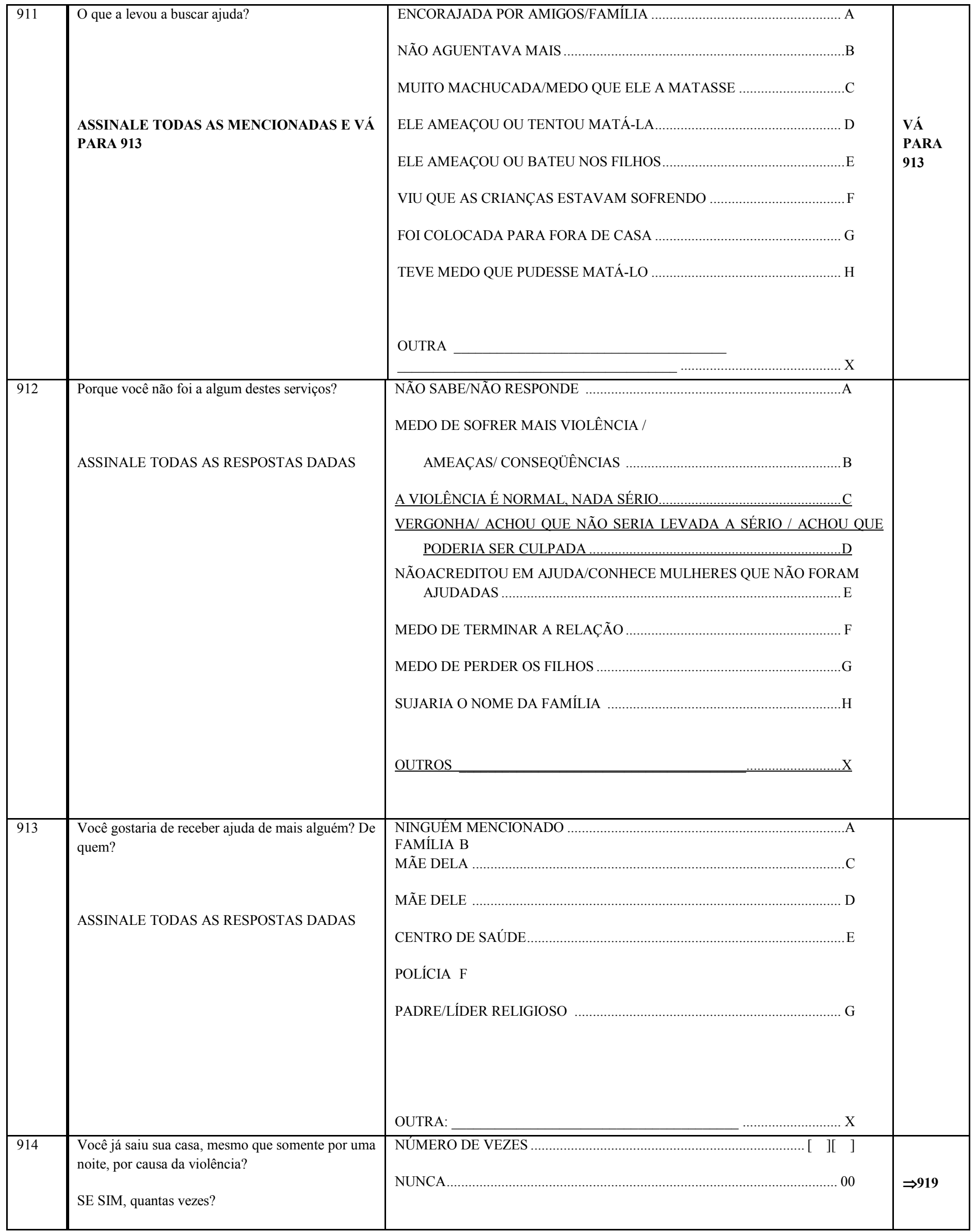




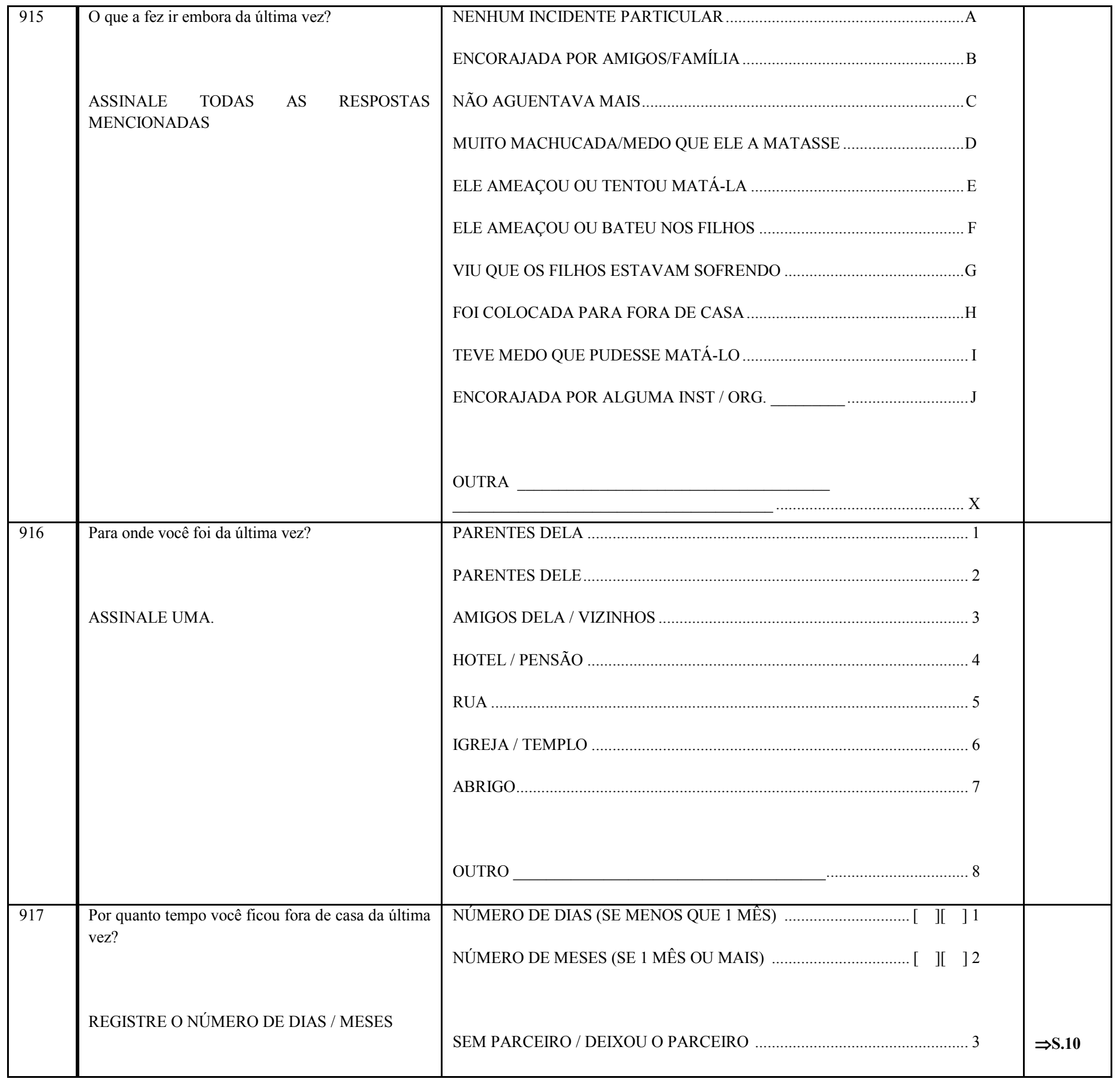




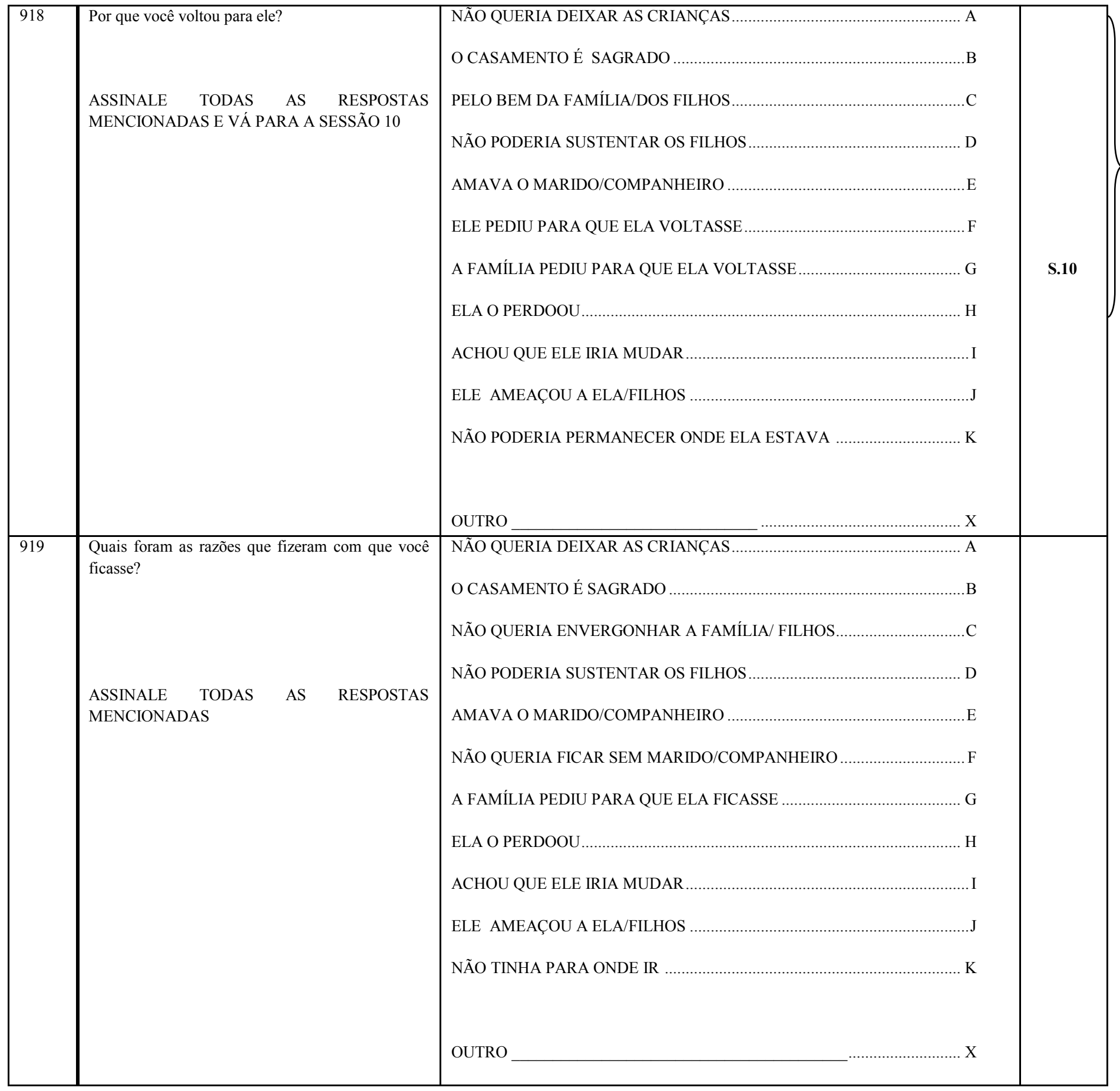


SEÇÃO 10 - OUTRAS EXPERIÊNCIAS

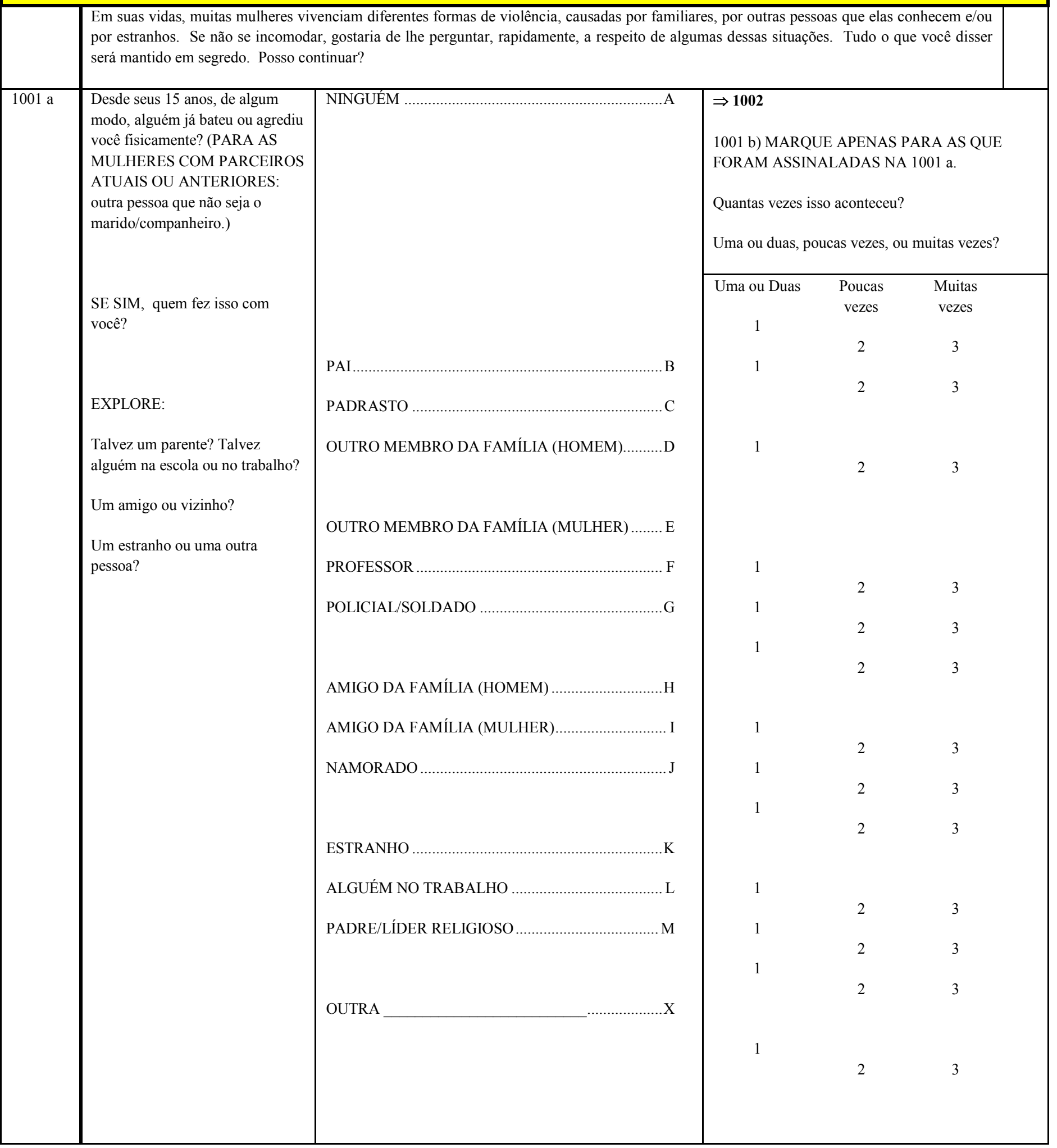




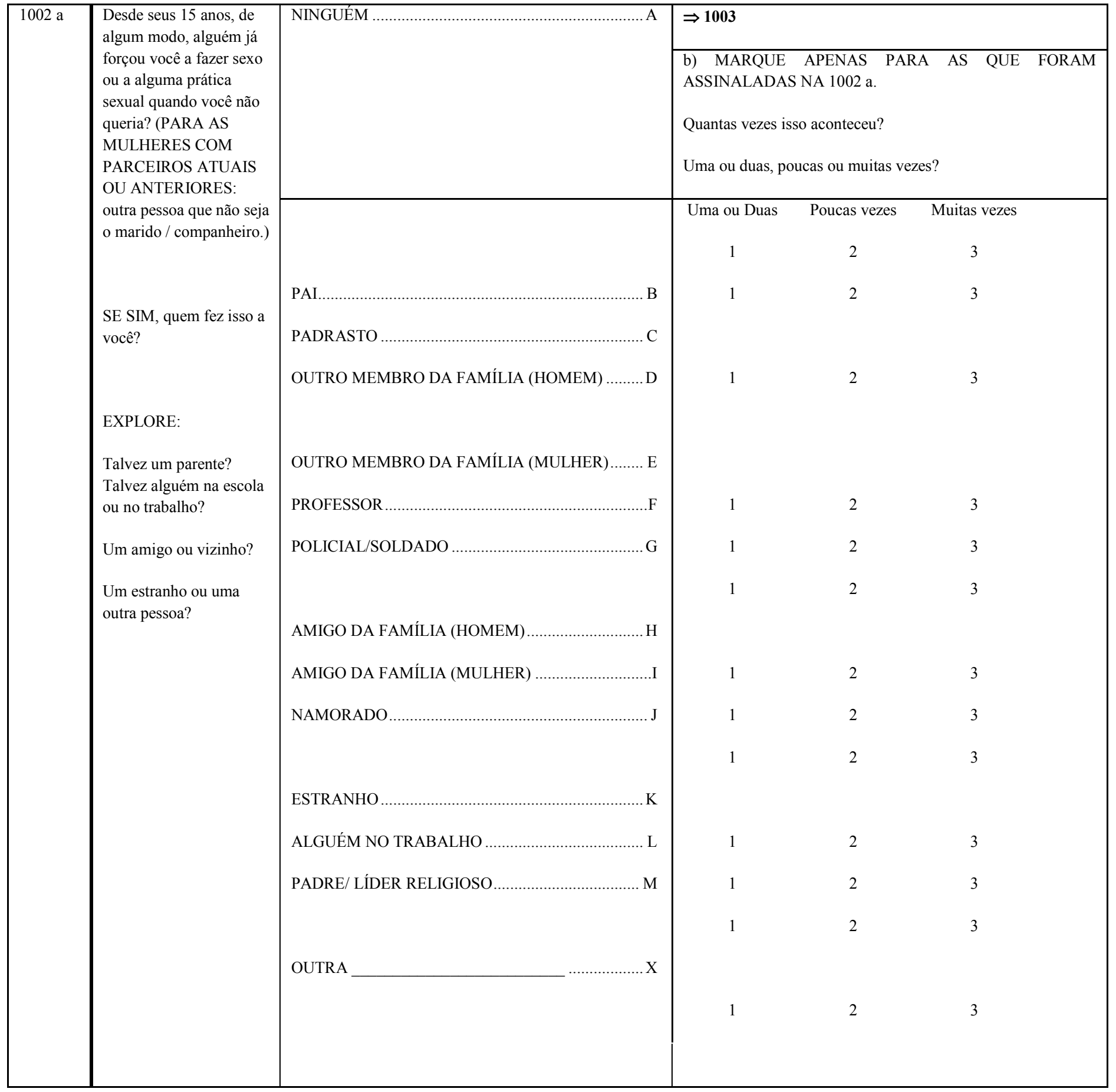




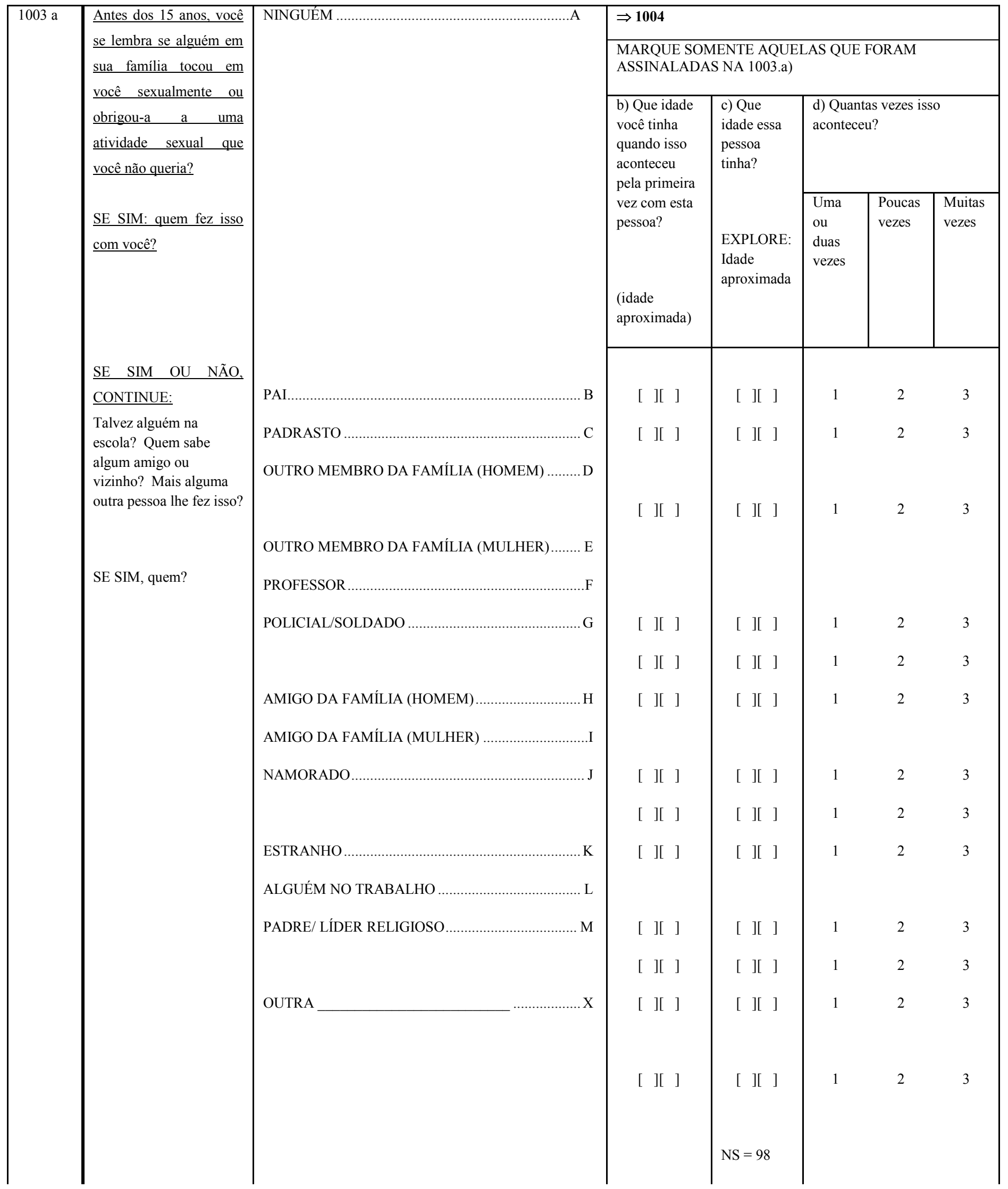




\begin{tabular}{|c|c|c|c|}
\hline 1004 & $\begin{array}{l}\text { Que idade você tinha quando teve relações sexuais pela } \\
\text { primeira vez? }\end{array}$ & ANOS (IDADE APROXIMADA) ……............................ [ ][ ] & $\Rightarrow 1006$ \\
\hline 1005 & $\begin{array}{l}\text { Como você descreveria sua primeira experiência sexual? } \\
\text { Você queria, não queira mas acabou acontecendo, ou foi } \\
\text { obrigada a fazer sexo? }\end{array}$ & NÃO QUERIA, MAS FEZ & \\
\hline 1006 & $\begin{array}{l}\text { Quando você era criança, sua mãe era agredida fisicamente } \\
\text { pelo seu pai (ou pelo marido dela, ou namorado)? }\end{array}$ & SIMO & 1008* \\
\hline 1007 & Quando criança, você viu ou ouviu esse tipo de violência? & SIM & \\
\hline
\end{tabular}




\begin{tabular}{|c|c|c|c|}
\hline $\begin{array}{l}\text { * Ver: (Fl. } \\
\text { Ref. Box A }\end{array}$ & $\begin{array}{l}\text { ESTEVE/ESTÁ CASADA/VIVENDO COM UM } \\
\text { HOMEM/COM PARCEIRO SEXUAL REGULAR } \\
(\text { Opção 1, 2) I । } \\
(\text { Opção 5) } \downarrow\end{array}$ & $\begin{array}{l}\text { NUNCA CASOU / NUNCA VIVEU COM UM HOMEM } \\
\text { /SOLTEIRA/ SEM PARCEIRO SUXAL REGULAR } \\
\qquad \begin{array}{l}\text { (Opção 4) } \\
\end{array}\end{array}$ & $\Rightarrow 1011$ \\
\hline 1008 & $\begin{array}{l}\text { Pelo que você sabe, a mãe de seu marido/companheiro } \\
\text { (atual ou mais recente) era agredida fisicamente ou apanhou } \\
\text { do marido/companheiro dela? }\end{array}$ & SIM & 1010 \\
\hline 1009 & $\begin{array}{l}\text { O seu marido/companheiro atual ou mais recente viu ou } \\
\text { ouviu esse tipo de violência? }\end{array}$ & SIM & \\
\hline 1010 & $\begin{array}{l}\text { Pelo que você sabe, o seu marido/companheiro (atual ou } \\
\text { mais recente) apanhava regularmente ou era agredido } \\
\text { fisicamente por alguém da família dele? }\end{array}$ & SIM & \\
\hline 1011 & $\begin{array}{l}\text { Quantas irmãs você tem (nascidas da mesma mãe), com } \\
\text { idade entre } 15 \text { e } 49 \text { anos? }\end{array}$ & 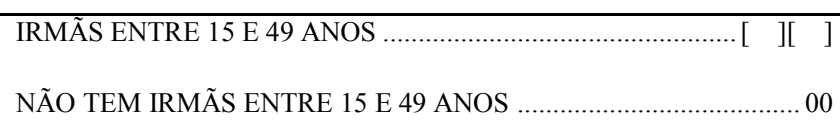 & $\Rightarrow \mathrm{S} .11$ \\
\hline 1012 & $\begin{array}{l}\text { Quantas destas irmãs já foram casadas ou viveram com um } \\
\text { companheiro? }\end{array}$ & IRMÃS QUE JÁ TIVERAM COMPANHEIRO ……............... [ ][ ] & $\Rightarrow \mathrm{S} .11$ \\
\hline 1013 & $\begin{array}{l}\text { Alguma (s) de sua (s) irmã (s) já foram agredidas } \\
\text { fisicamente ou apanhava pelo marido/companheiro dela } \\
\text { (s)? } \\
\text { SE SIM, EXPLORE: quantas irmãs? }\end{array}$ & 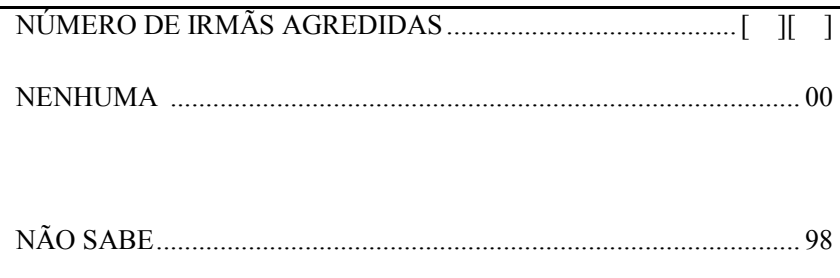 & \\
\hline
\end{tabular}


SEÇÃO 11 - AUTONOMIA FINANCEIRA

Agora, gostaria de fazer algumas perguntas sobre o que você tem e seus ganhos. Precisamos dessas informações para compreender a situação financeira das mulheres hoje em dia.

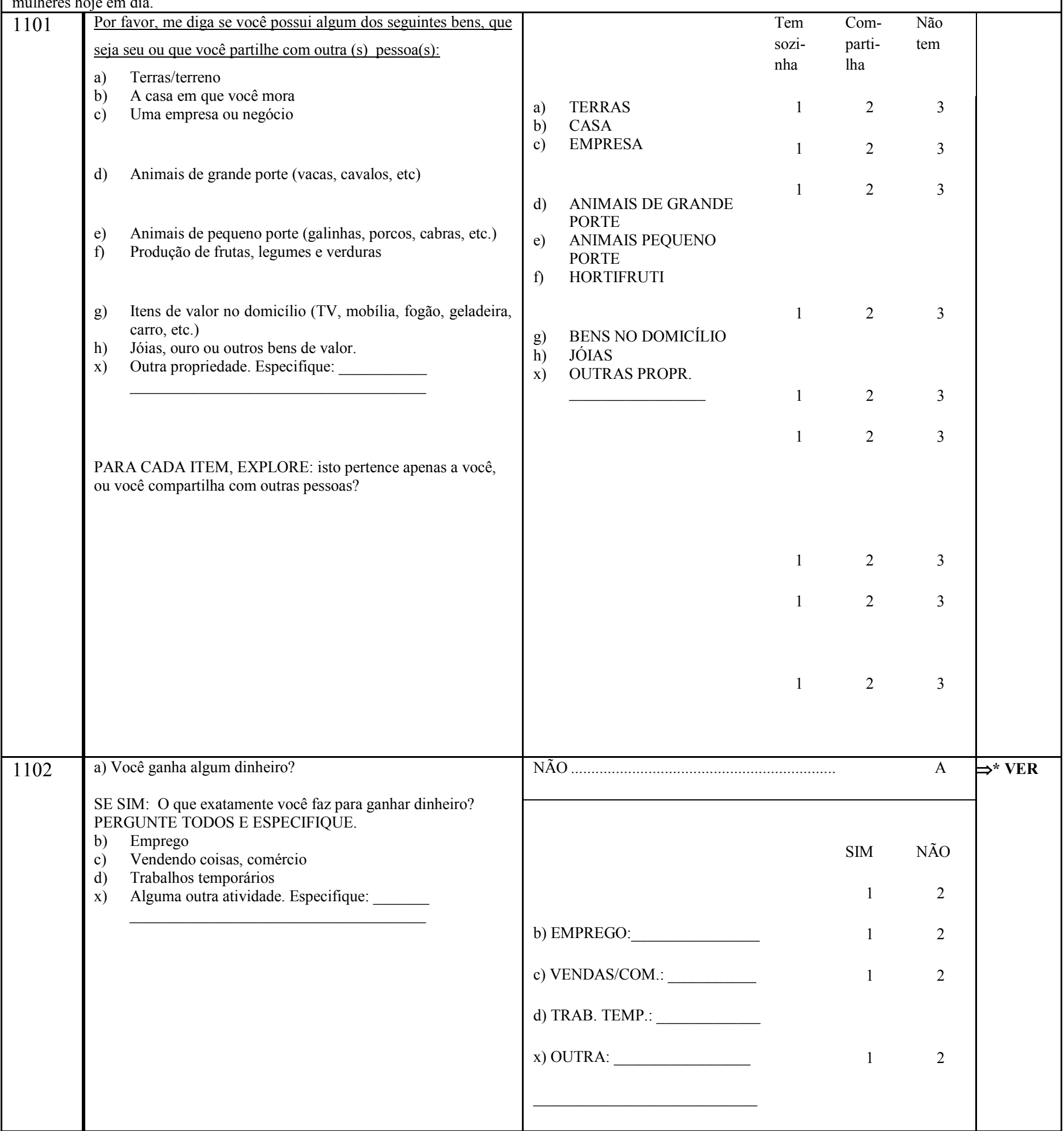




\begin{tabular}{|c|c|c|c|}
\hline $\begin{array}{l}\text { * VER: } \\
\text { (Fl. Ref. } \\
\text { Box A) }\end{array}$ & $\begin{array}{l}\text { CASADA ATUALMENTE / VIVENDO COM UM HOMEM } \\
\begin{array}{cc}\text { (Opção 1) } & \text { I l } \\
& \Downarrow\end{array}\end{array}$ & $\begin{array}{l}\text { NÃO ESTÁ CASADA / NÃO VIVE COM UM HOMEM } \\
\qquad(\text { Opção 2, 4, 5) } \quad \text { [ }] \Rightarrow\end{array}$ & $\Rightarrow$ S.12 \\
\hline $\begin{array}{l}\text { VER: } Q \\
1102\end{array}$ & 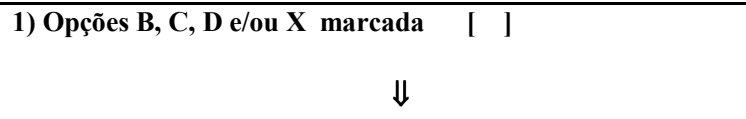 & 2) Opção A & $\Rightarrow 1105$ \\
\hline 1103 & $\begin{array}{l}\text { Você pode gastar o dinheiro que ganha como achar melhor ou } \\
\text { tem que dar todo o dinheiro ou uma parte dele ao seu } \\
\text { marido/companheiro? }\end{array}$ & 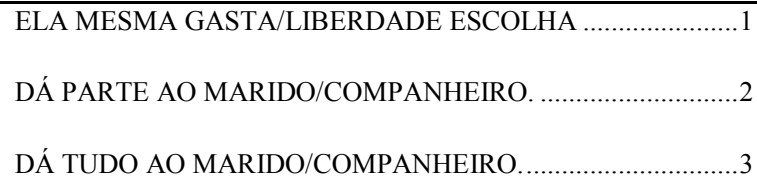 & \\
\hline 1104 & $\begin{array}{l}\text { Você diria que o dinheiro que você coloca em casa é maior, } \\
\text { menor ou igual à contribuição de seu marido/companheiro? }\end{array}$ & MAIOR & \\
\hline 1105 & $\begin{array}{l}\text { Você já recusou algum emprego ou desistiu de um trabalho } \\
\text { remunerado porque seu marido/companheiro não queria que } \\
\text { você trabalhasse? }\end{array}$ & SIM & \\
\hline 1106 & $\begin{array}{l}\text { Alguma vez seu marido/companheiro pegou seu salário ou } \\
\text { poupança contra a sua vontade? } \\
\text { SE SIM: ele fez isso uma ou duas, poucas, ou muitas vezes? }\end{array}$ & UMACA OU DUAS VEZES & \\
\hline 1107 & $\begin{array}{l}\text { Seu marido/companheiro, mesmo tendo dinheiro para outras } \\
\text { coisas, já se recusou em contribuir com as despesas da casa? } \\
\text { SE SIM: ele fez isso uma ou duas, poucas, ou muitas vezes? }\end{array}$ & UMA OU DUAS VEZES & \\
\hline 1108 & $\begin{array}{l}\text { Em caso de emergência, você acha que sozinha conseguiria obter } \\
\text { dinheiro suficiente para dar casa e comida a sua família por um } \\
\text { mês? Isto poderia ser feito vendendo coisas que você possui, } \\
\text { emprestando dinheiro de conhecidos, de banco ou de agiota? }\end{array}$ & SIM & \\
\hline
\end{tabular}


SEÇÃO 12 - COMPLEMENTO

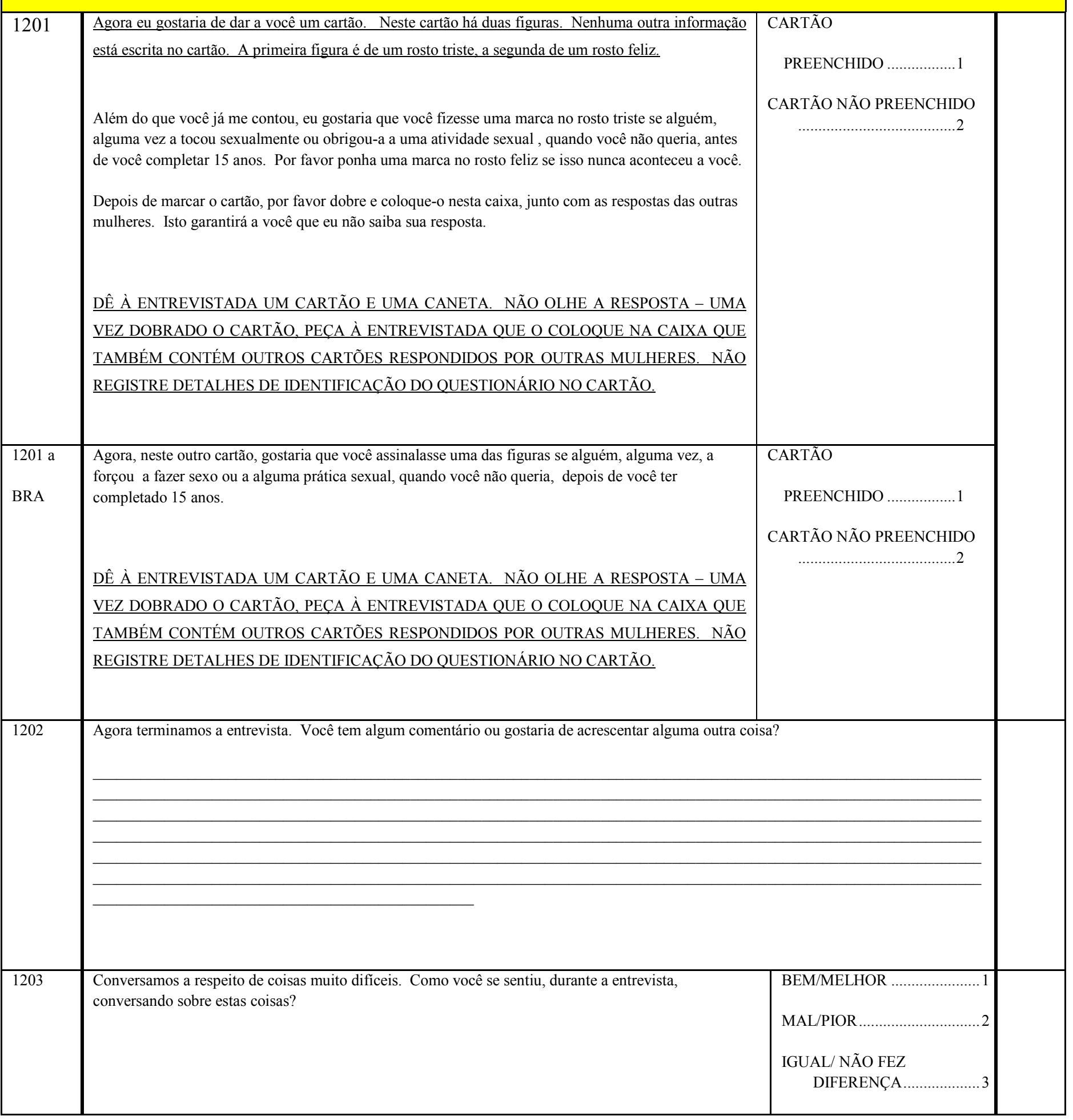




\begin{tabular}{|l|l|l|}
1204 & $\begin{array}{l}\text { Finalizando, você concordaria em nos receber novamente (nas próximas semanas) para esclarecer } \\
\text { alguma questão, caso seja necessário? }\end{array}$ & SIM.................................... \\
\hline
\end{tabular}


VERSÃO 1 - CASO A ENTREVISTADA TENHA INFORMADO PROBLEMAS/VIOLÊNCIA

Quero agradecer muito a sua ajuda. Apreciamos o tempo que você gastou. Percebo que estas perguntas podem ter sido difíceis para você responder, mas só ouvindo as mulheres diretamente é que realmente podemos entender mais sobre a saúde delas e as experiências de violência.

Pelo que você nos contou, vejo que atravessou alguns momentos muito difíceis em sua vida. Ninguém tem o direito de tratar outra pessoa desse modo. Porém, com base no seu relato, percebo que você é forte, tendo ultrapassado circunstâncias difíceis.

Esta é uma lista de organizações que oferecem apoio, conselhos legais e serviços de auxílio e aconselhamento às mulheres em SÃO PAULO. Por favor contate-os se você quiser discutir sua situação com alguém. Os serviços listados são gratuitos e eles manterão tudo que você disser em sigilo. Você pode ir quando você se sentir pronta para isso, seja agora, ou mais tarde.

\section{VERSÃO 2 - CASO A ENTREVISTADA NÃO TENHA INFORMADO PROBLEMAS / VIOLÊNCIA}

Quero agradecer muito a sua ajuda. Apreciamos o tempo que você gastou. Percebo que estas perguntas podem ter sido difíceis para você responder, mas só ouvindo as mulheres diretamente é que realmente podemos entender mais sobre a saúde delas e suas experiências de vida

Caso você ouça falar de outra mulher que precise de ajuda, aqui está uma lista de organizações que oferecem apoio, conselhos legais e serviços de auxílio e aconselhamento às mulheres em SÃO PAULO. Por favor contate-os se você ou quaisquer de suas amigas ou parentes precisar de ajuda. Os serviços listados são gratuitos e eles manterão tudo que se diga a eles em sigilo. 
COMENTÁRIOS DA ENTREVISTADORA DEVERÃO SER FEITOS APÓS O ENCERRAMENTO DA ENTREVISTA 
FOLHA DE REFERÊNCIAS

\section{Box A. ESTADO MARITAL}

Marque apenas uma das alternativas abaixo para o estado marital da entrevistada:

1. [ ] Atualmente casada e/ou vivendo com um homem (Questão 119: qualquer uma das opções 1 e 3)

2. [ ] Anteriormente casada/viveu com um homem (Questão 120: opção 1)

4. [ ] Solteira - não foi casada/não viveu com um homem e sem parceiro sexual regular (Questão 120: opção 2)

5. [ ] Atualmente mantém um parceiro sexual regular (Questão 119: opção 4)

6. Número de vezes que se casou / viveu junto com um homem (Questão 123):

[ ] ] ]

Box B. HISTÓRIA REPRODUTIVA

Verifique e complete tudo que se aplica para história reprodutiva da entrevistada:

1. A entrevistada engravidou pelo menos 1 vez (Questão 302: opção 1) SIM

NÃO

2. A entrevistada teve pelo menos uma criança nascida viva (Questão 301: 1 nascido vivo ou mais)

SIM [ ] NÃO

3. A entrevistada tem crianças vivas atualmente (Questão 303: 1 criança ou mais) SIM

NÃO

4. A entrevistada está grávida atualmente (Questão 310: opção 1)

NÃO

5. Número de gestações relatadas (Questão 308) 
Box C. VIOLÊNCIA E LESÕES

Verifique e complete tudo o que se aplica à respondente:

1. A entrevistada teve/tem sido vítima de violência física (Questão 707) SIM

NÃO

2. A entrevistada teve/tem sido vítima de violência sexual (Questão 708) SIM 
Tabela de Codificação da Escolaridade:

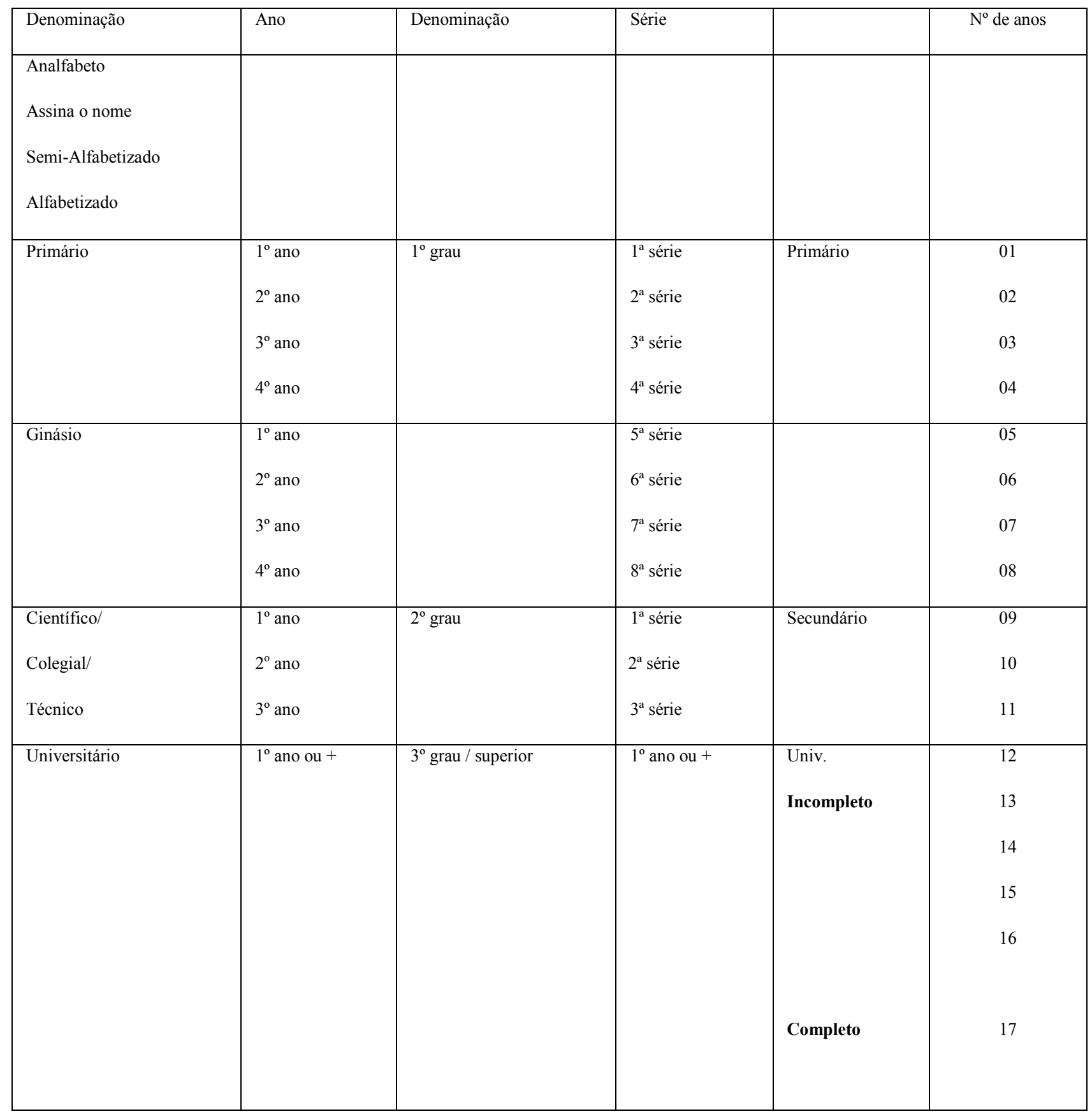

